العدد السابع (يوليو 2021)

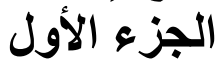

"العلوم الإنسانية والاجتماعية الأول

موقف المنطق الحسسي من مبادئ المنطق التقليدي

\author{
هاحي كما غازي عثماوي حسنين \\ باحثة دكتور راهـ قُم الدراستات الفلسفية \\ كلية الآداب- جامعة عين شمس الفر
}

\title{
Huda.ghazy@art.asu.edu.eg
}

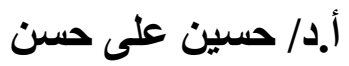

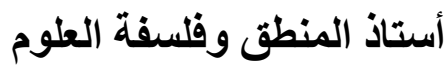 \\ كلية الآداب، جامعة عين شمس وفلة المطوم \\ plato_48@yahoo.com
}

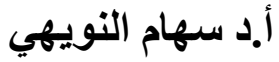 \\ أستاذ المنطق وفلسفة العلوم \\ كلية البنات، جامعة عين شمس ولئن \\ s_alnoaihi2@yahoo.com
}

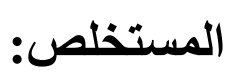

يتناول هذا البحث موقف المنطق الحدسي من مبادئ المنطق التقليدي؛ وترجع أهمية هذا المنطق التقاء

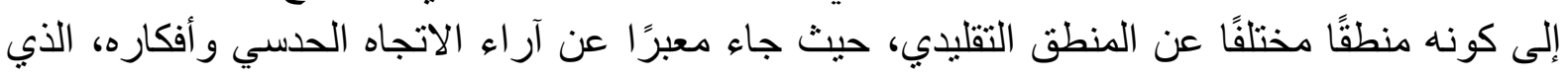

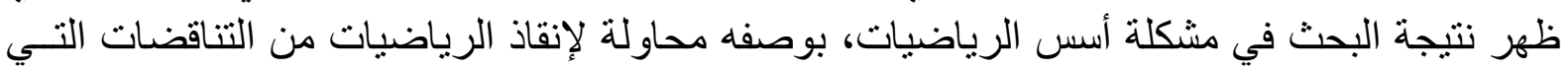

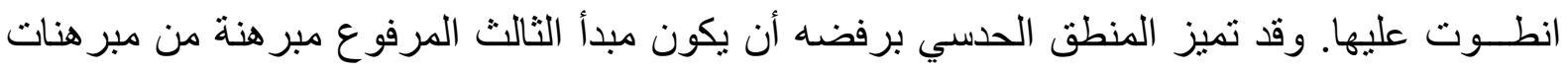

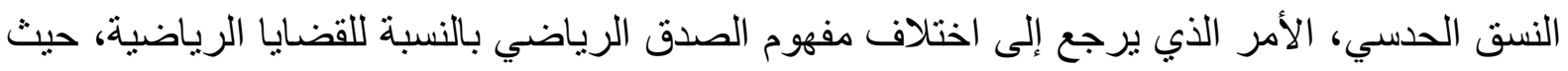

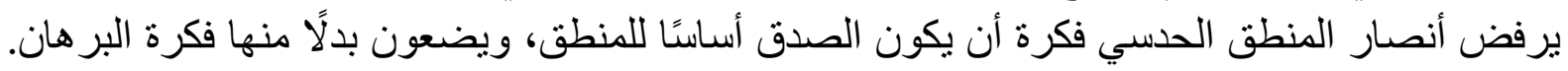

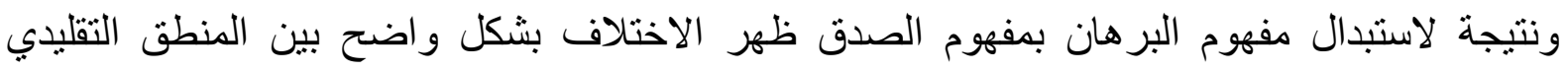

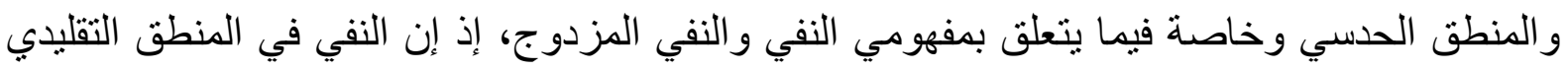

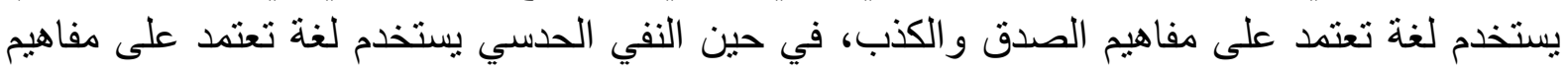

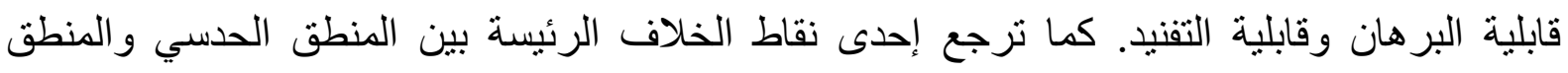

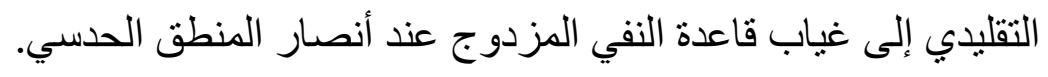

الكلمات الدالة: المنطق الحدي، المنطق التقليدي، مبدأ الثالث المرفوع، الصدق، البرهان، النفي . 


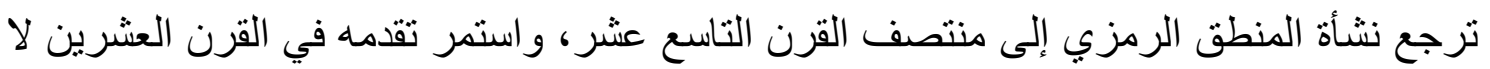

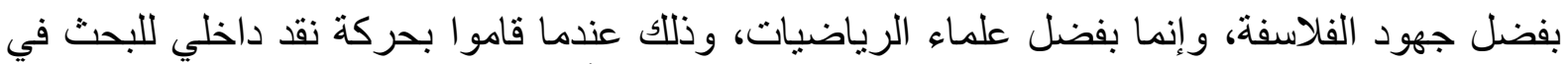

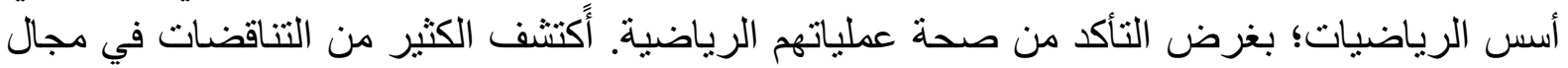

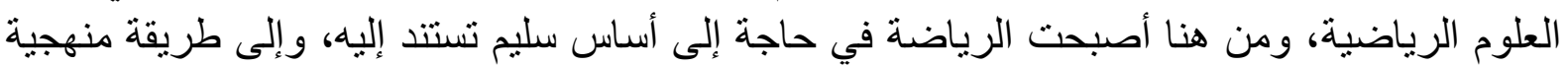

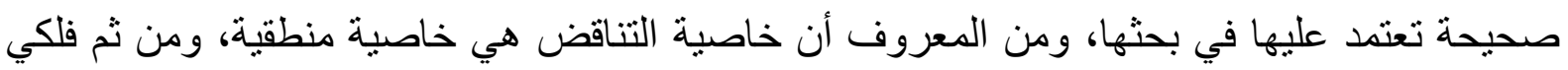

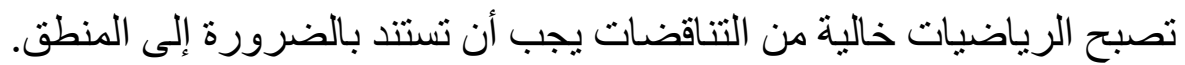

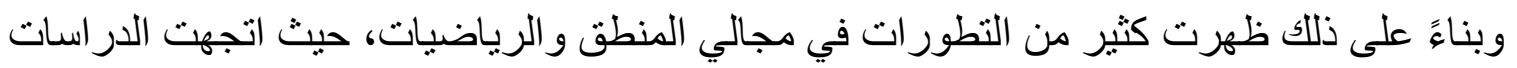

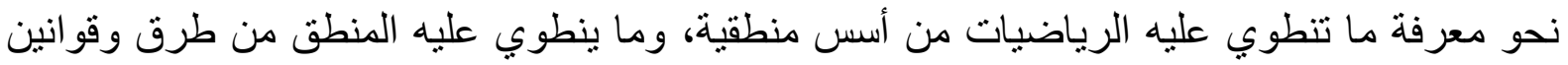

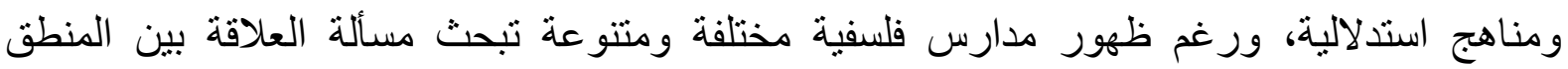

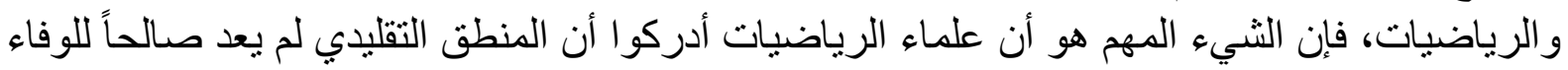

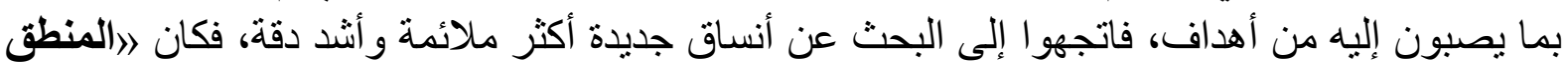

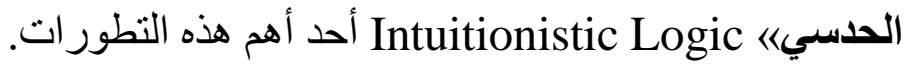

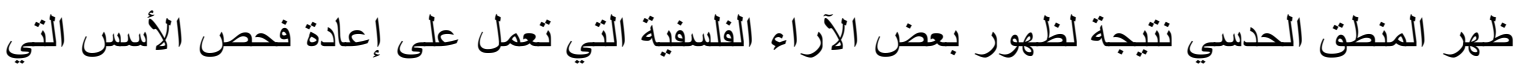

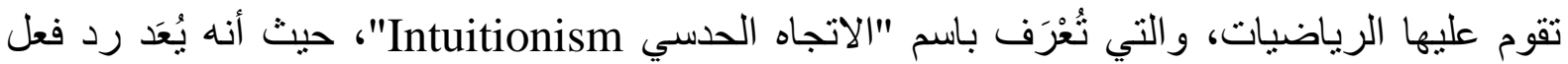

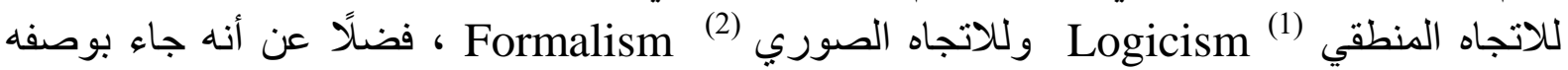

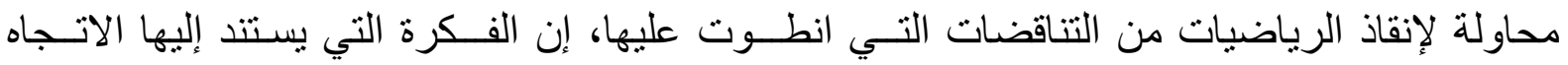

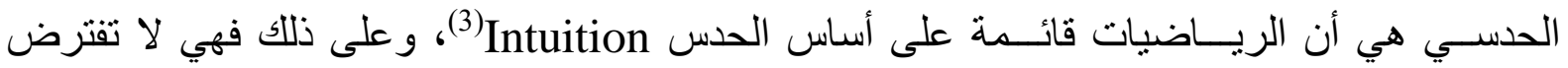

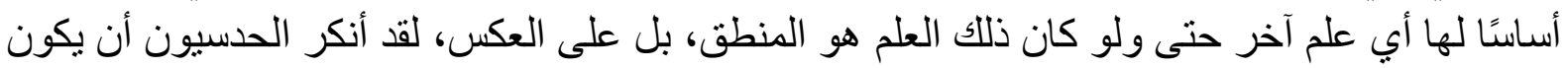

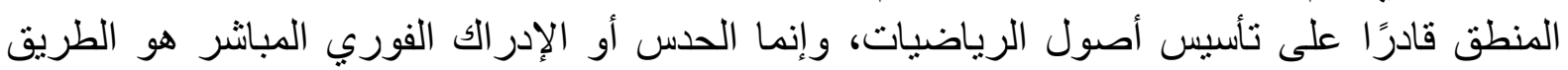

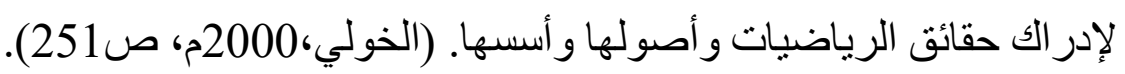

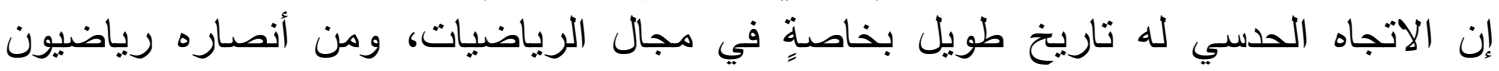

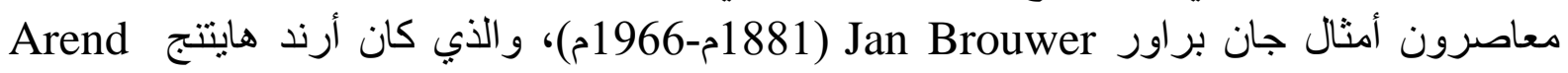
(1898) Heyting

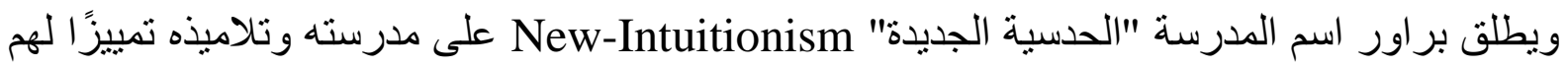

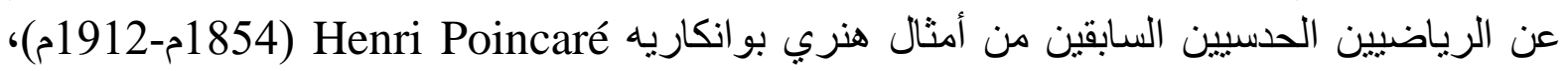

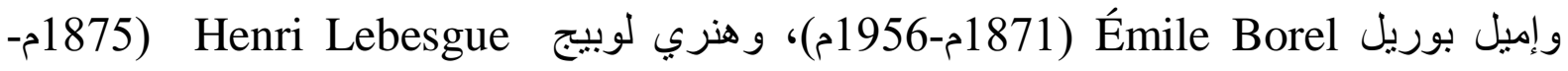

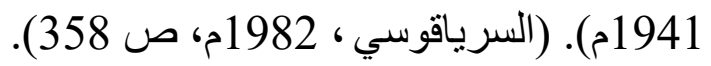

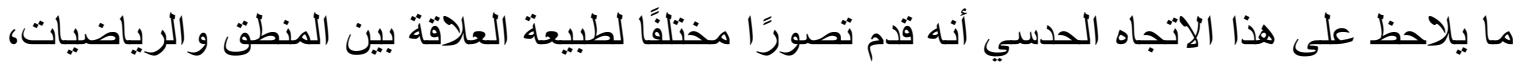

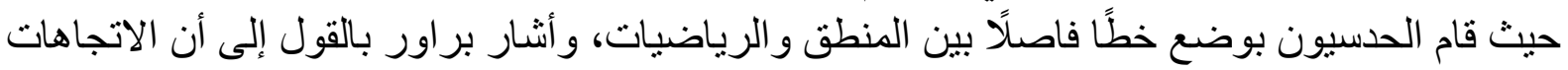

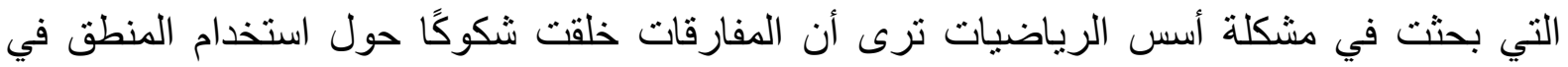

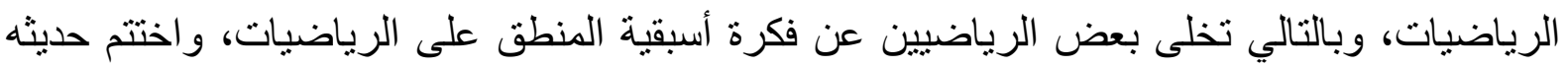

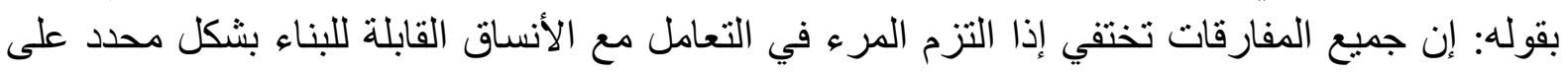

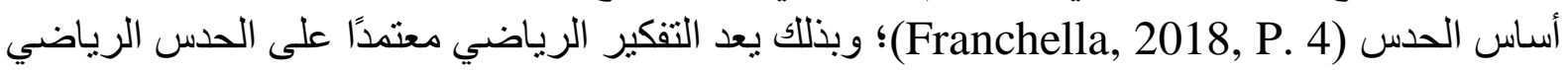

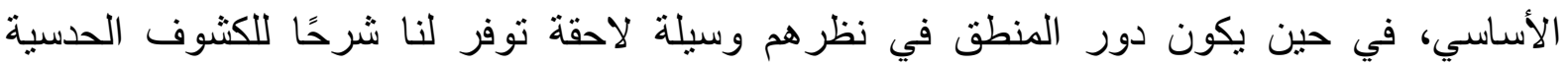
الرياضية. ويصوغ هايتنج طبيعة هذه العلاقة، فيقول: "إنَّ المنطق هو جزئة لاحثة توفر من الرياضيات، وبالتالي لا 
يمكن بأي حال من الأحوال أن يكون بمنزلة أساس تستند إليه الرياضيات. كيف يكون ذلك جائزًا، وهو

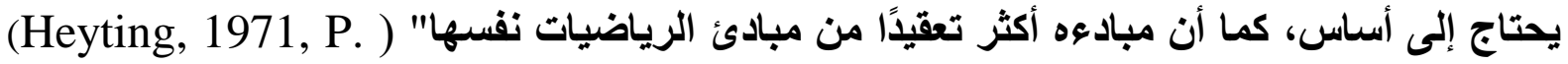

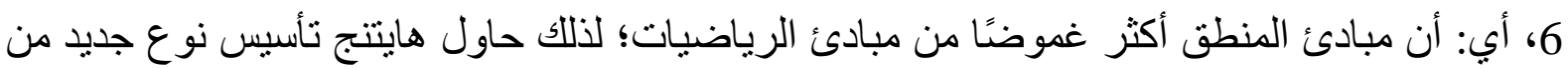

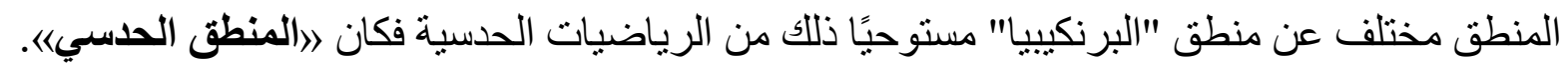

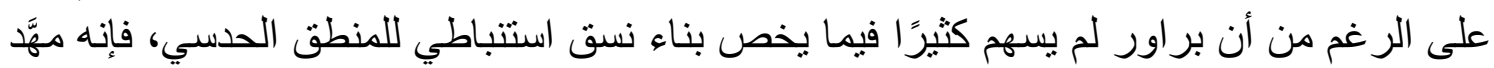

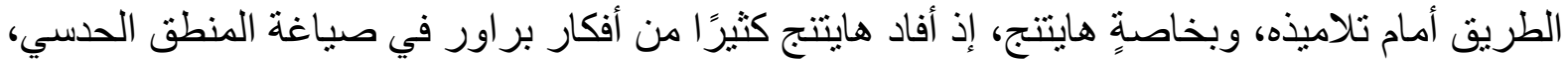
وقد جاء هايتتج عام 1930م بصياغة للحساب المنطقي لما يطلق عليه "المنطق الحدسي" بوصفئه نسقًا استنباطيَّا. و على ذلك يمكن القول: إن نقطة بداية المنطق الحدسي عند هايتنج ترجع إلى إسهامات براور، فقد

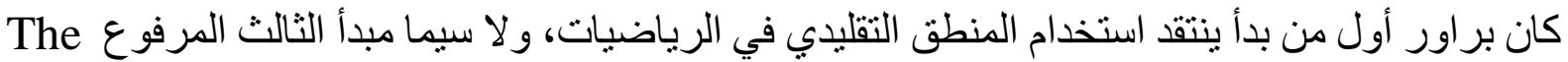
Principle of the Excluded Middle إلى رفض فكرة أن يكون الصدق أساس المنطق؛ و على ذللك اختلف مفهوم الصدق الرياضي بالنسبة

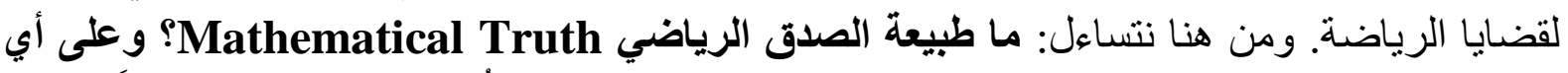

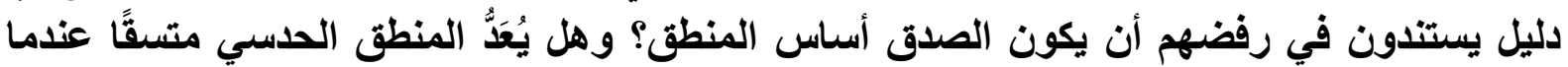

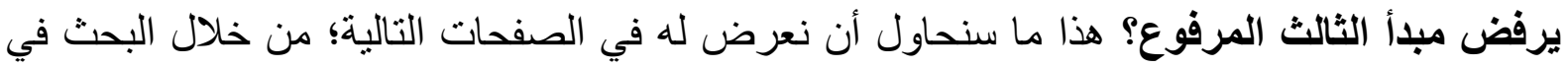
موقف المنطق الحدسي من مبادئ المنطق التقليدي.

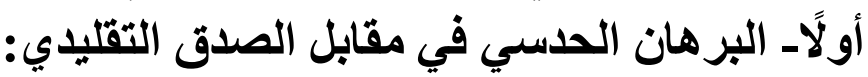

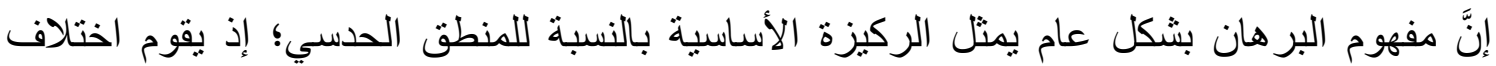
المنطق الحدسي عن المنطق التقليدي على تحديد مفهوم الصدق؛ وذللك لأن أنصار المنطق الحدسي قدئ قدموا مفهوم الصدق بطرق مختلفة جوهريًّا عن المنطق التقليدي. إن السمة المميزة للاتجاه الحدسيـ تحديدًا-

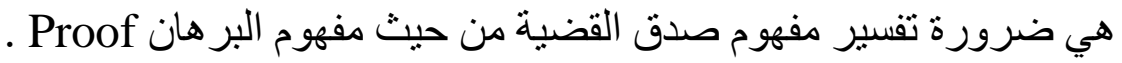

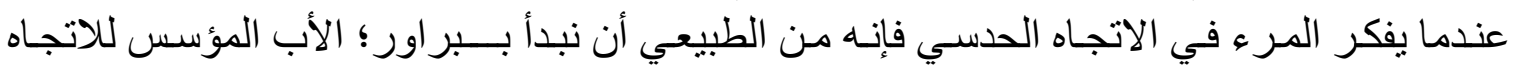

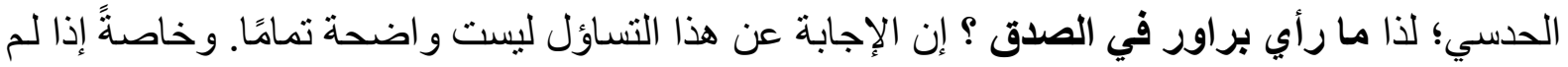

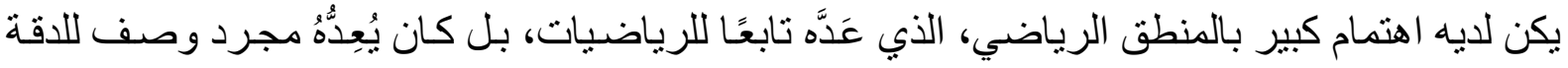

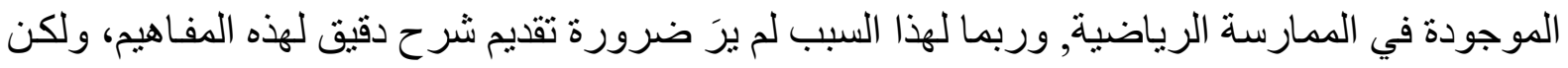

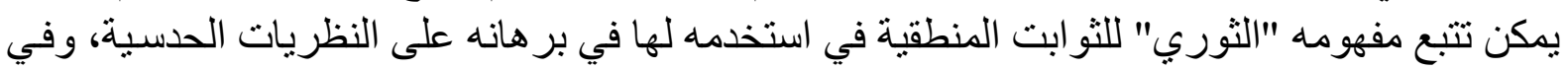
التعليقات المصاحبة لتلك البر اهين. يمكن أن نقتبس بعضًا من آراء براور حول الصدان الصدق، ففي إحدى مقالته يقول: "الصدق هو فقط في

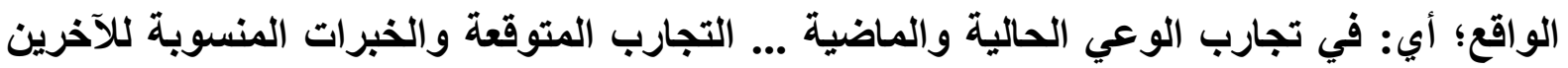
صادقة فقط كتوقعات وفرضيات، ولكن في محتوياتها لا يوجد صدق". (Brouwer, 1975, P. 488).

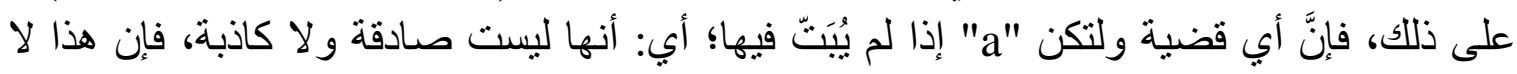

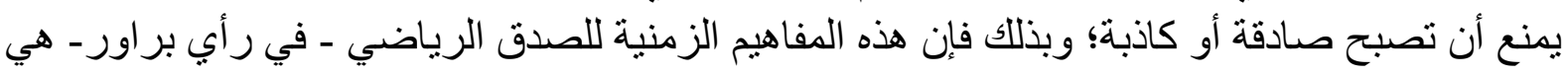
المفاهيم الوحيدة المقبولة. (Dummett, 2000, P. 12).

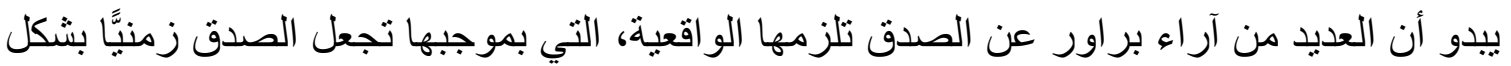

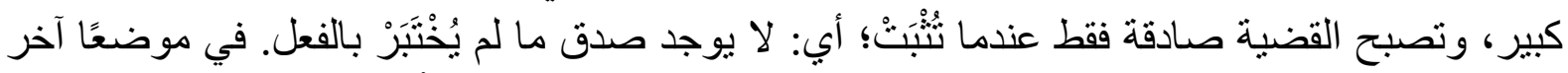

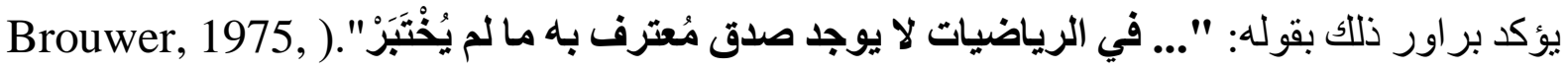


P. 552 (P.). بتعبير آخر يعتقد براور أن القضية صادقة فقط إذا أُنْبَتْ بالفعل؛ أي: وجود برهان على هذه

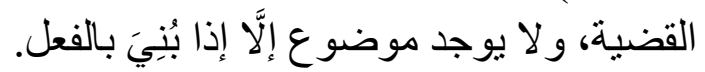

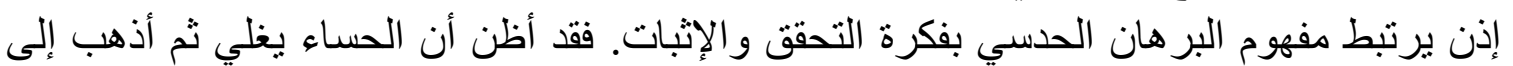

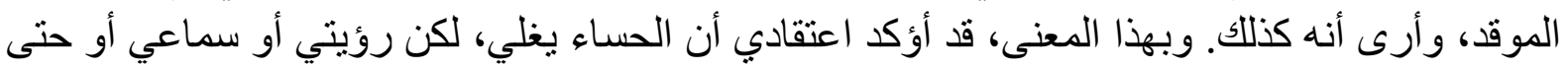

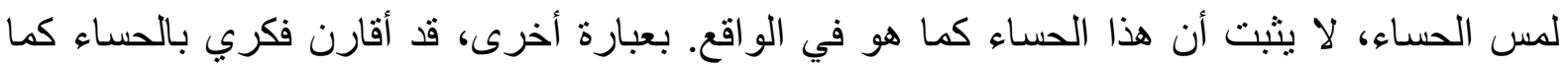
أتصور، ولكنتي لم أكن أحسبه أبدًا كما هو في حد ذاته، ولكن إذا لم يكن من الممكن معرفة العلاقة بين أفكاري و الو اقع نفسه، فعندئذ لا يمكن أبدًا معرفة الصدق. (Nolt, 1997, PP. 427, 428).

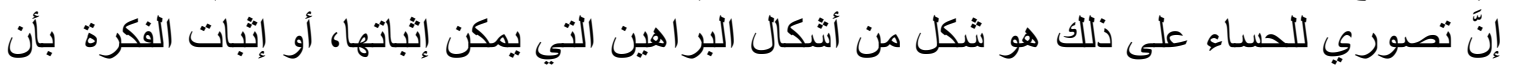

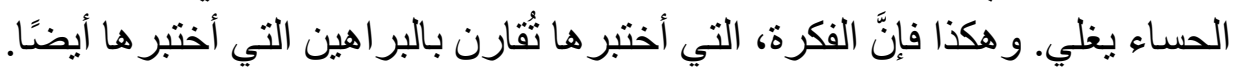

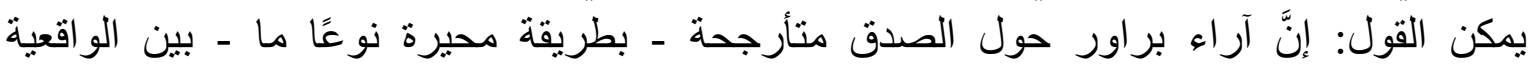

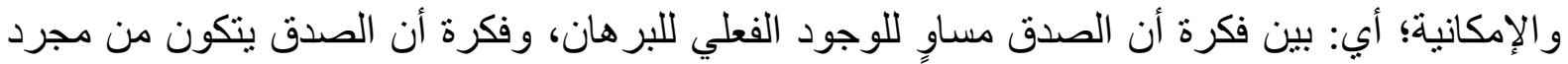
إمكانية بناء البرهان. ربما كان هذا هو مصدر الغموض وانية الارتباك في في الاتجاه الحدسي منذ ذلك الحين.

(Raatikainen, 2004, P. 134)

لذلك يمكن تفسير عبارة "يوجد برهان على القضية" أو "لاينا بر هان على ذلك" بطريقتين مختلفتين؛

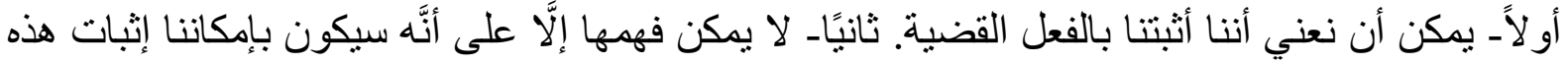
القضية، لقد سَمَىى هذان التفسيران بالرؤية الواقعية Actualist View و الرؤية الممكنة عiew على التو الي. (Raatikainen, 2013, P. 2). إن أنصار المنطق الحدسي يرفضون النظر إلى فكرة الصدق بوصفها أساسًا للمنطق، ويضعون بدلًا

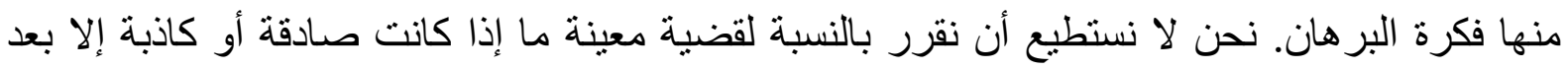

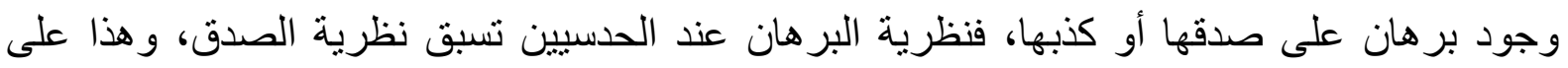

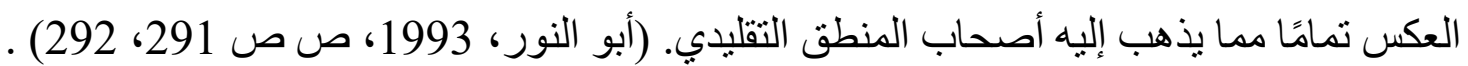
إذا كان الافتر اض الأساسي للرياضيات التقليدية هو أننا نضفي على القضى القضايا الرياضية معنى يجعلها

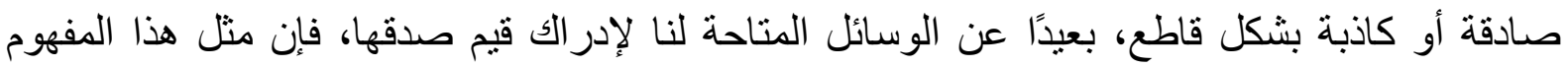
الخاص بصدق القضايا الرياضية- من وجهة نظر حدسية- بعد وهمًا؛ وذللك لأن فهم القضية الرياضية فئية

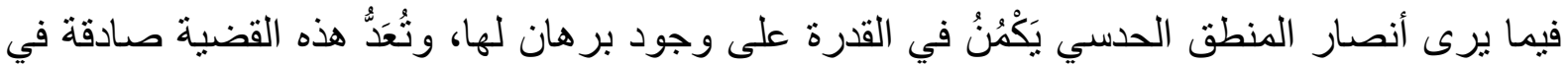
حالة وجود مثل هذا البر هان. (Dummett, 2000, P. 3-4). يجب أنْ نلاحظ هنا أنَّ أنصار المنطق الحدسي لم يلغو ا فكرة الصدق و الكذب للقضايا في حد ذاتها،

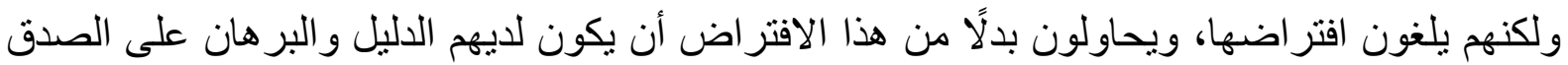

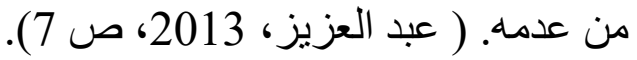

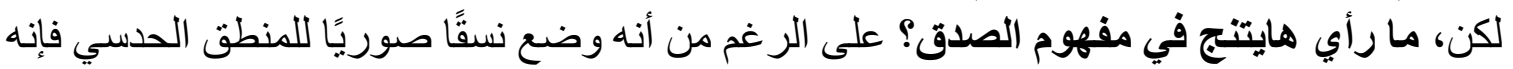

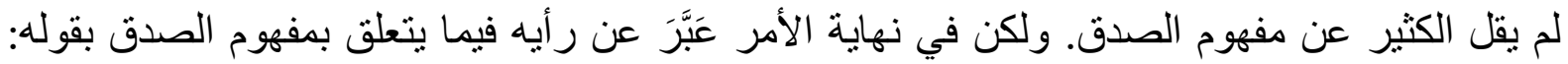

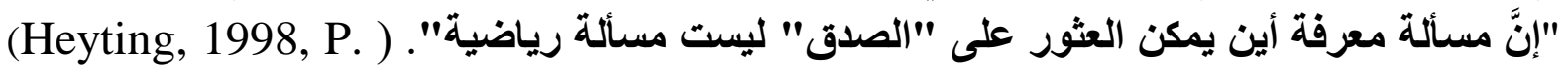
309. مضافًا إلى ذلك قوله: "ليس من سمات الفكر الرياضي الاهتمام ببلوغ صدق العاله العالم الخارجي، وإنما الاهتمام فقط بالبناءات العقلية". (Heyting, 1971, PP. 8, 9).

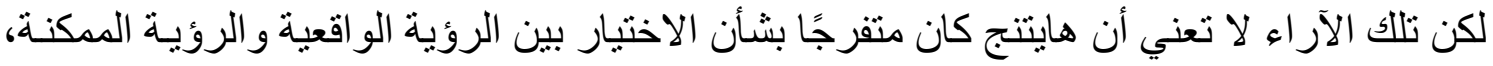

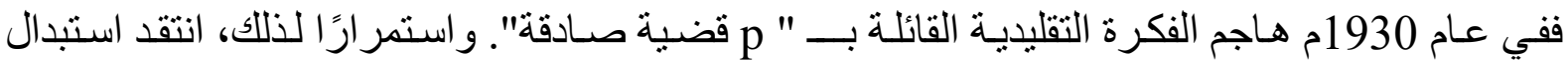

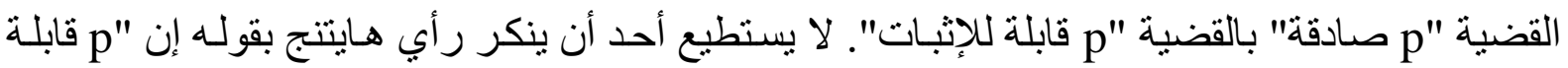


للإثبات" تكافئ "وجود بر هان لـ p"، ولكن بدلًا من ذلك، يجب على المرء استبدال الفكرة التقليدية بعبارة

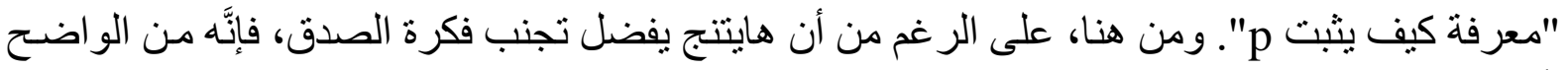

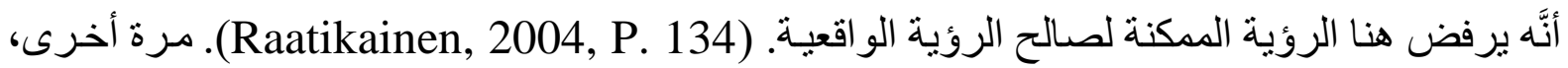

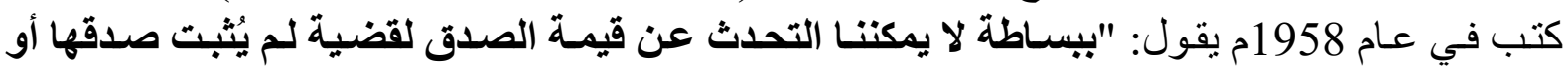

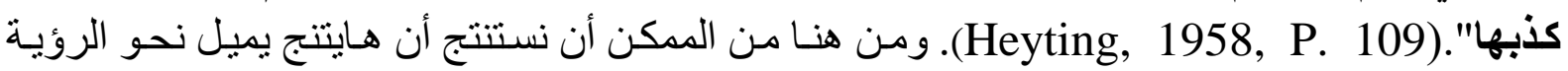
الو اقعية.

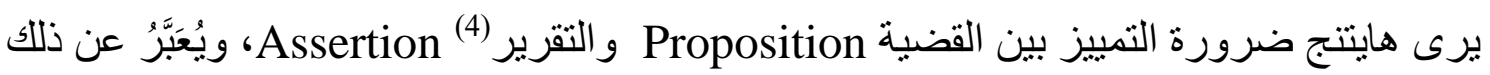

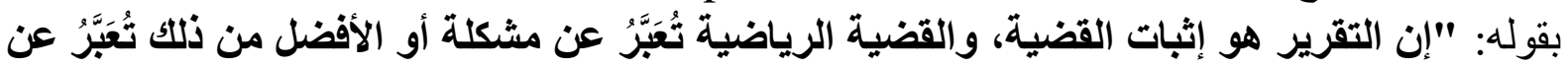

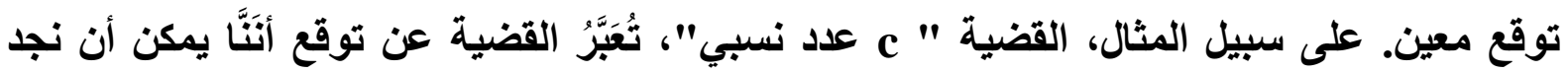

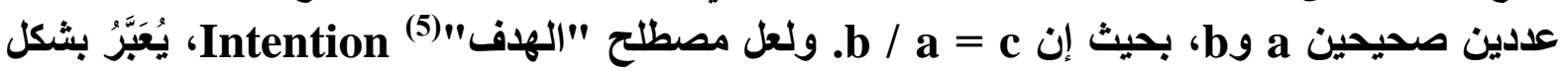

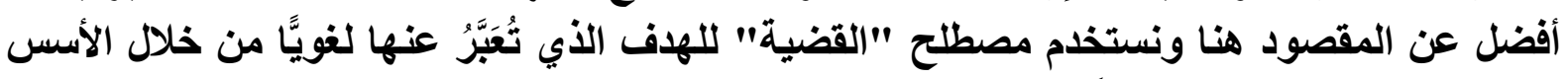

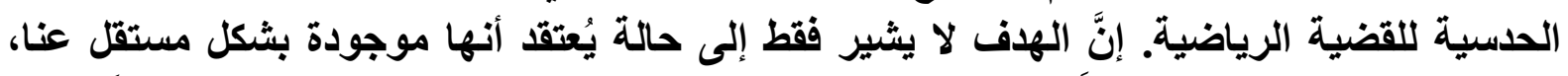

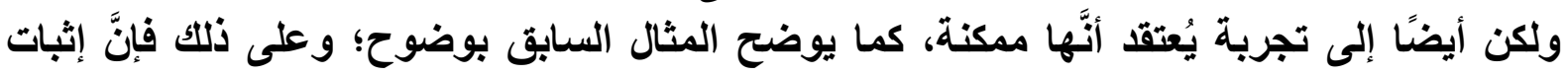
القضية يعني تحقيق الهرفي". (Heyting, 1983, P. 58, 59). يتضح من خلال ذلك أنَّ هايتنج يستخدم التقرير بمعناها الرياضي، الذي يعني ببساطة الإثبات الفعلي

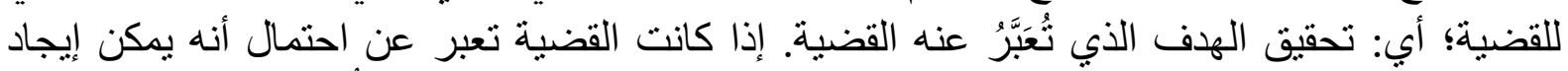

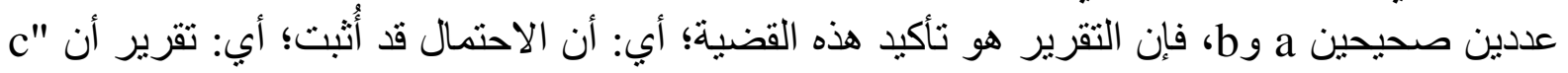

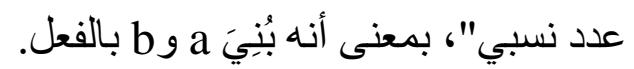

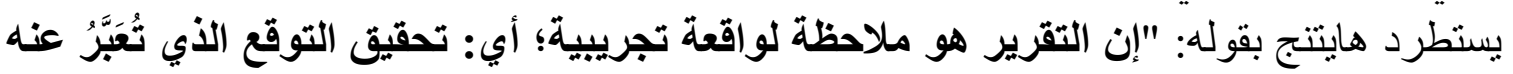

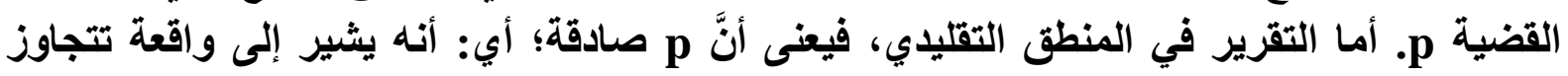

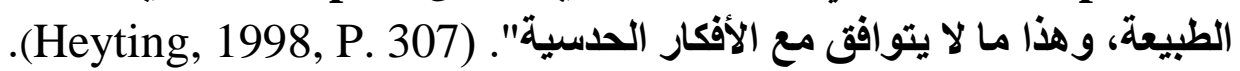

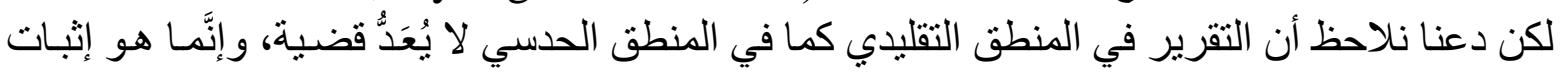

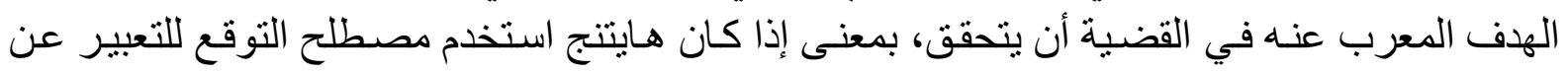

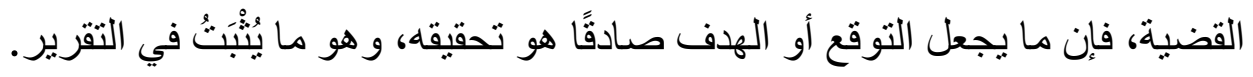

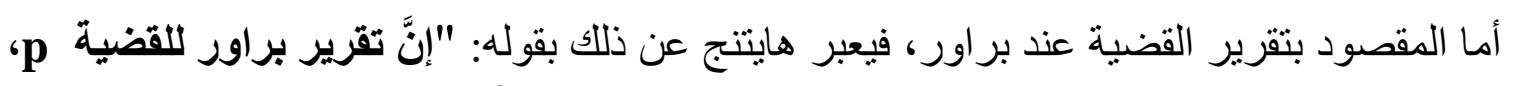

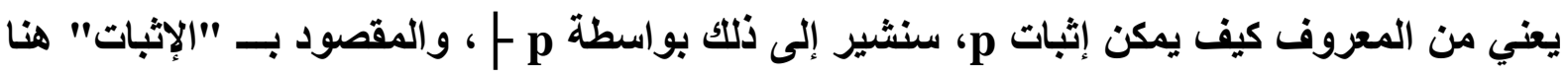
"الإثبات من خلال البناء". (Heyting, 1998, P. 307).

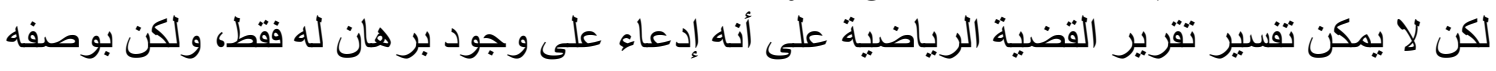

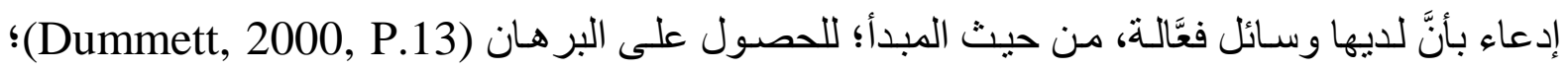

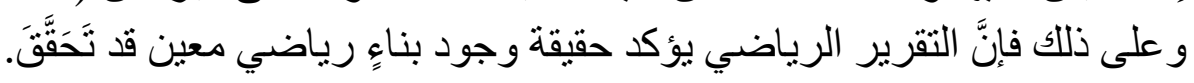

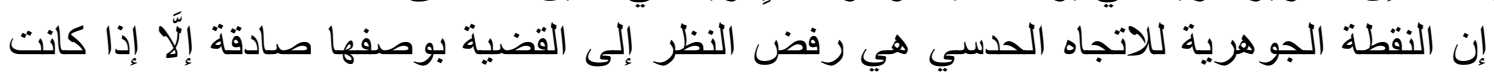

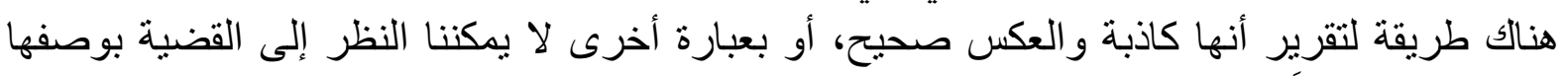

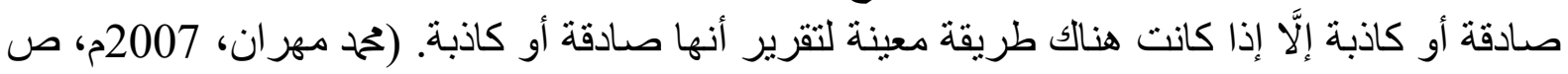

إذا كان هايتتج قد قدم بعضيًا من التساؤلات الفلسفية الخاصة بـالمنطق، مثنل مـا القضية؛؟ كيف تكون

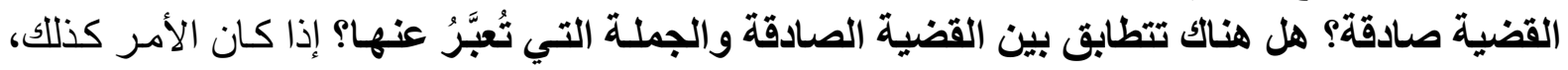

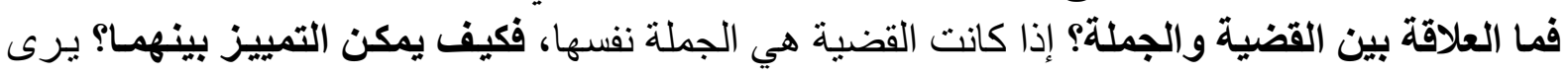




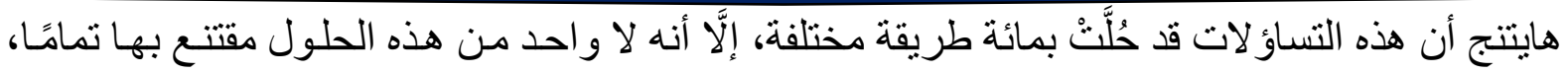

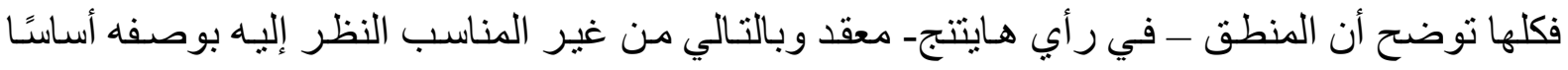
للرياضيات. (Heyting, 1974, P. 79). إنَّ المنطق على ذللك لا يكفي وحده لعرض المسائل و القضايا الرياضية، وكون الرياضيات نابعة من

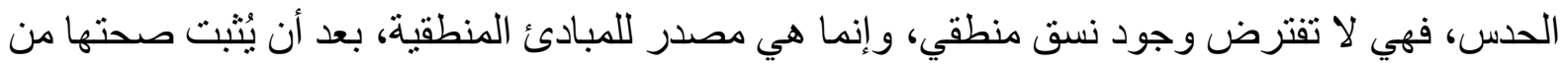

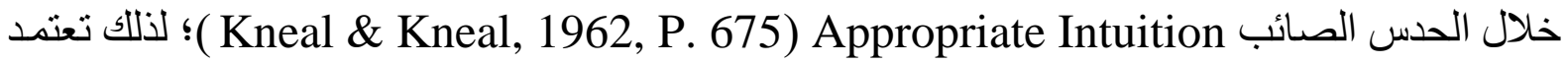
الأفكار الرياضـية والطرق البرهانيـة على الحـس، ومـن هنـا ارتبطت فكرة صـحة البرهـان بالحسس

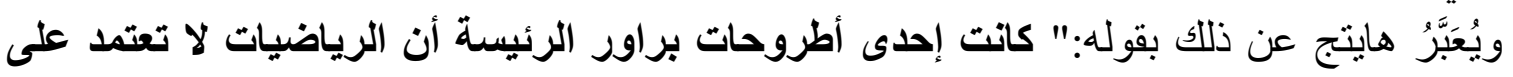

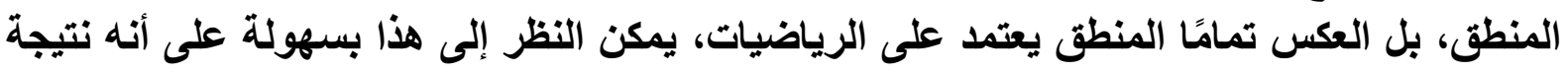

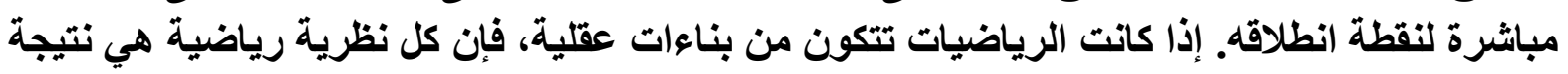

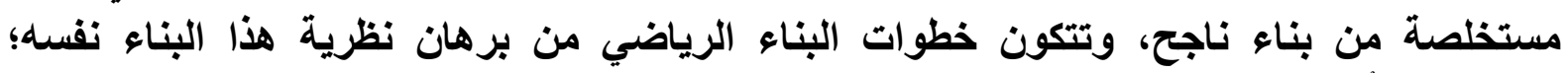

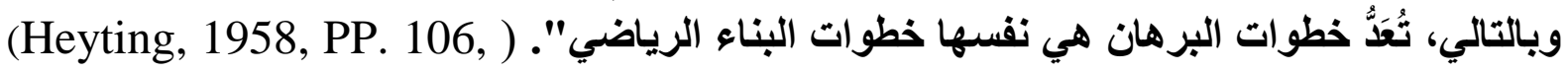

لكن منل هذا البرهان لا يمكن أن يكون برهانًا صـوريًا، و إنَّمـا هو بر هـان مقبول حدسيَّا، بمعنى أن

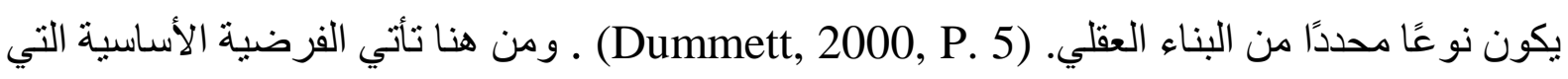

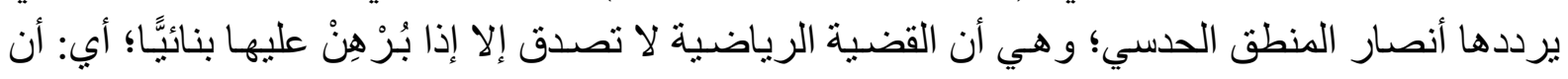

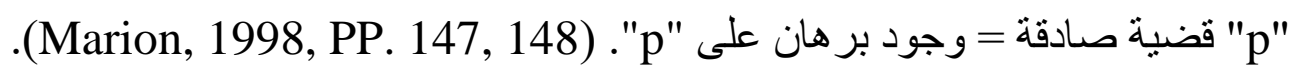

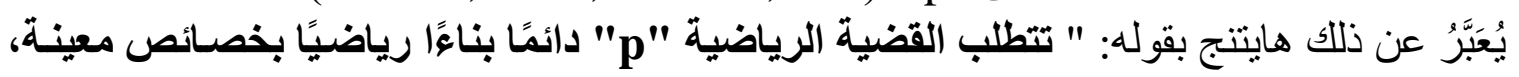

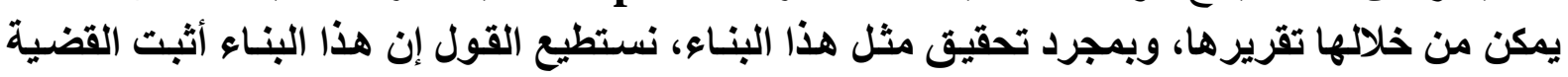

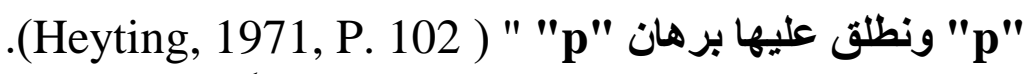

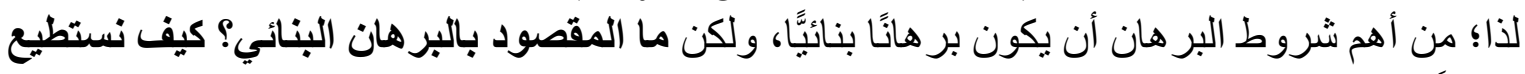

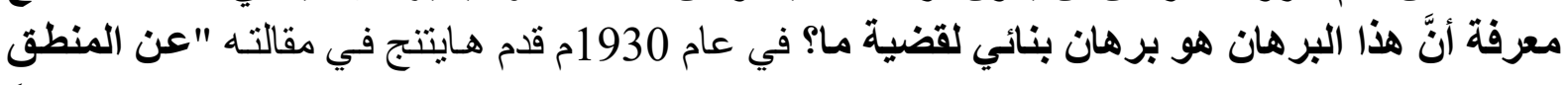

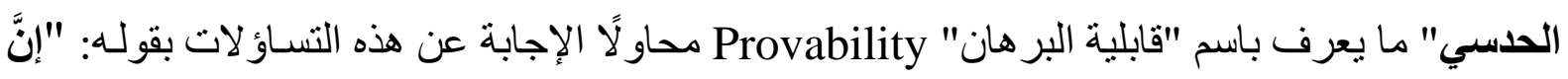

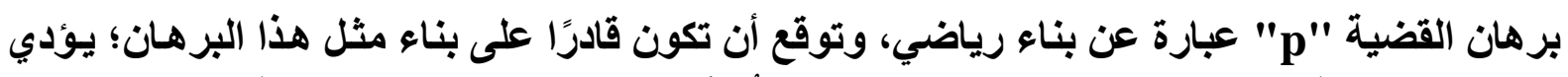

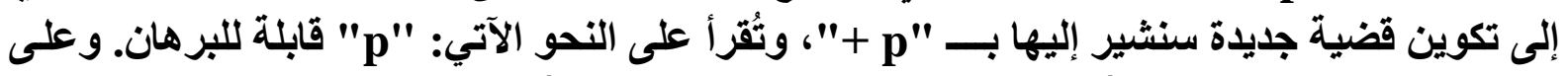

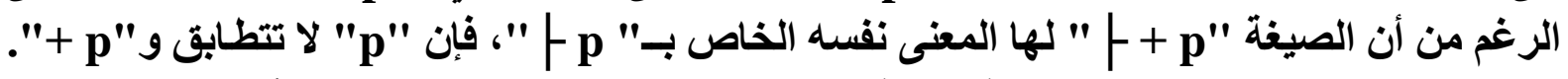

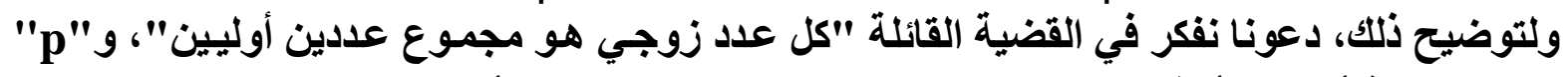

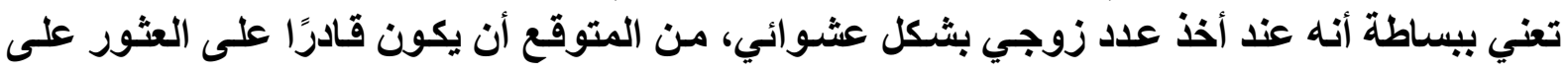

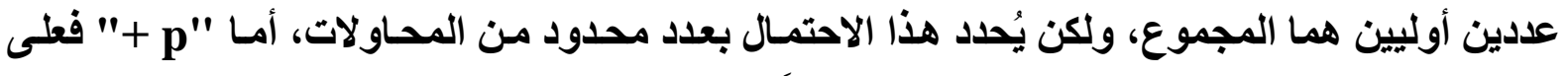

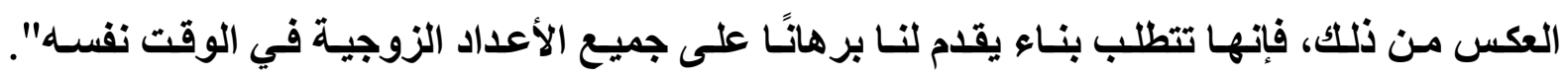
(Heyting, 1998, P. 308) من خلال ذللك، يتضح لنا أنَّ من أهم شروط البرهان البنائي هو أنه لا تُقْبَلُ أية قضية في الرياضيات

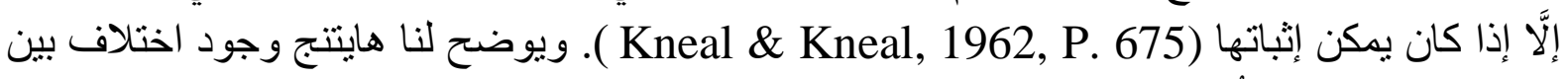

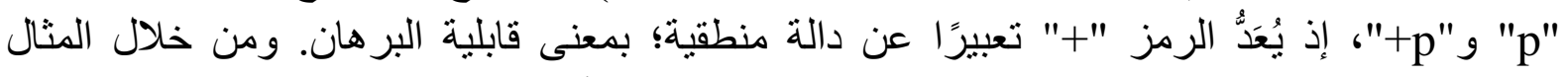
المذكور أعلاه، ويتضح الفرق بينهما على أساس أنه لا يمكن أن نُبرهن هن على قضية الرية "كل عدد زوجي هو 


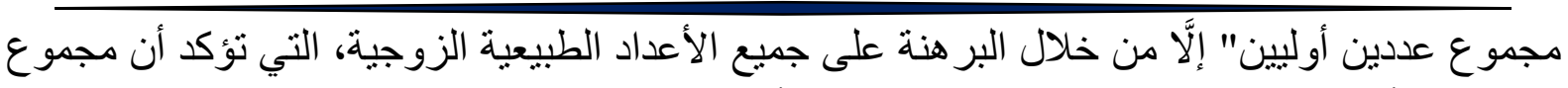

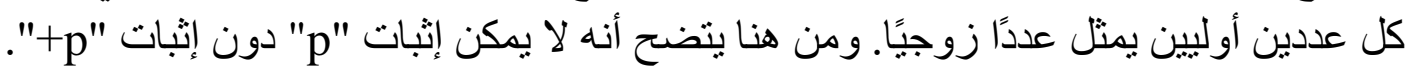

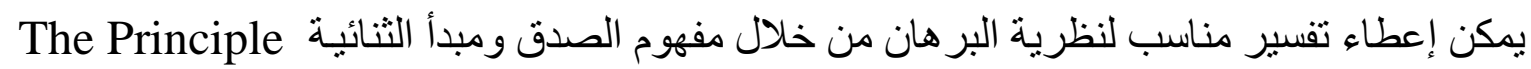
كof Bivalence

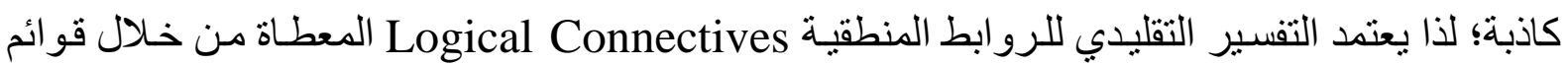

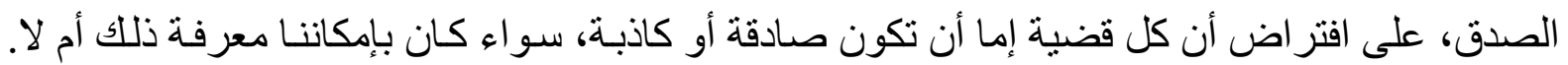

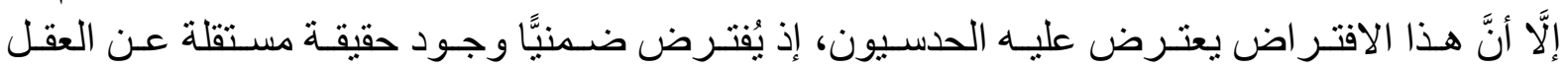

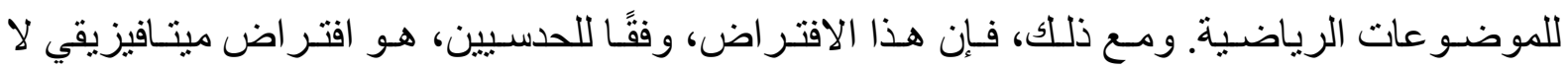

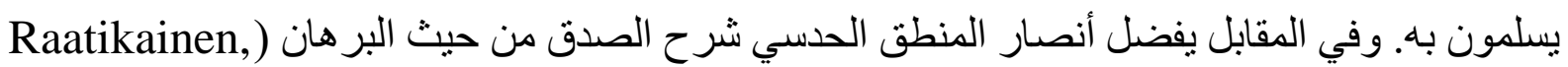
. $(2013$, P. 2

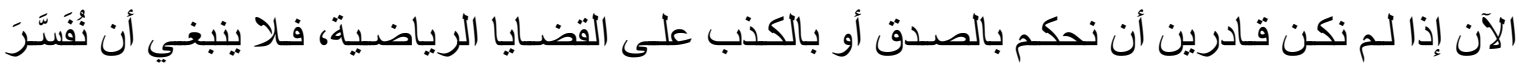
"الثو ابت المنطقية" Logical Constants من خلال شروط الصدق و الكذب لرو ابط الثوابت المنطقيـة،

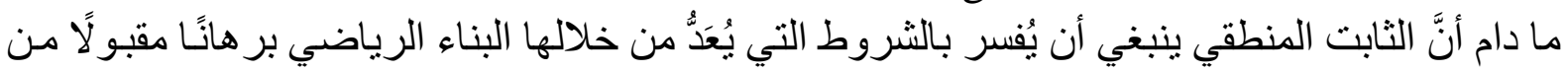

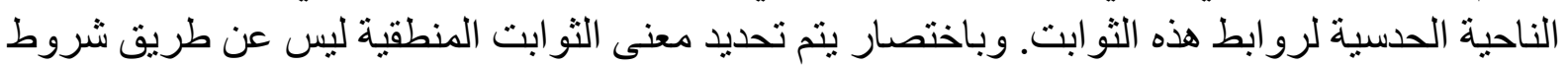

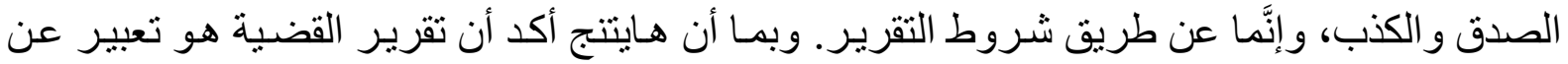

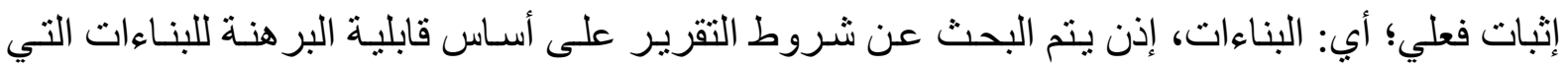

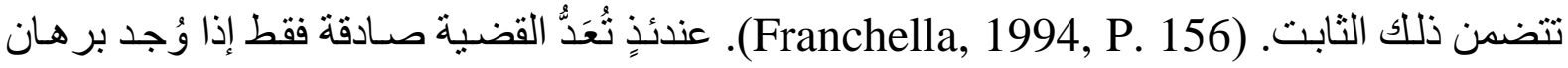

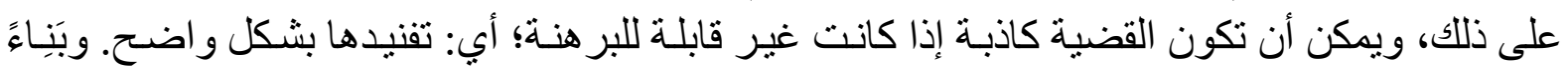
على ذلك، سيكون مـن الصسب الحكم على بعض القضـايا الرياضية جيدة التكوين Well-Formed بالصدق أو الكذب. (McCarty, 2006, P. 90).

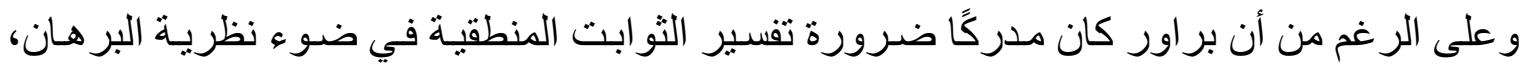

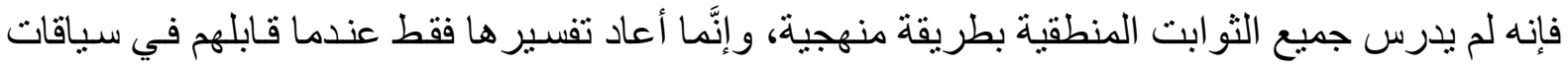
مختلفة من مناقنته للقو انين المنطقية، فقد ظلت مهمة إعادة تفسير جميع الثوابت المنطقية مفتوحة إلى أن صيغت بشكل أدق من خلال هايتتج. قد سُمَّي التفسير الحدسي للثو ابت المنطقية بـ (BHK) نسبة إلى أقطاب المنطق الحدسي " بر اور

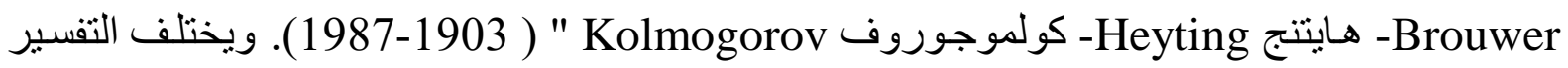

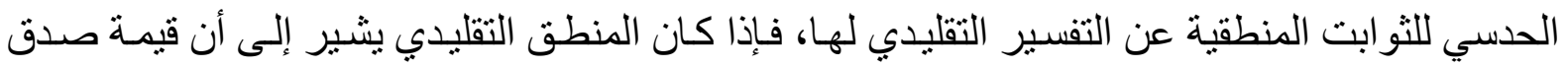

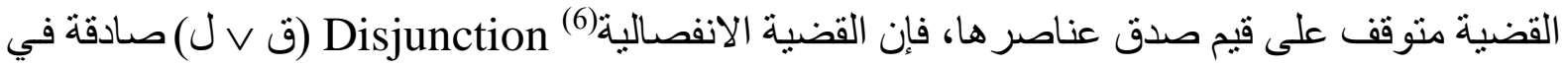

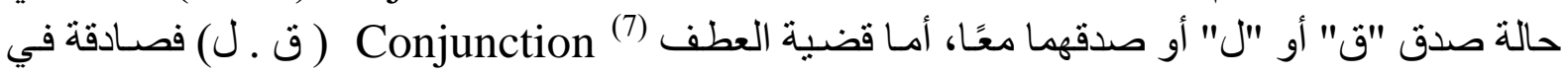

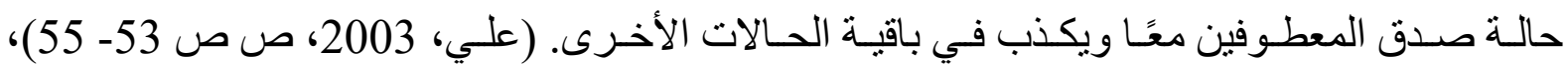

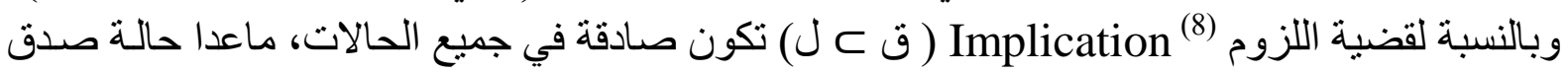
المقدم وكذب التالي (علي، 2003، صاله صله 65).

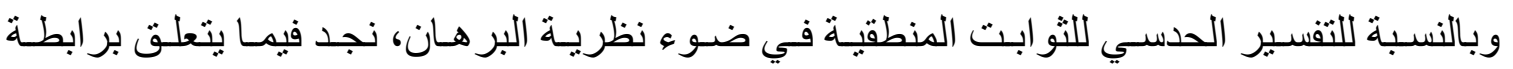

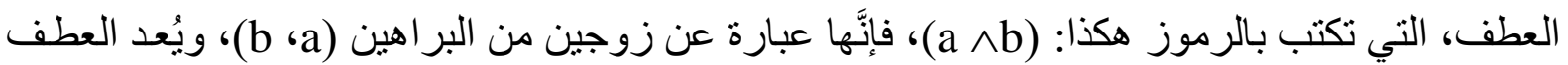

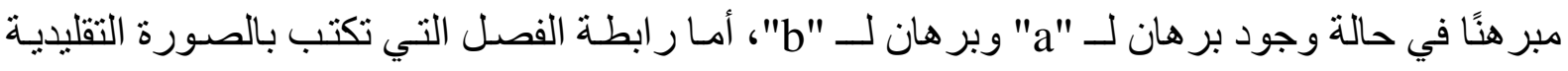

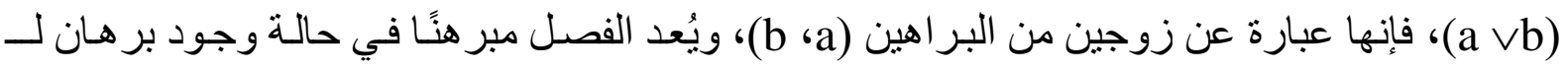

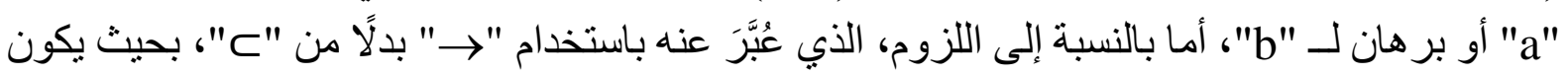




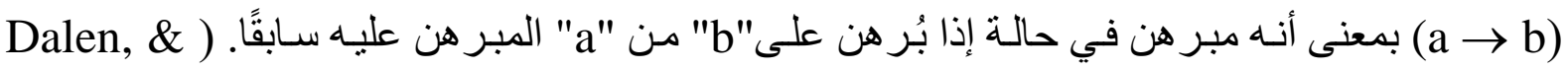
(Atten, 2006, P. 514 النتيجة الطبيعية لنظرية الصدق الخاصة بالقضايا الرياضية و غير الرياضية ـ على حد سواء- هي أن

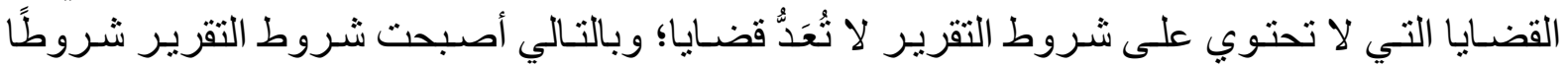
للصدق. (Benacerraf, \& Putnam, 1983. PP. 24, 25).

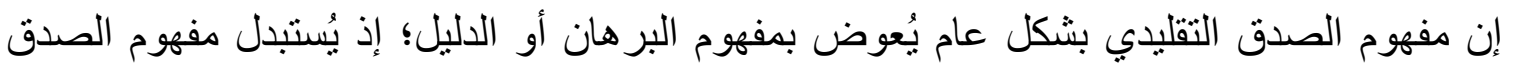

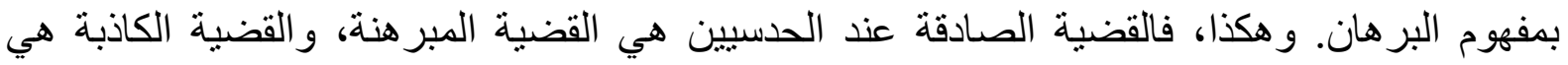

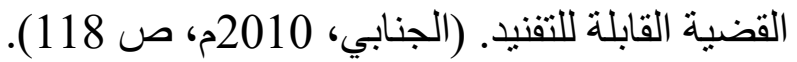

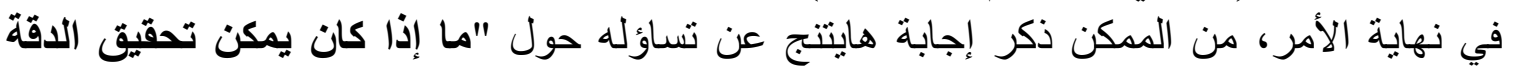

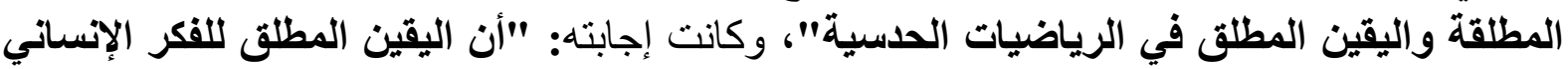

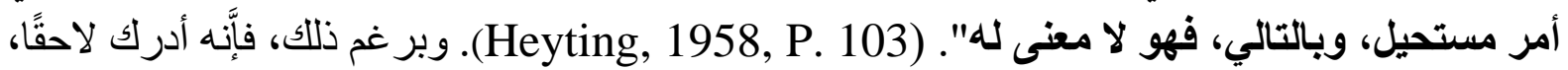

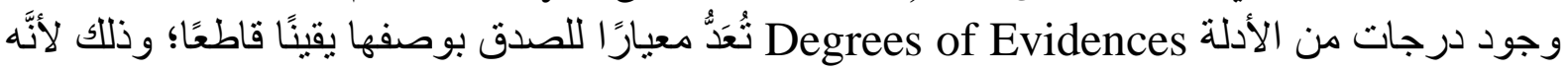

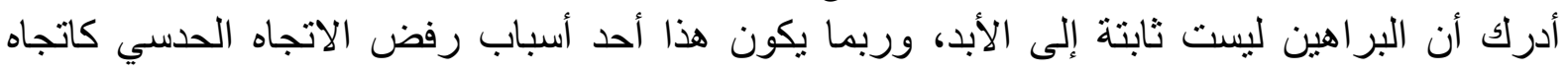

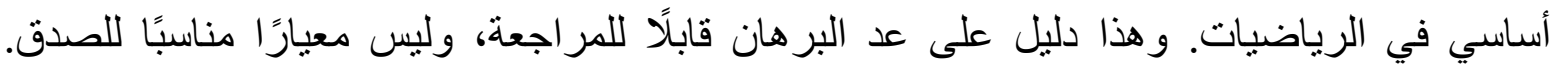
.(Franchella, 2007, P. 12)

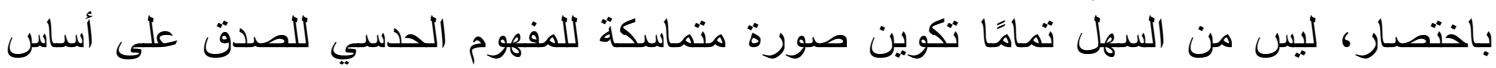

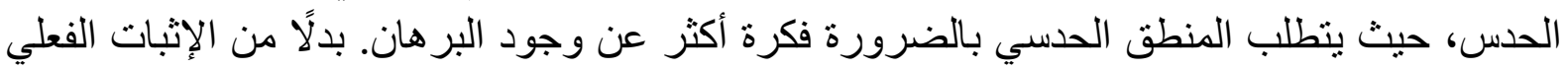

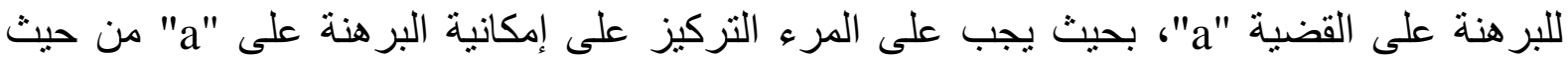

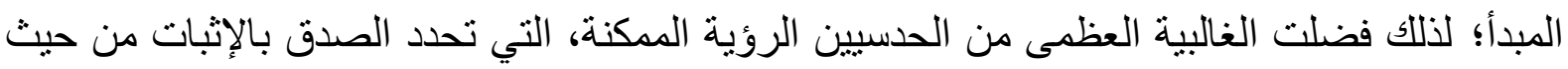

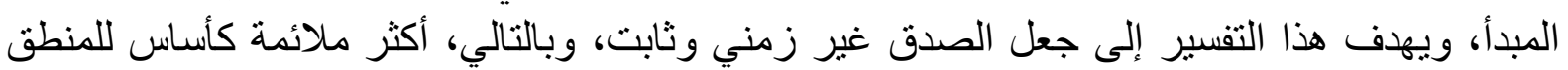
الحسي. (Raatikainen, 2013, P. 10).

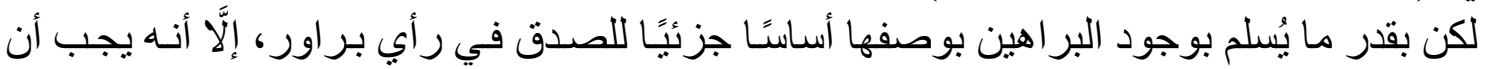

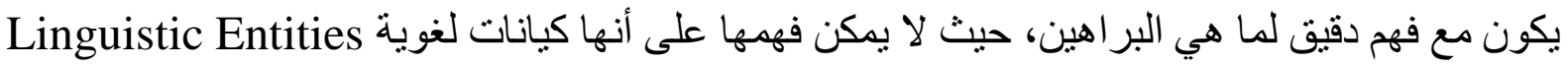

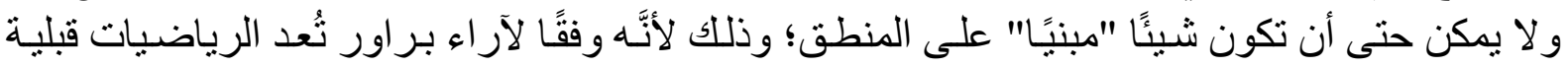

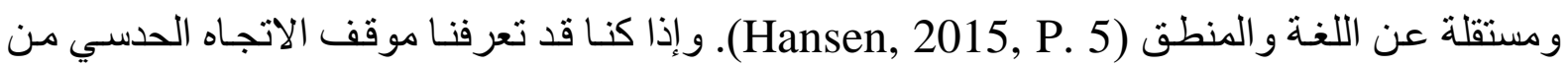

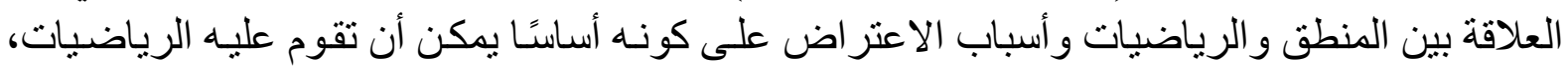

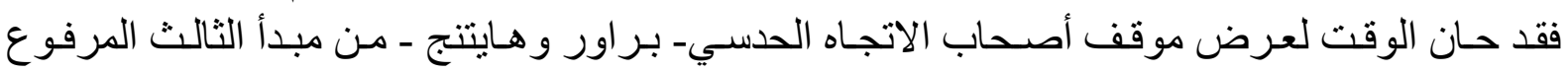

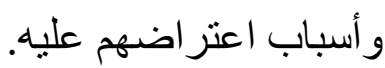

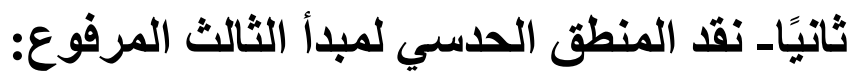

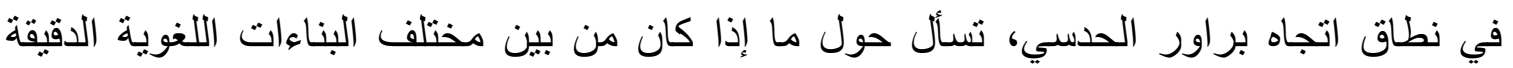

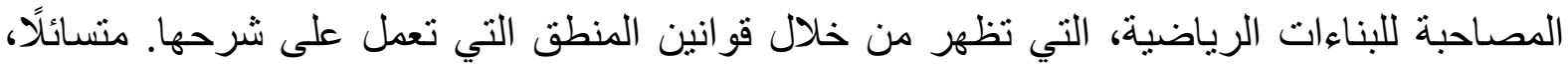

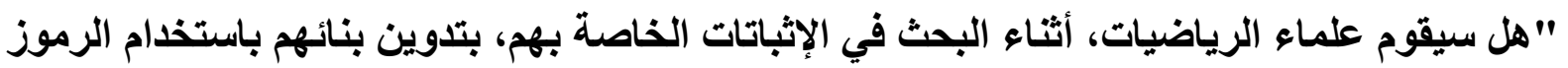
اللغوية للمبادئ المنطقية في جميع عملياتهم الحسابية الرياضية الثيات؟ ". (Brouwer, 1975, P. 443).

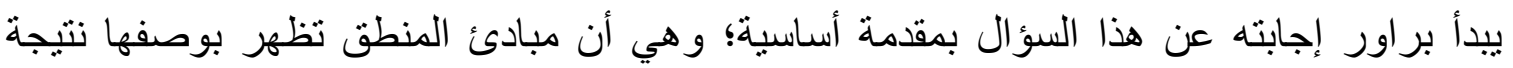

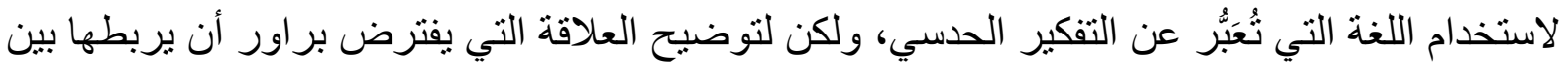

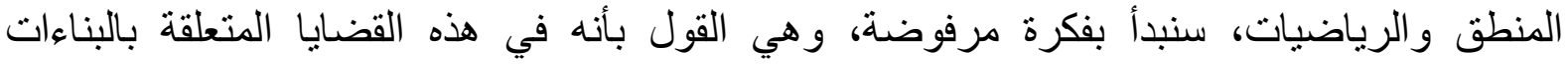

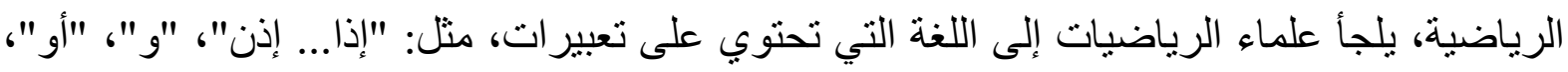


"لا "،"كل"، التي تشير إلى ما نسميه اليوم بالروابط المنطقية والأسوار. من وجهة نظره، سيكون من

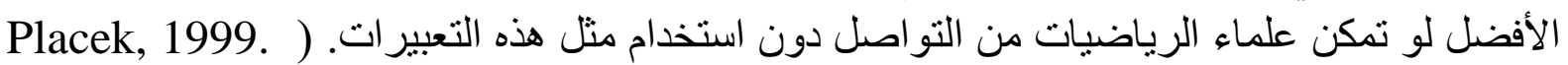

(PP. 62, 63 و على ذللك، قام براور في أطروحته برفض تطبيق المبادئ المنطقية كروابط بنائية، حيث يرى أنه

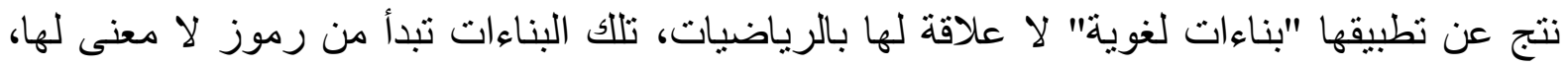

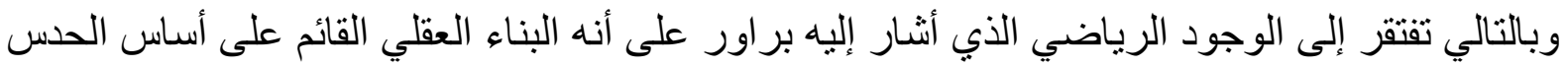

وحده. (Stigt, 1990, PP. 233, 234 ).

من هنا، تحولت القضية من التساؤل حول الوجود الرياضي إلى التساؤل حول صحة المبادئ

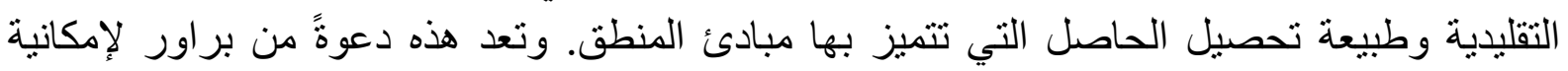

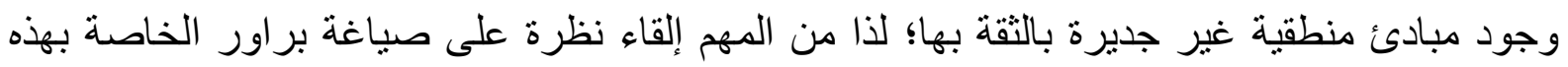

المشكلة، وخاصةً أنَّ نقده للمنطق التقليدي يقوم على على ما يأني(Dalen, 2002, P. 3):

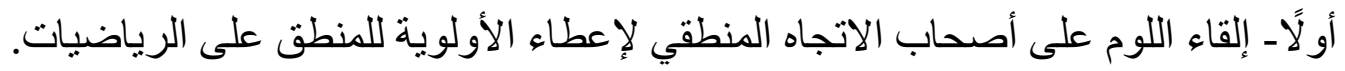

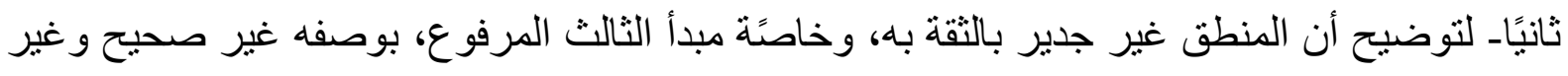
مُبرر. نتيجة لرفض أنصار المنطق الحدسي المفهوم التقليدي للصدق، ترتب علي ذلك التخلي عن بعض التض

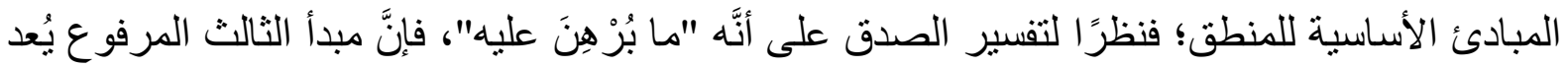

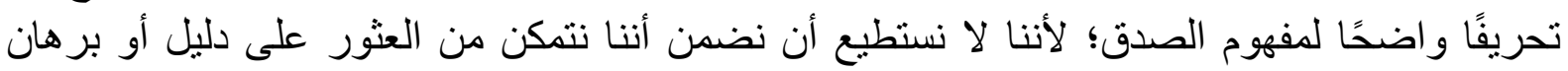

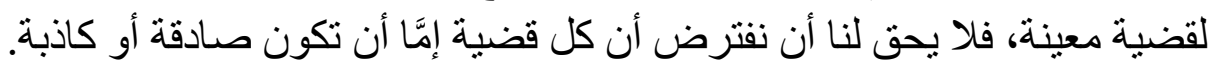
و على ذلك من الضروري معرفة رأي المنطق الحدسي في المبادئ المنطقية التقليدية، وخاصةً

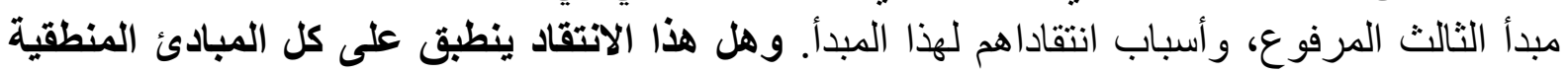

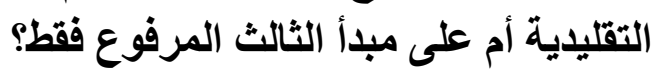

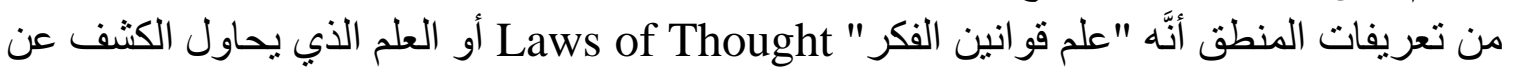
المبادئ التي يسير عليها الفكر الإنساني، وقد حصر أرسطو Aristotle (384 ق.م -322 ق. ق.م) هذه

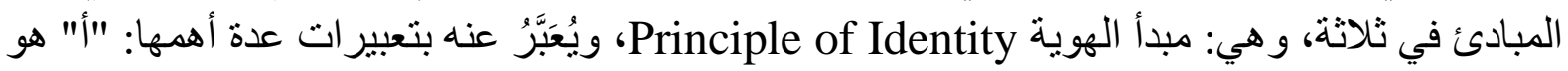

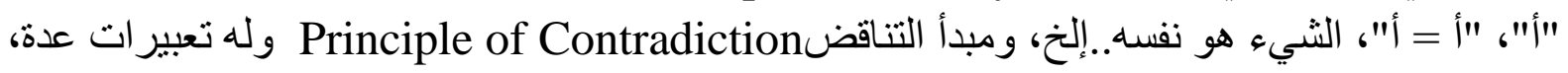

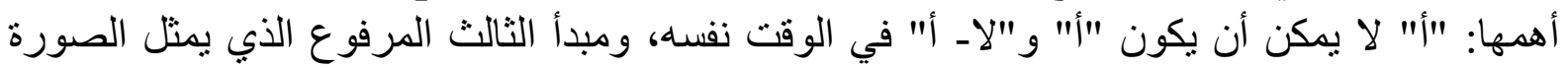

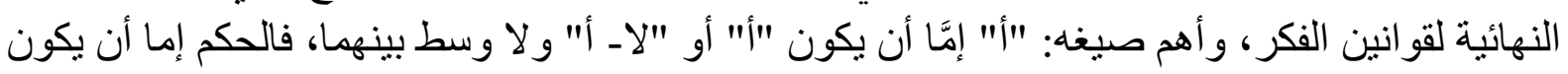

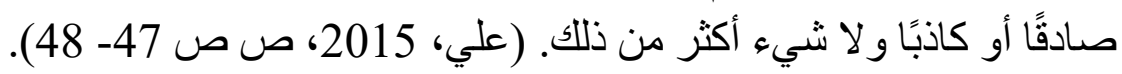

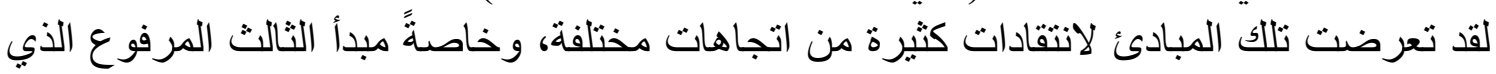

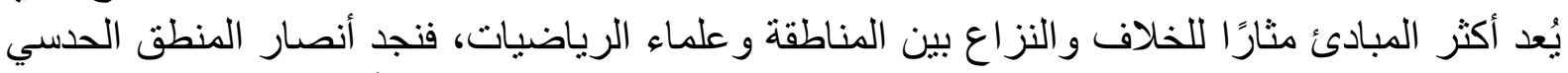

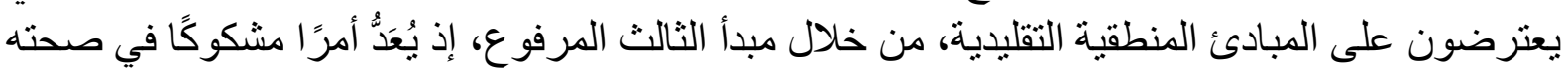
من منظور حدسي. ويمكن تسجيل أول اعثرض عليه من خلال تفسير المنطق الحدسي لمفهوم الصدق،

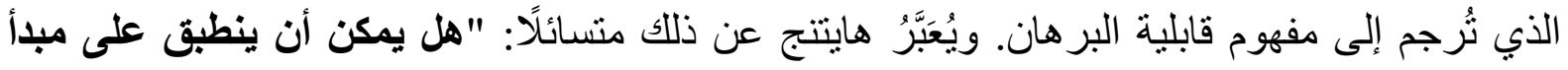

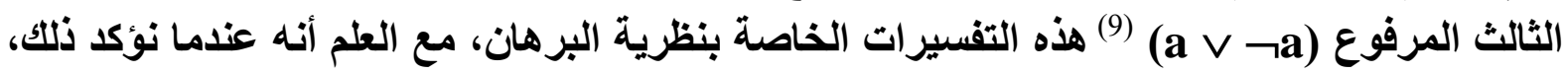

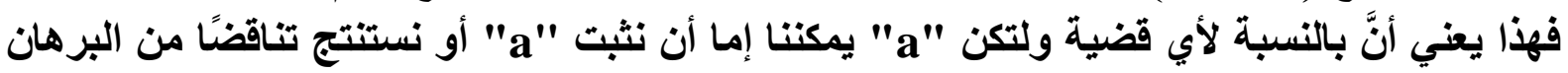

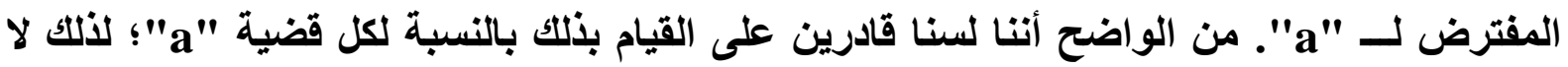


يمكن إثبات مبأ الثالث المرفوع. إذا لم نكن نعرف ما إذا كاتت "a" إدادقة أم لا، فمن الأفضل ألا نقرر ذلك". (Heyting, 1974, P. 87).

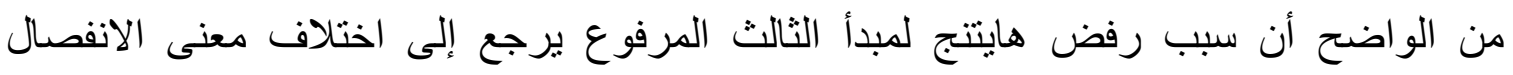

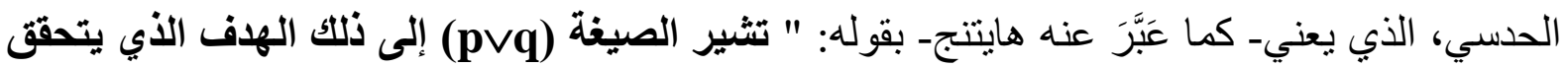

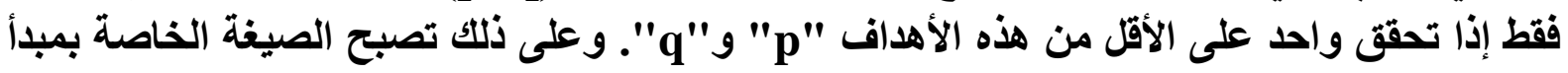

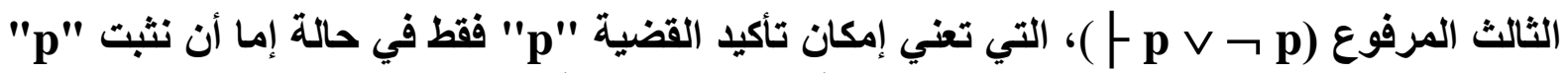

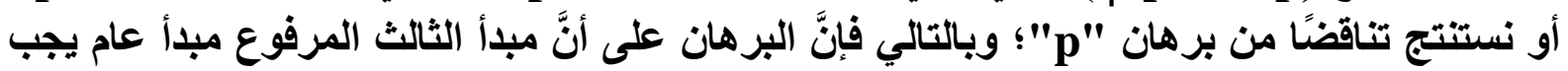

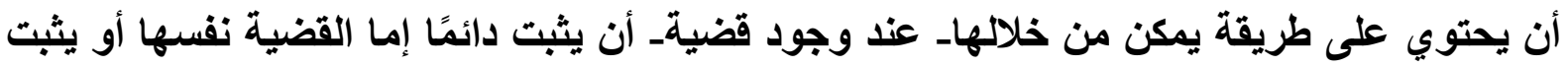

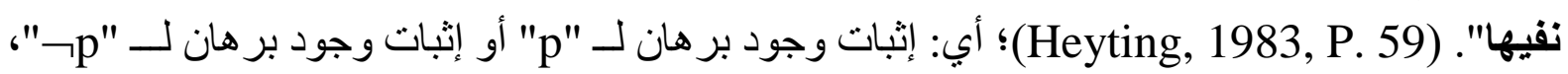

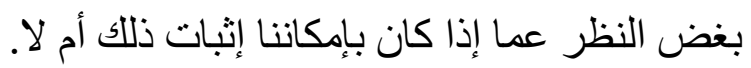

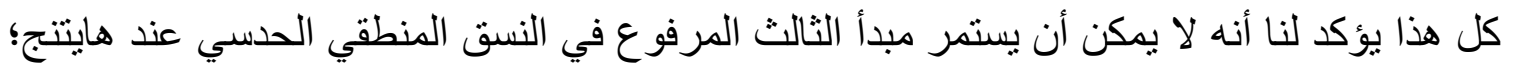

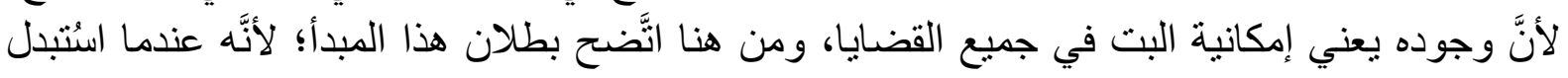

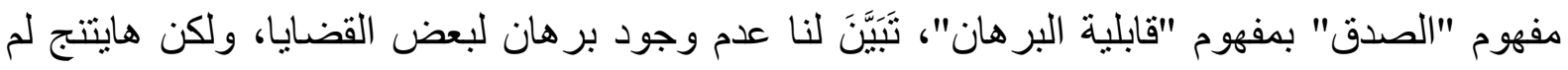

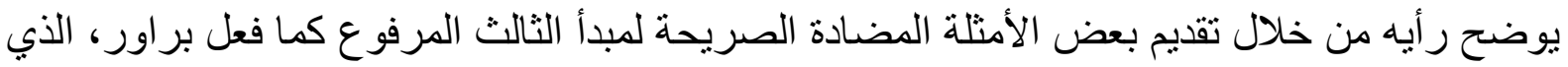

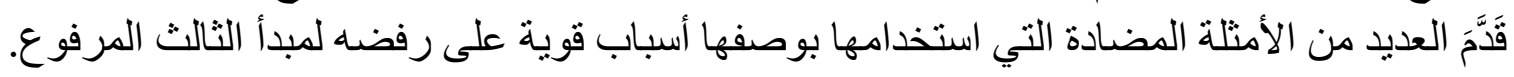

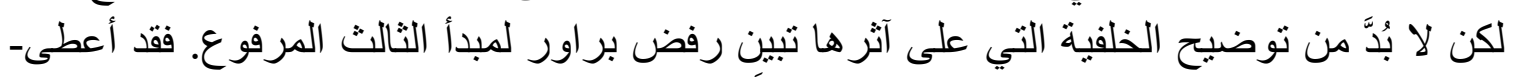

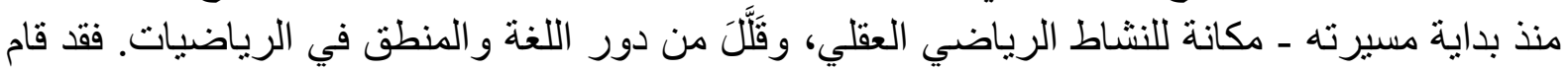

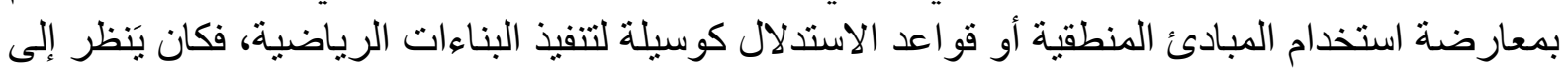

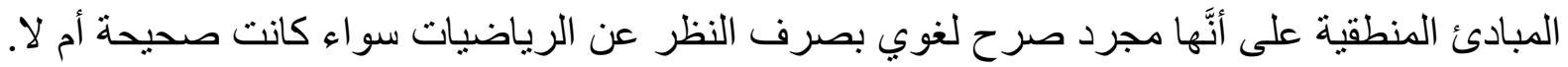

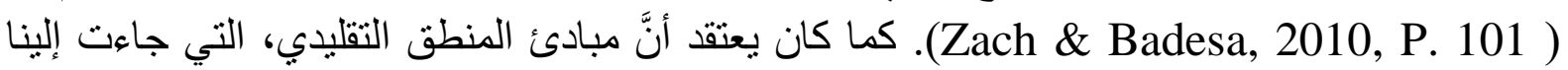

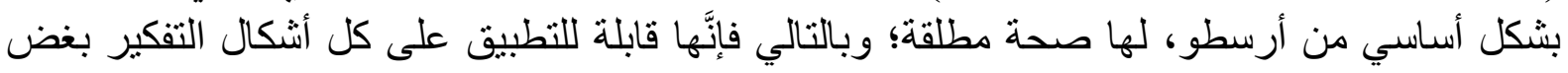

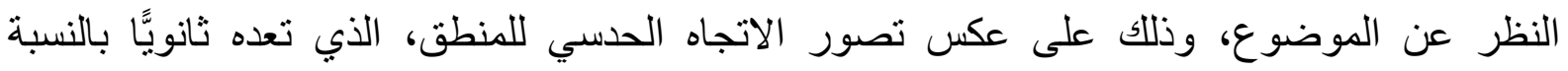

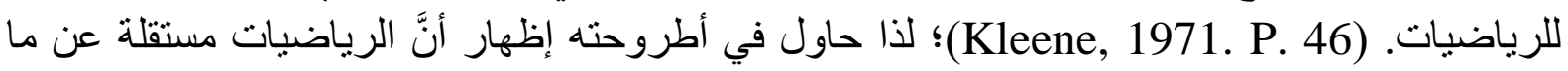

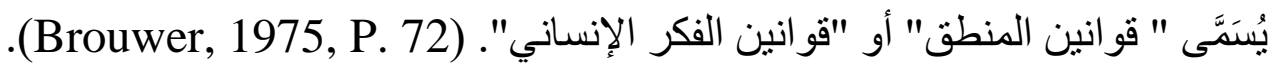

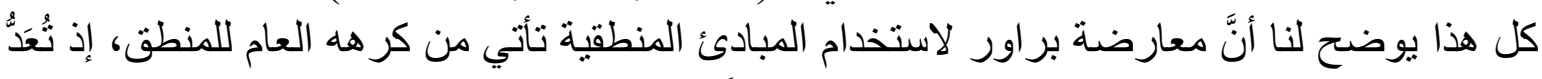

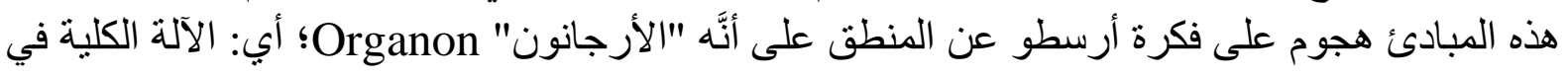

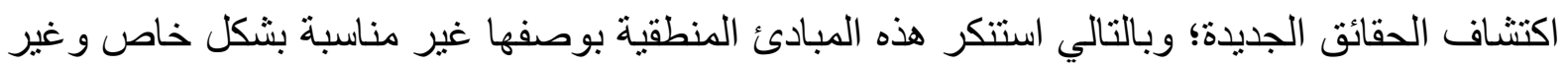

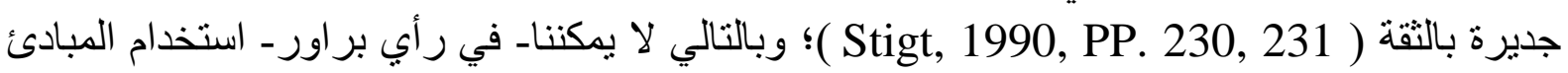
المنطقية التقليدية من أجل شرح ماهية الرياضيات أو وصف كيفية تنفيذ البناءات الرياضية (Kaneko,2002, P. 37)

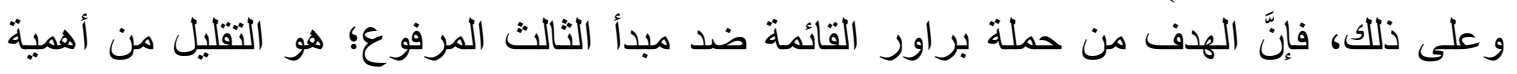

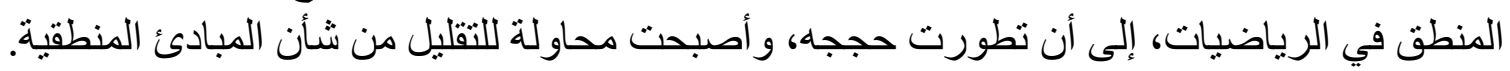

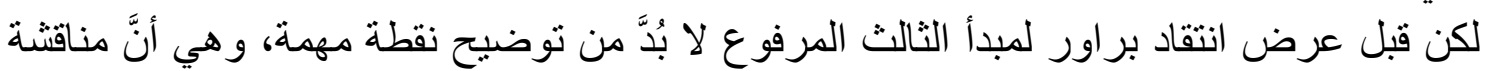

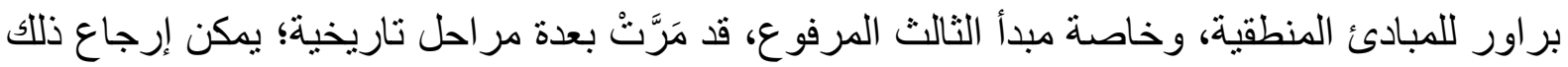

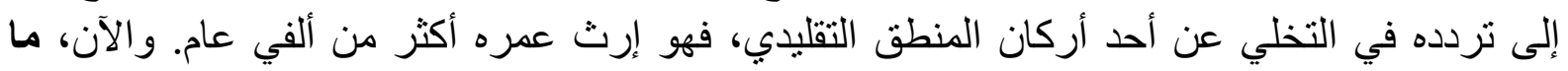
مراحل التطور الفكري الخاصة بالمبادئ المنطقية عند براور؟ النّا؟ 


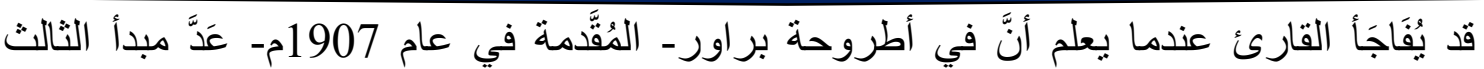

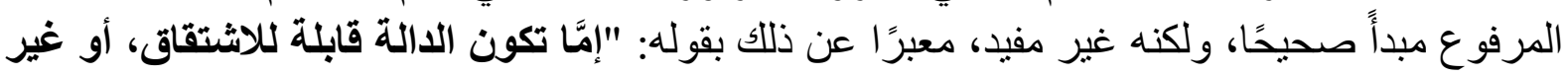

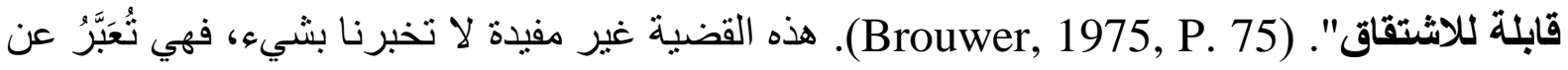

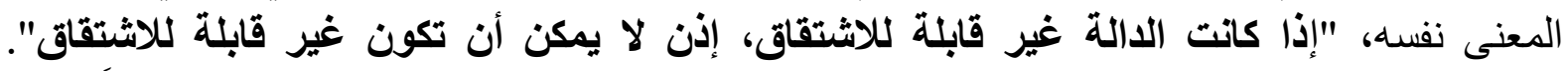
(Brouwer, 1975, P. 75)

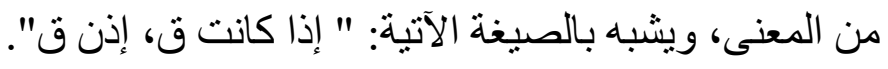

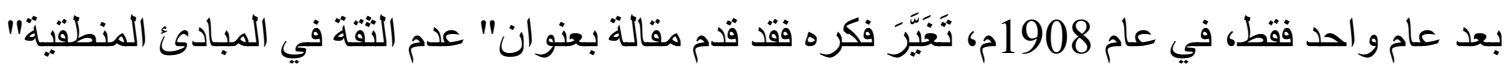

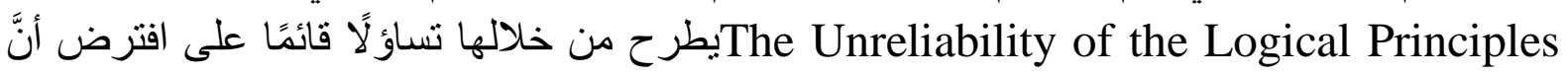

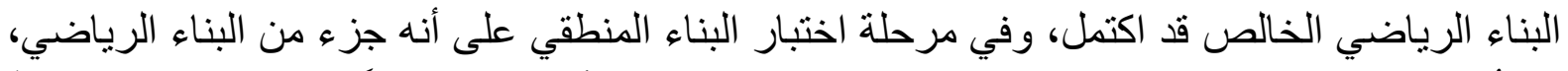

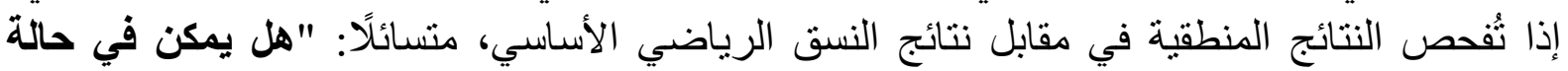

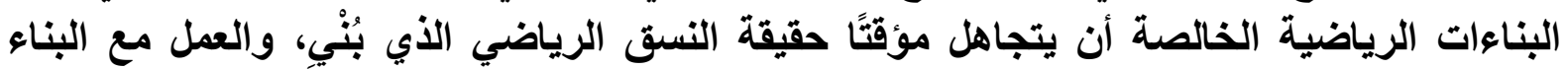

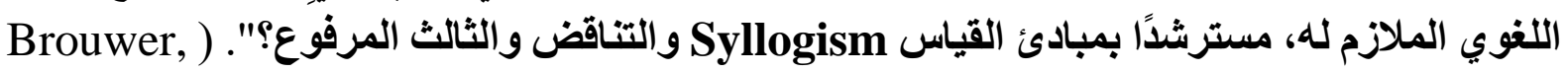

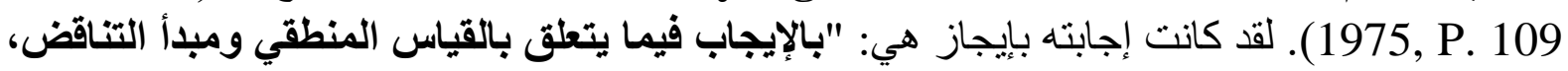

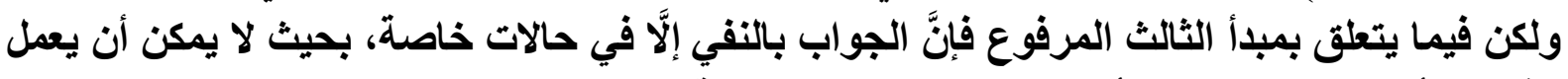

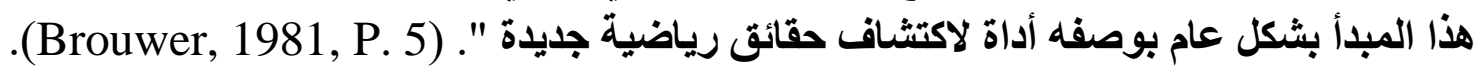

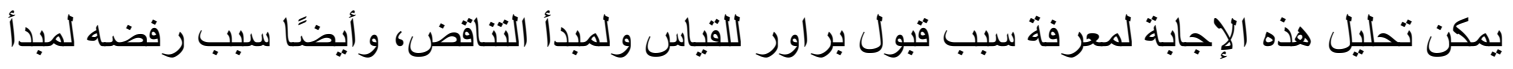

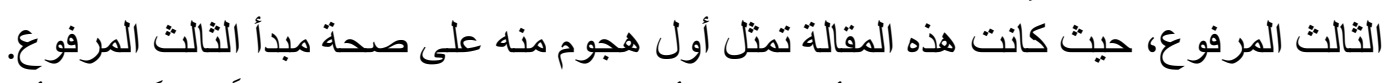

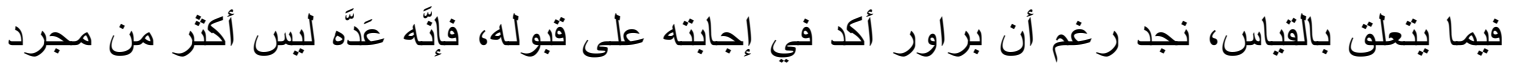

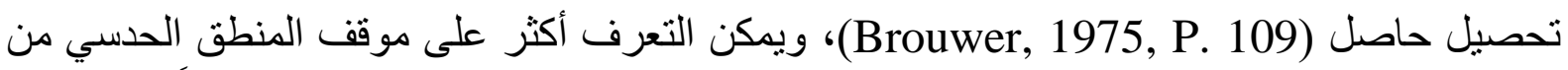

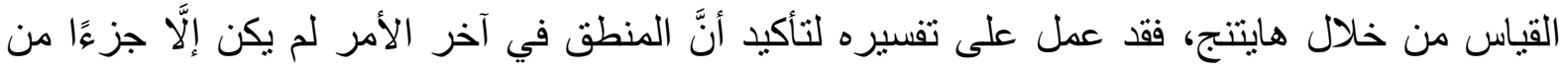

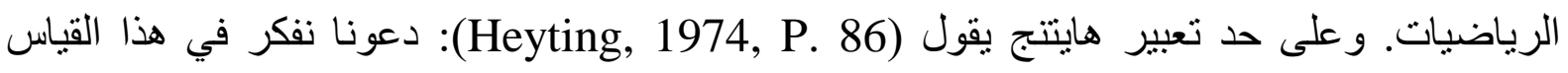
المنطقي:

$$
\begin{aligned}
& \text { (1) سقر اط إنسان }
\end{aligned}
$$

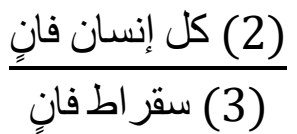

$$
\begin{aligned}
& \text { أولًا - يمكن التعبير عنه باللغة الرمزية هكذا: } \\
& \text { (1) "أ" هو "ب" }
\end{aligned}
$$

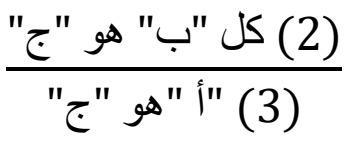

فإذا اتفق (1) و(2)، من المتوقع أن يتفق أيضًا مع (3) (3).

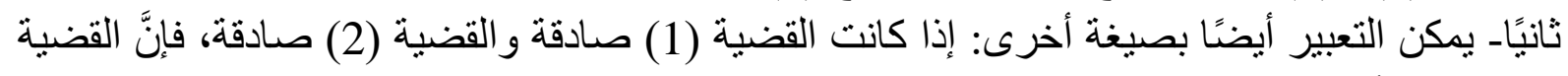
(3) صادقة أيضًا.

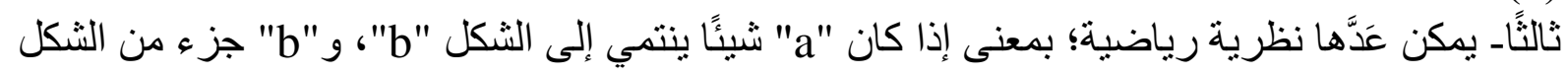

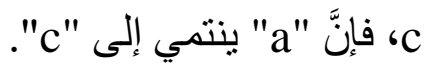

$$
\begin{gathered}
a \in b \\
\frac{b \subset c}{a \in c}
\end{gathered}
$$




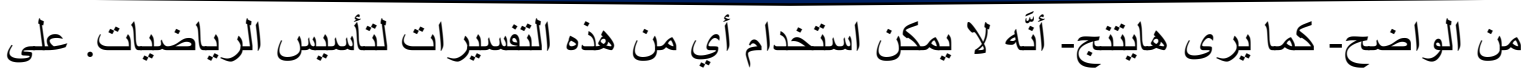

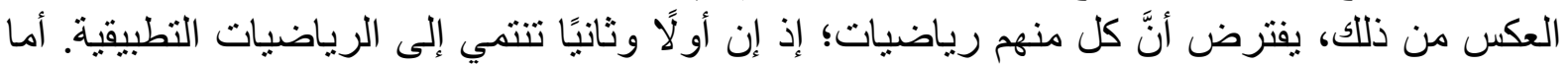

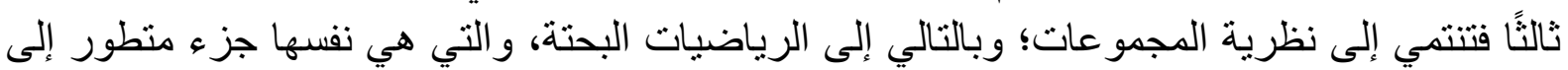
حد ما من الرياضيات (Heyting, 1974, P. 86).

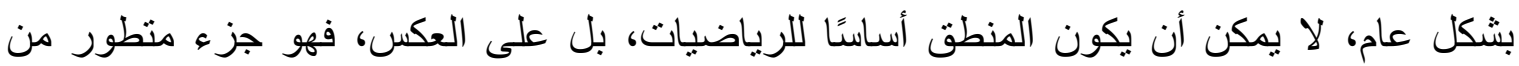

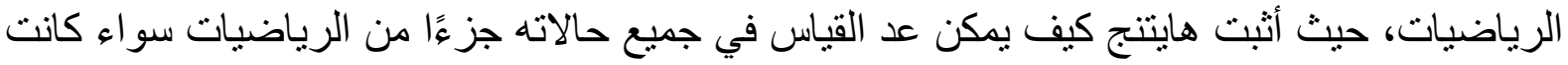

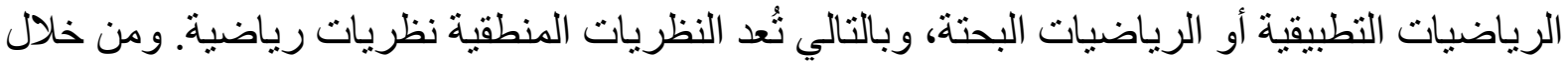

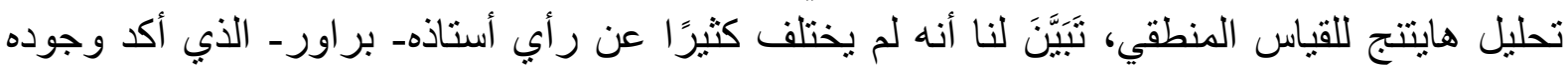

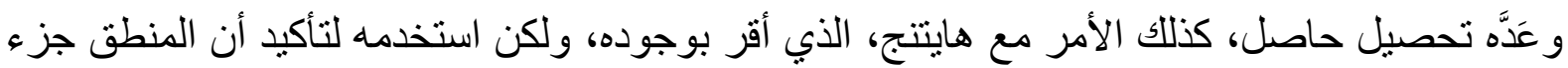

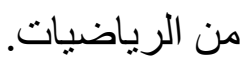

هذا عن سبب قبول براور للقياس، أمَّا فيما يتعلق بمبدأ التناقض فقد ذهب الحدسيون إلى أنَّ المبدأ

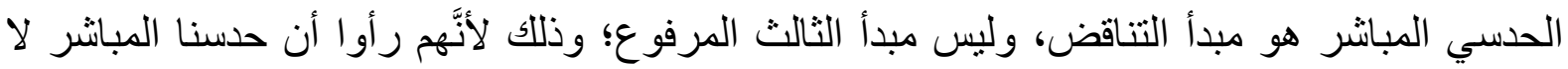
يقبل التناقض (محح، 1982م، ص 19 19). فنجد براور أيد وجوده، وأكد أنَّه لا يقبل الجدل (

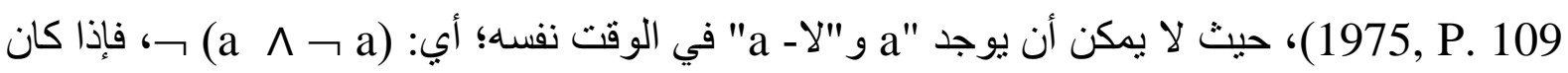

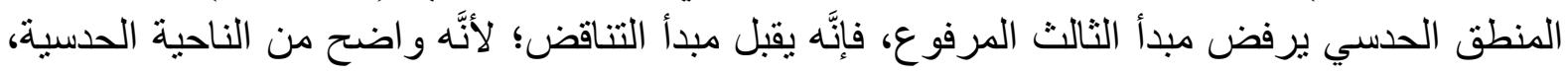

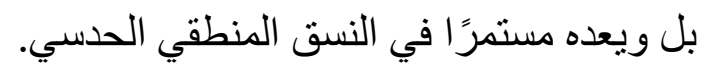
لكن فيما يتعلق بمبدأ الثالث المرفوع، لقد أثبت براور بطانلانها معبرًا عنه بالصيغة الرياضية

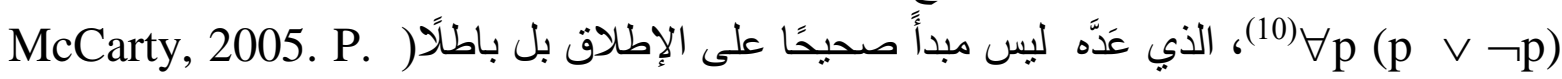

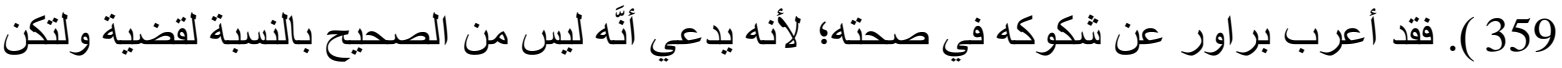

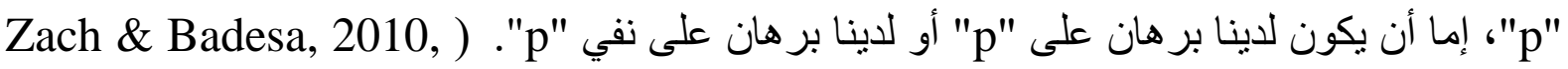

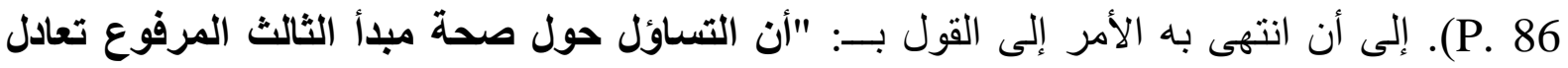

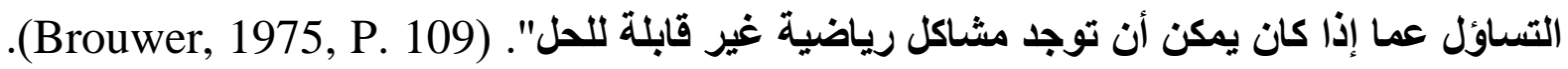

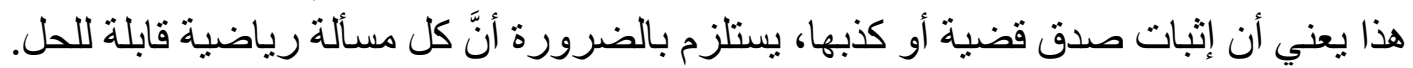

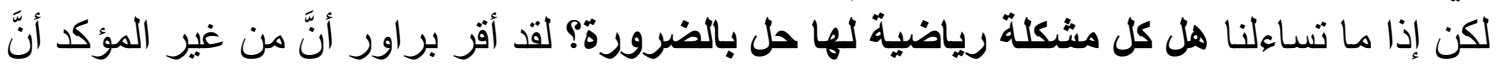

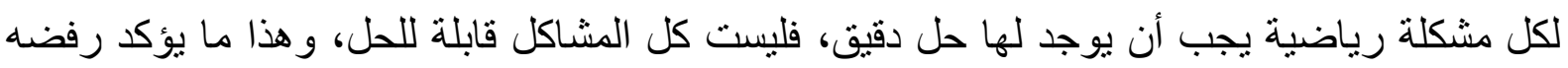

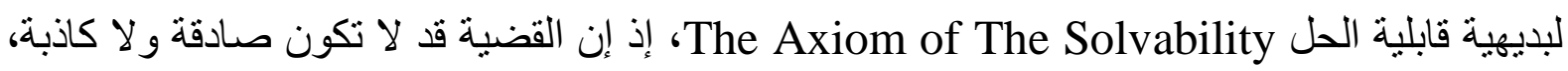

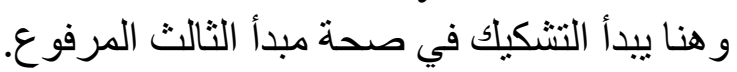

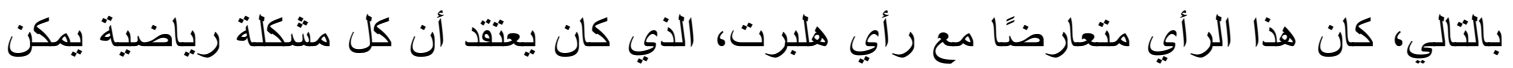

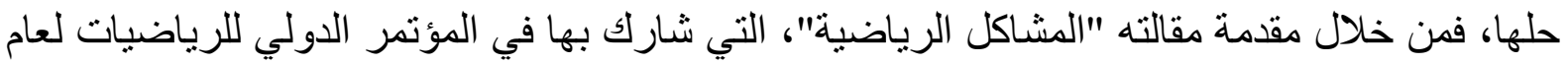

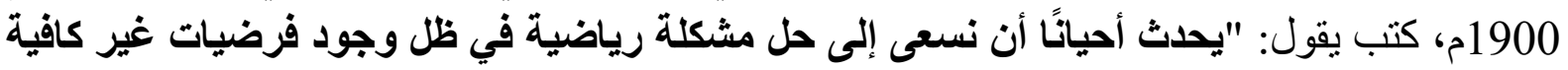

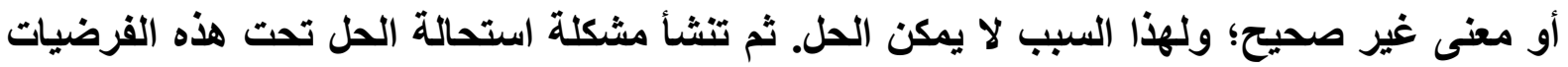

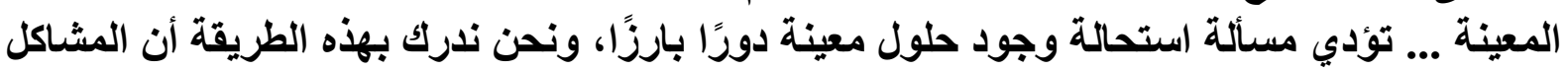

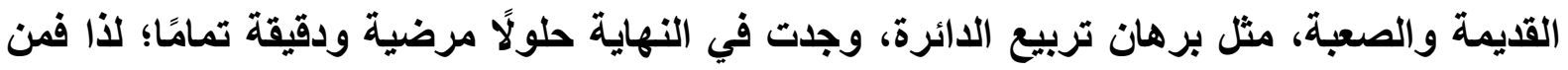

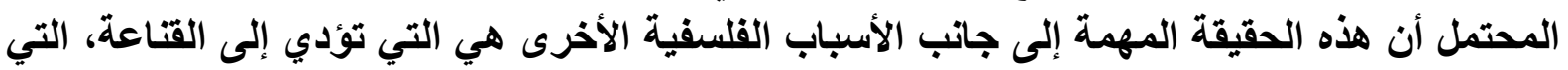

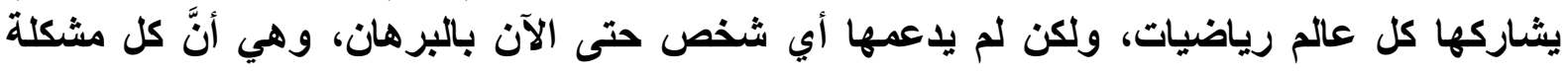

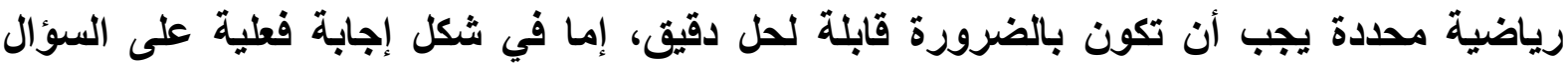

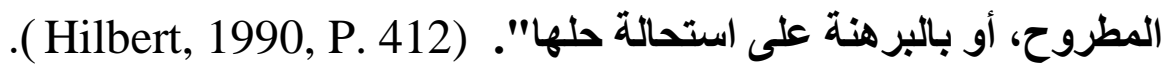




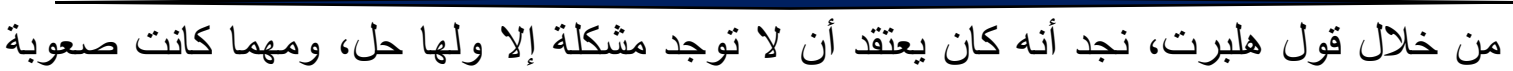

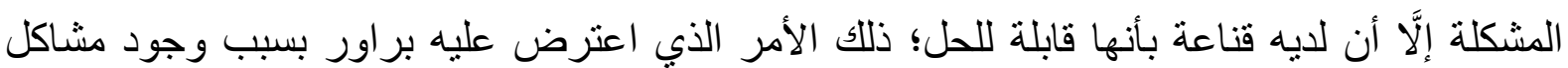

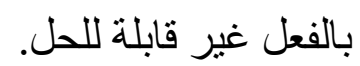

لكن، لماذا يفترض براول

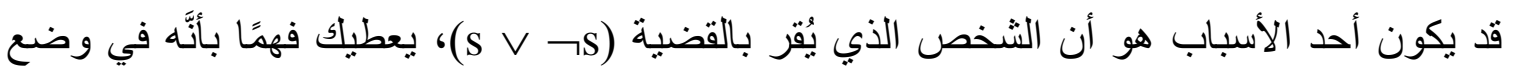

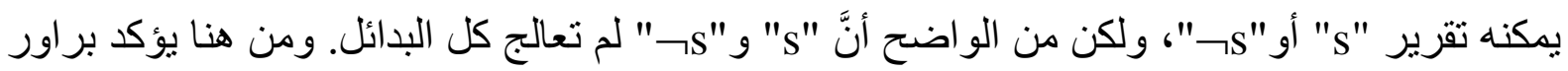

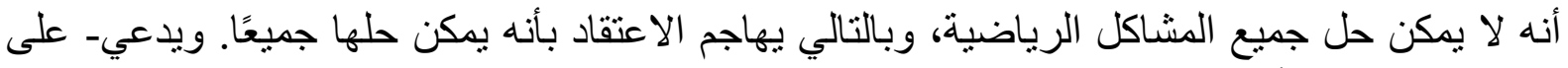

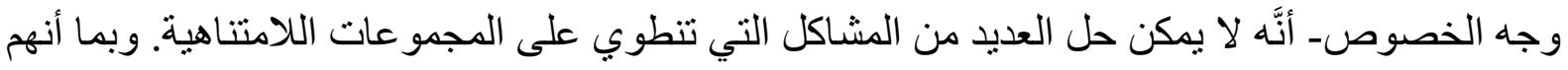

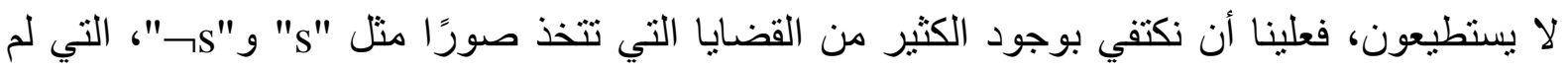

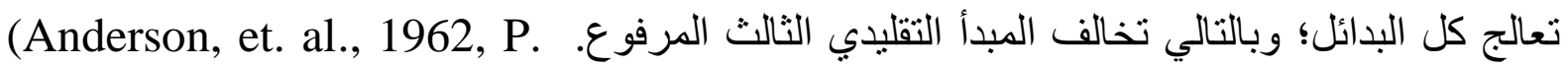

ومن الملاحظ أنَّ براور استثهـ بمقالة هلبرت الخاصة بــــ "المشاكل الرياضية"، من أجل تأكيد

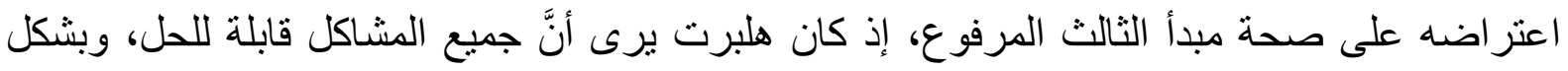

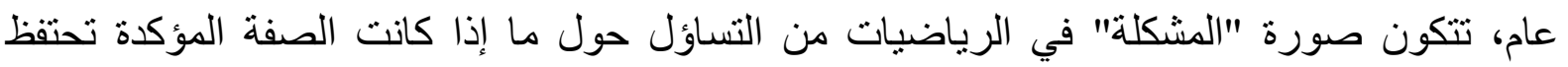

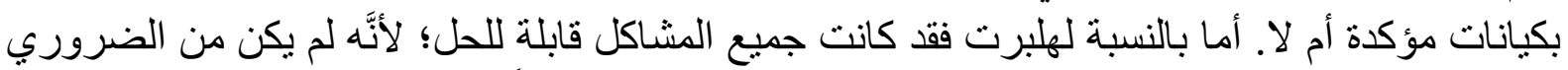

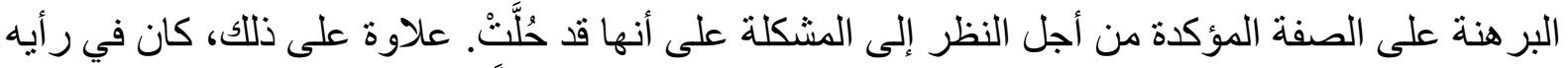

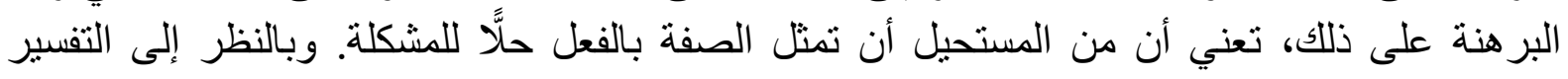

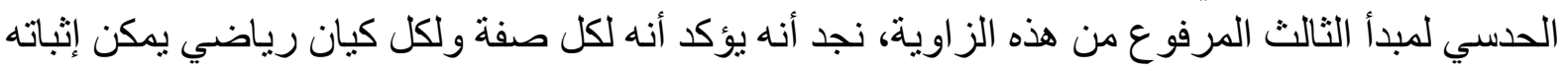

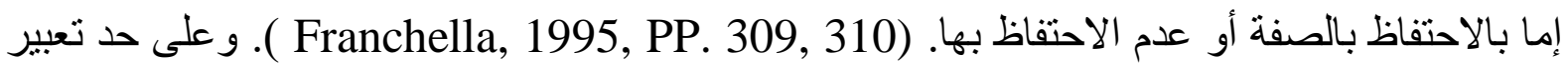

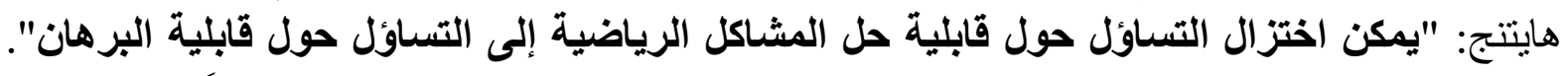
(Heyting, 1983, P. 59) تعلق صحة مبدأ الثالث المرفوع.

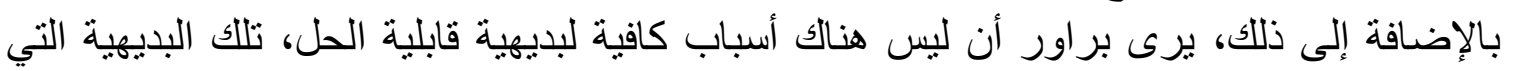

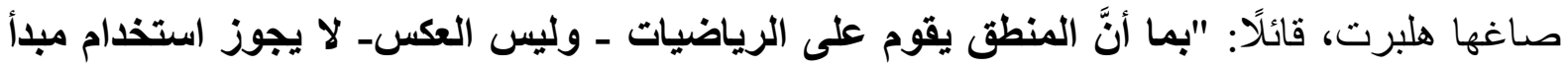

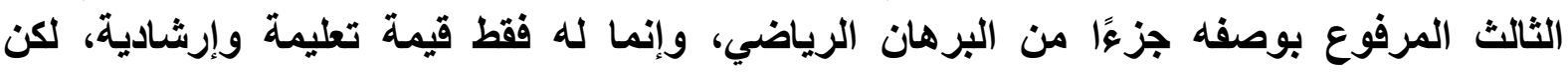

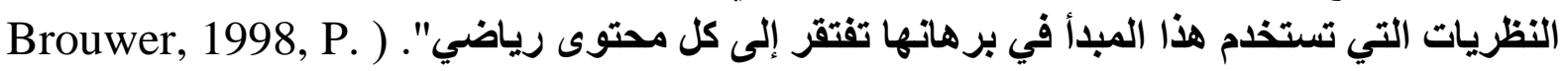

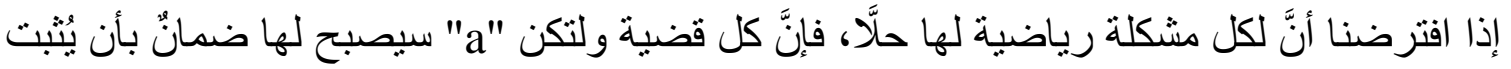

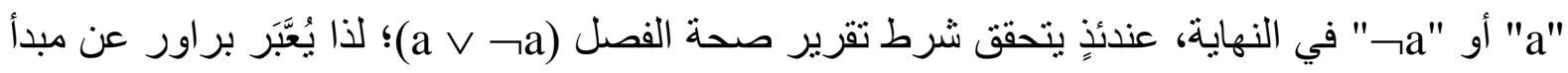

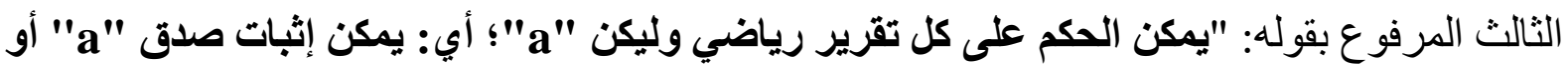
إثبات تناقض "a" " ". (Brouwer, 1975, P. 524).

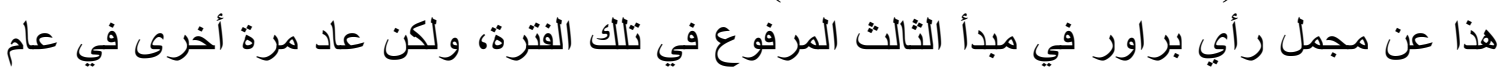

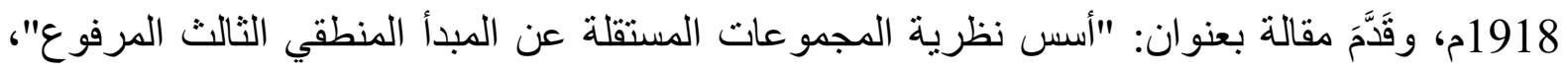

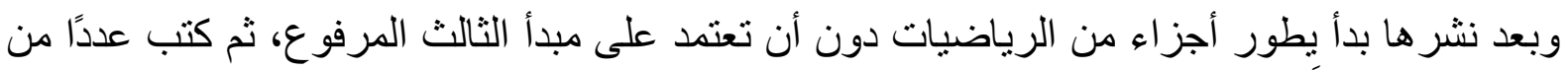

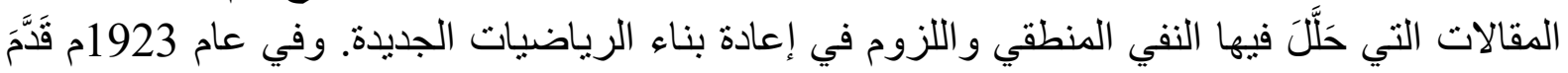

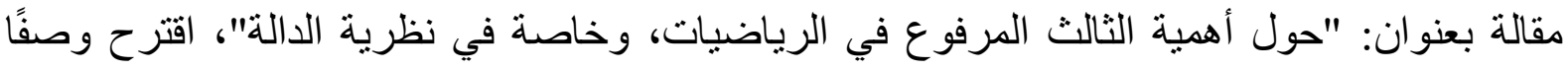


إيجابيَّا لكيفية انتقال مبدأ الثالث المرفوع، بشكل غير منطقي، من المجال المتناهي إلى الهجال

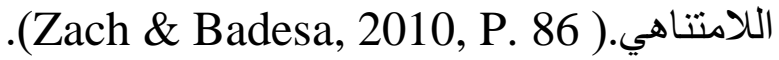

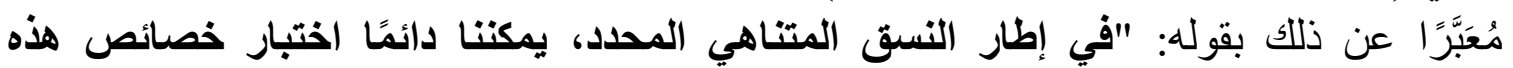

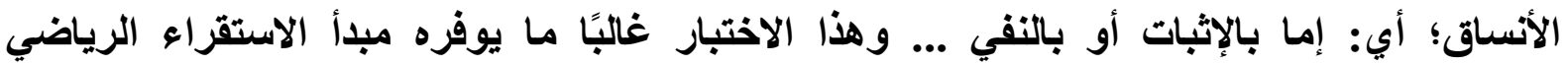

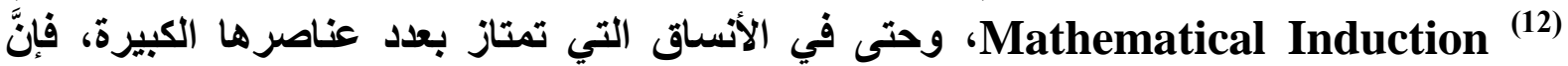

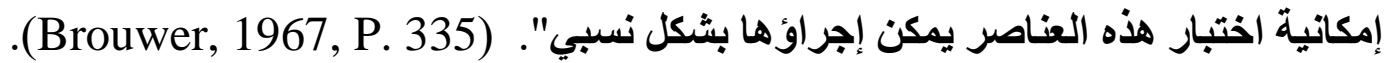

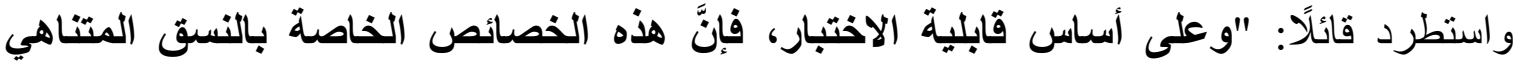

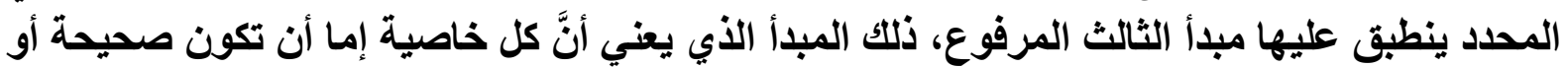

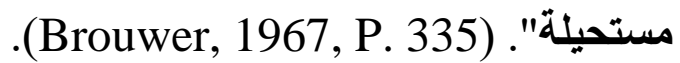

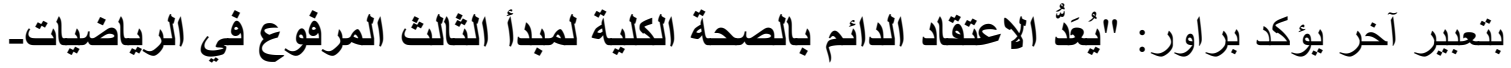

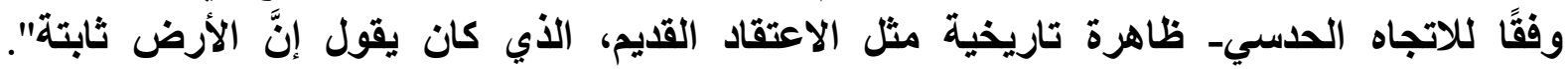
(Brouwer, 1975, P. 492)

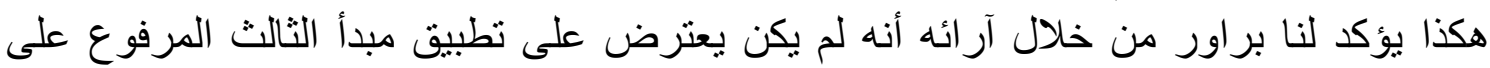

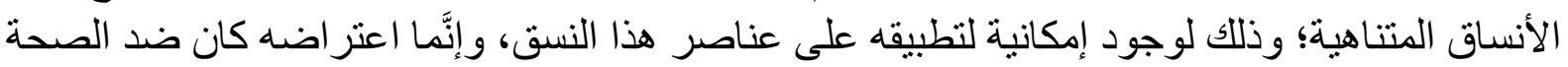
الكلبة لمبدأ الثالث المرفو ع خصوصنًا فيما بتعلق بالأنساق اللامتناهية.

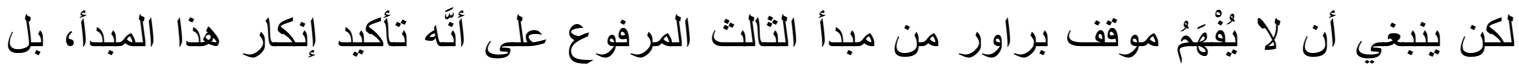

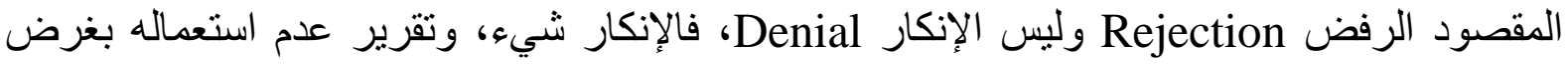

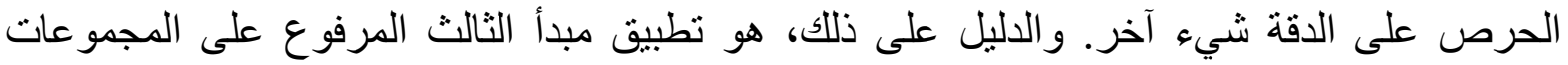

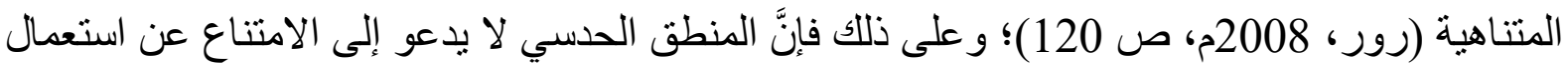

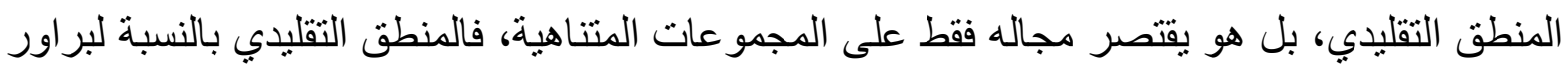
مناسب للمجال المتناهي فقط وليس للمجال اللامتناهي. (Posy, 2005, P. 335).

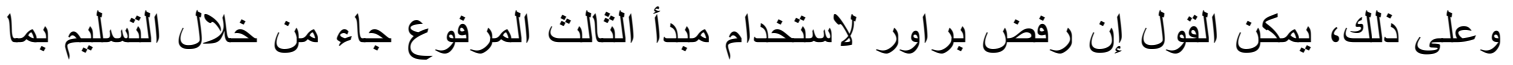
يأتي(Brouwer, 1998, P. 41) 1- أنَّ البحث في الأسباب التي تبرر هذا المبدأ، ومجال صحته تمثل هدفًا أساسيًا من أهداف البحث

$$
\text { في الأسس الرياضية. }
$$

2- أن يقتصر مجال صحته في الرياضيات الحسية على الأنساق المتناهية فقط.

بذلك يرى براور أنَّ تطبيق مبدأ الثالث المرفوع لا يمكن أن يتم دون قيد و ولا شرط، و وإنَّما في ميدان

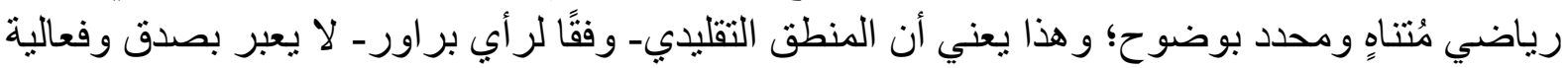

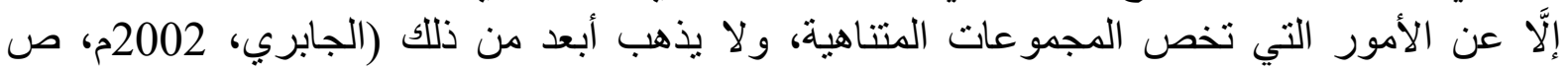

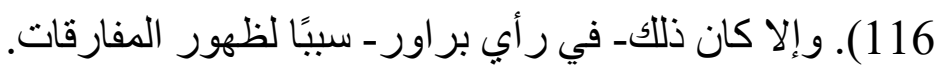

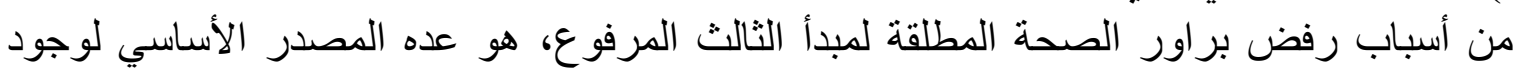

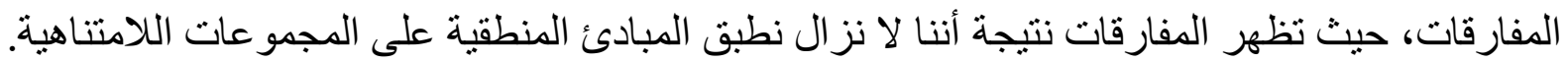

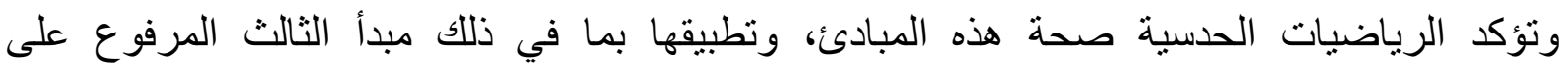

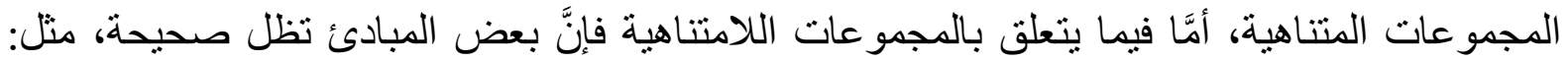
الهوية، و التناقض، بينما مبدأ الثالث المرفوع وما يرتبط به من استدلالات لا تكون صحيحة بالنسبة لهذه 
المجمو عات. (Kneal \& Kneal, 1962, P. 675)؛ وذلك لعدم وجود وسيلة محددة للتأكد من صدق أو كذب القضايا المتعلقة بالمجمو عات اللامتناهية.

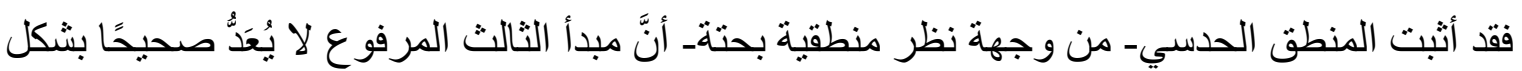

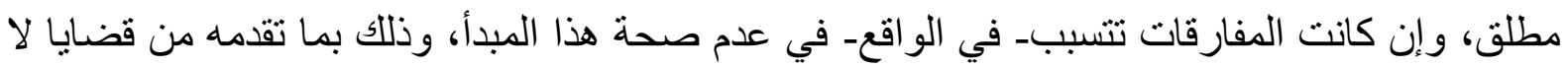

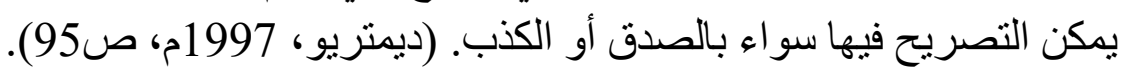

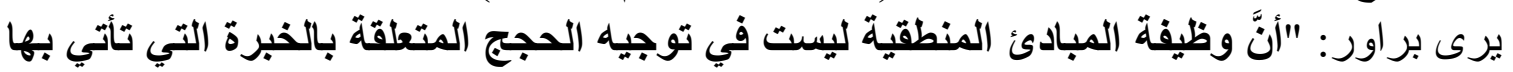

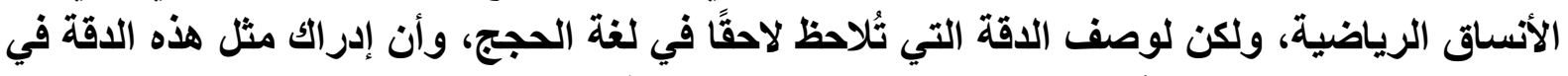

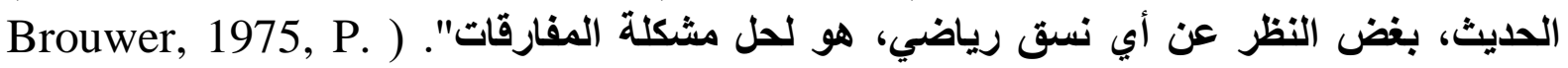

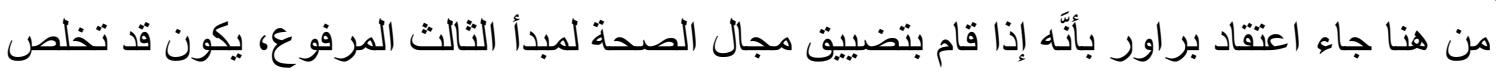

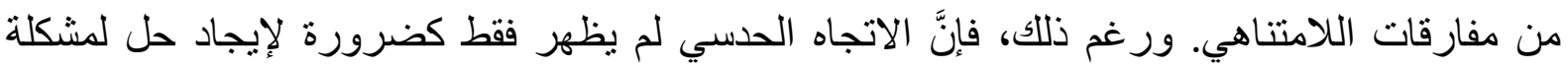

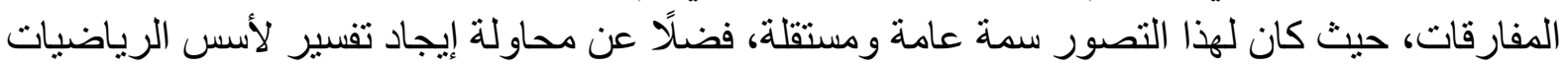

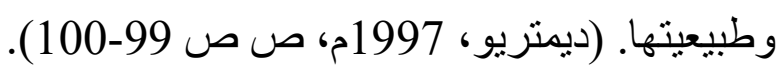

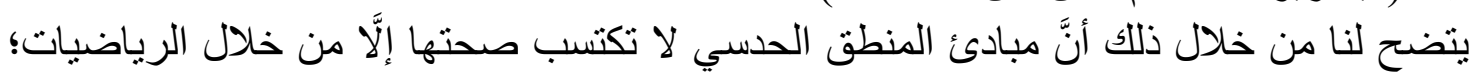

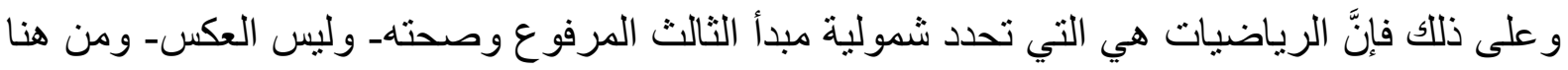

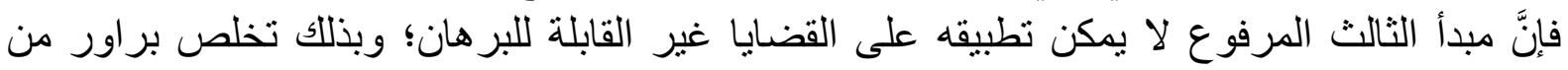

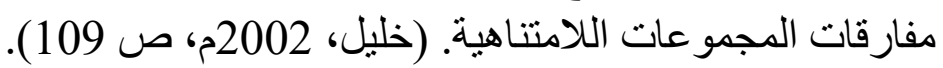

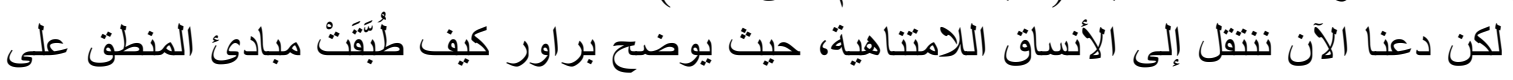

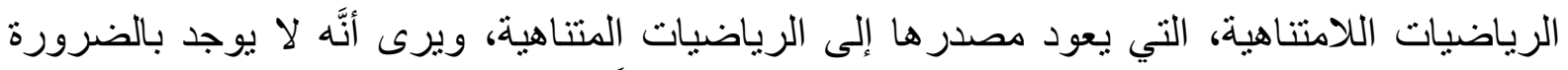

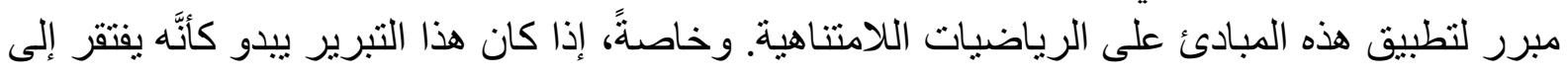

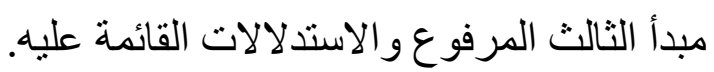

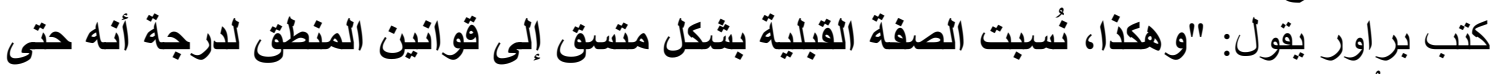

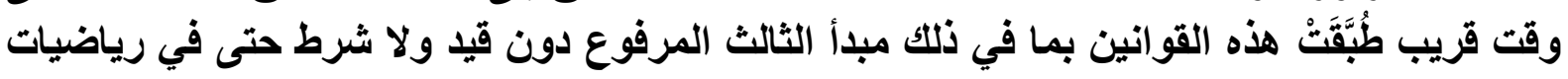

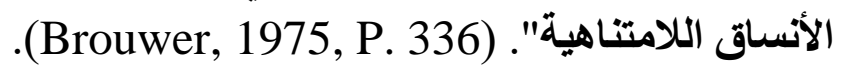

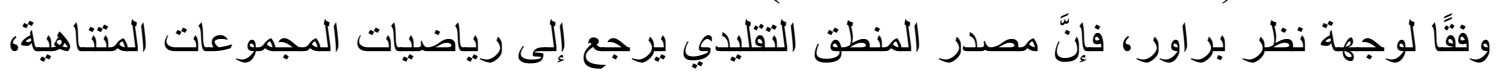

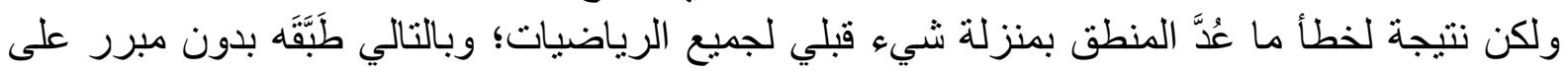

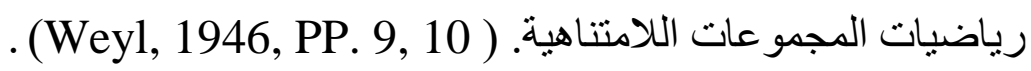

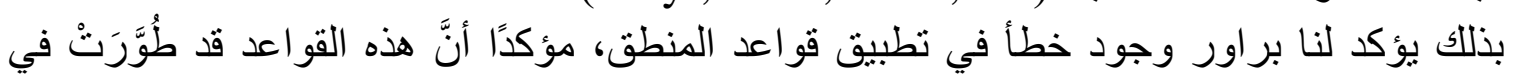

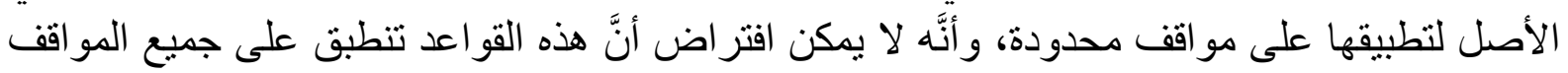

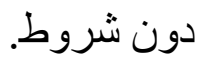

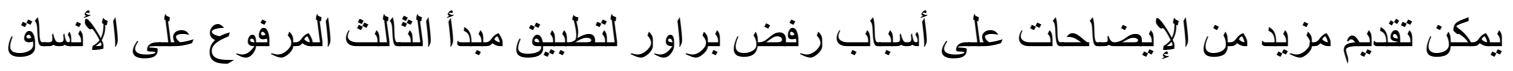

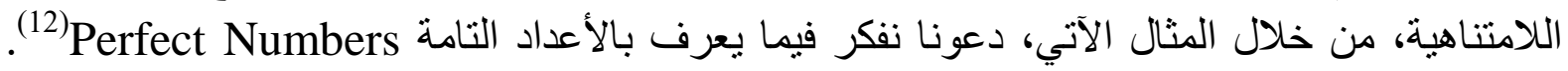

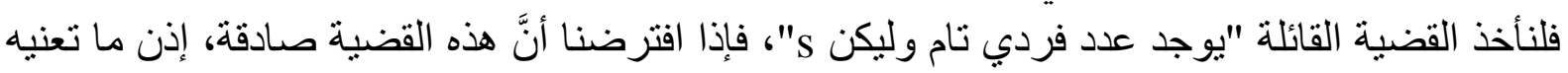

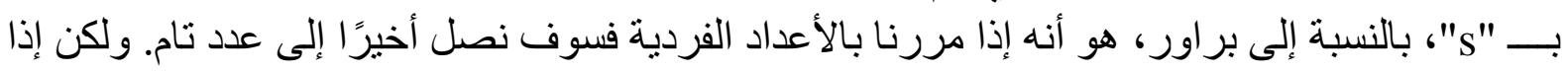

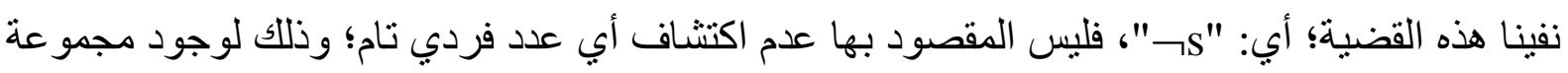

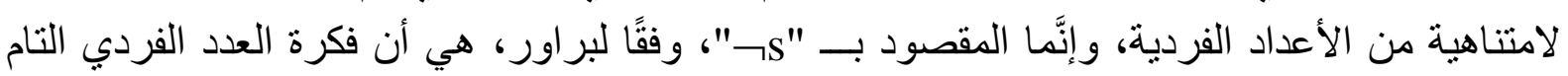

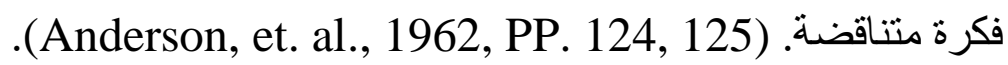


من هنا فإنَّ مشكلة مبدأ الثالث تنشأ فقط فيما يتعلق بالمجموعات اللامتناهية، مثل تلك الخاصة

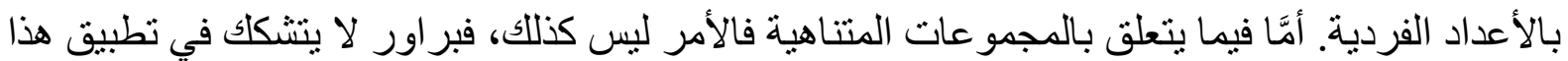

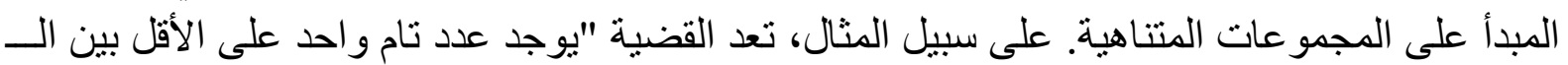

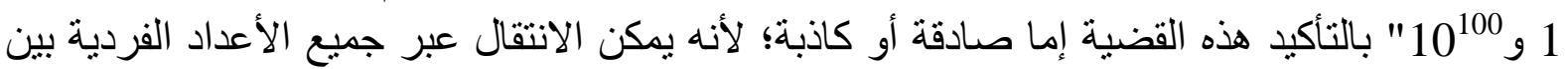

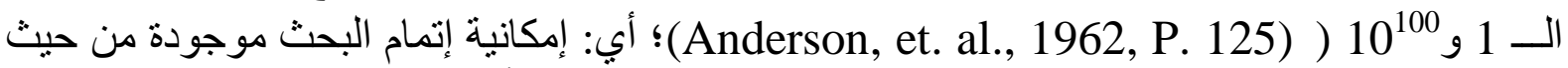

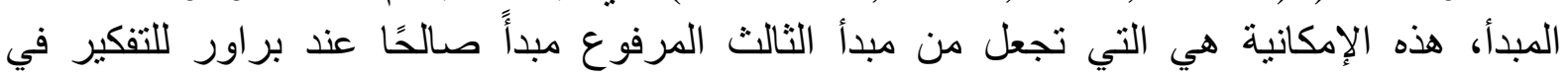
المجمو عات المتناهية. (Kleene, 1971. P. 47). بصفة عامة، جادل بر اور بأنَّ مبدأ الثالث المرفوع غير جلير بالثة بالثقة في الأنساق اللانهائية. فقد قُدَّمَ أمثالة عكسية لهذا المبدأ، والمعروفة الآن باسم "الأمثلة المضادة البراورية" : Dalen, 2013, P. 104) منها Counterexamples ـ هل يوجد في النظام العشري لـ $\pi$ (14) عدد عشري يظهر على المدى الطويل أكثر من غيره؟ ـ هل يوجد في النظام العشري لـ $\pi$ عدد لا متناهِ من الأزواج العشرية المتتالية المتساوية؟ في كلتا الحالتين، ليس لدينا أي دليل على على صدق هذه القضايا أو كذبها؛ وبالتالي فإنَّ مبدأ الثالث

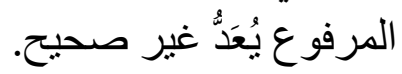
لنأخذ على سبيل المثال، القضية التي يرمز فير إليها بـ "p" التي تعبر عن "وجود سبع سبعات"(15)

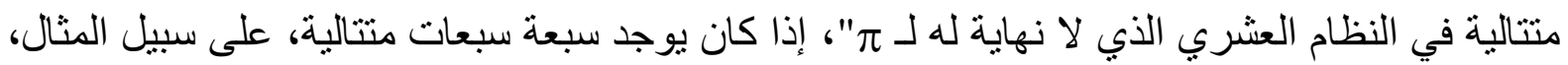

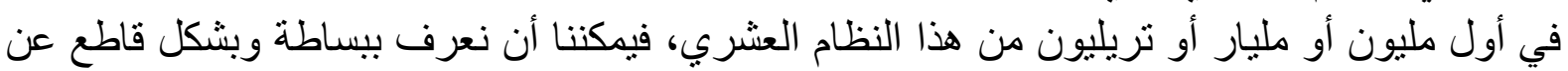

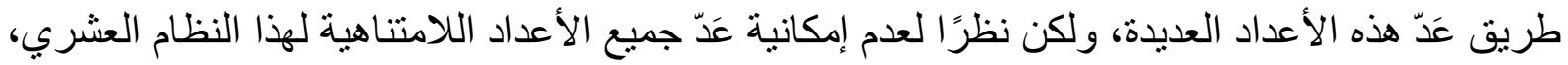

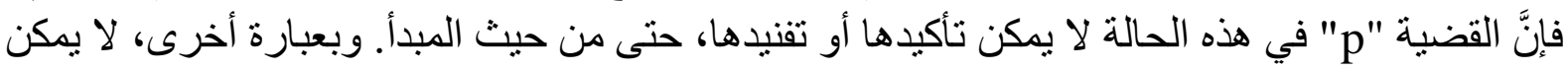

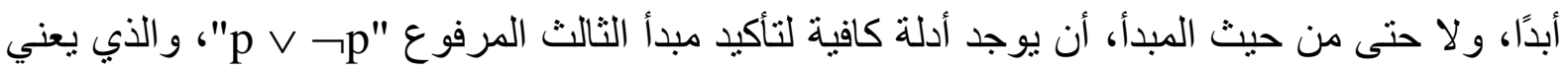

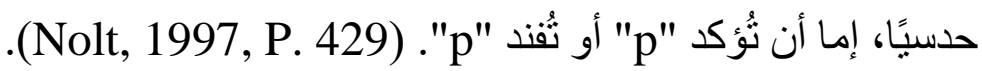
و على ذللك، يمكن القول إن محاو لات بر اور لرفض مبل مبدأ الثالث المرفوع كانت من خلال أمرين، هما

:(Stigt, 1990, P. 248 )

1. إثبات وجود أمثلة مضادة لمشكلات رياضية غير قابلة للحل بشكل أساسي.

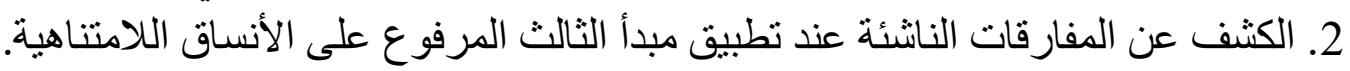
إذا كان مبدأ الثالث المرفوع - في رأي براور- عبارة عن تقرير مجموعة من الرموز التي تمثل

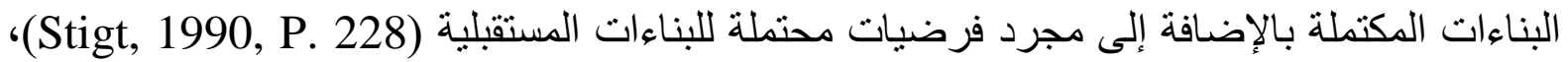
فإنَّه يؤكد عدم إمكانية التعبير عن البناءات الرياضية بلغة تعتمد على مبدأ الثالث المرفوع، وما بعتمد عليه

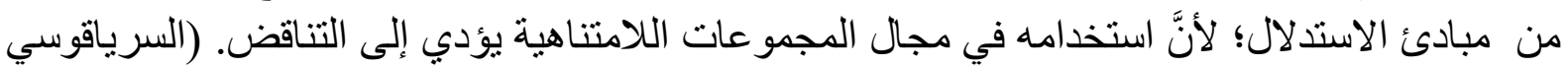

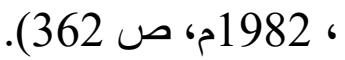
هكذا، يتضح لنا مِمَّا سبق أهم المحطات التاريخية في فكر براور، التي جاء من خلالها رفضه

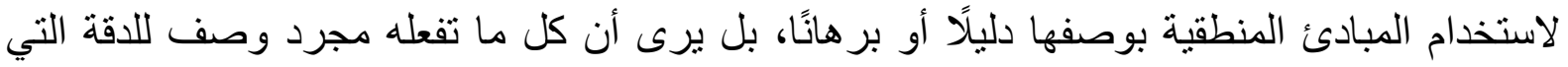
تُلاحظ في الممارسة الرياضية. وخير مثال على ذلك، مبدأ الثالث المرفوع؛ فهو مثال لمبدأ لمبأ منطقي أصبح

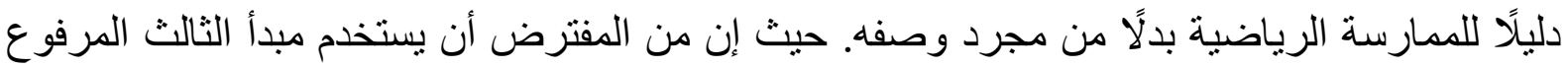

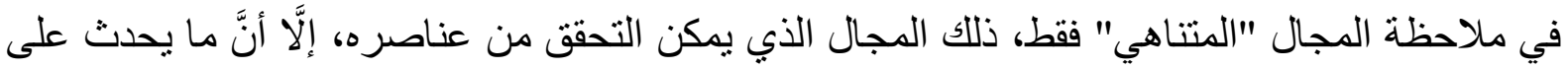

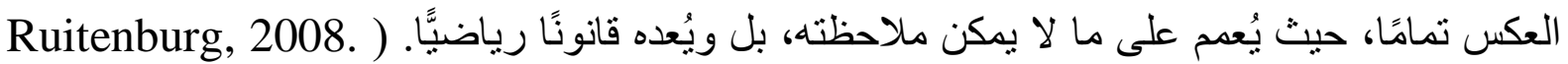

(PP. 134, 135 


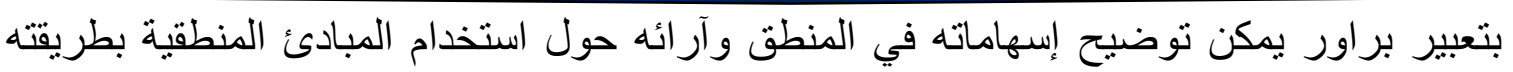

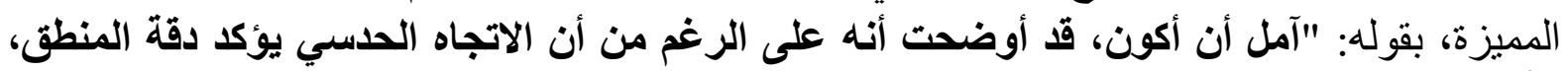

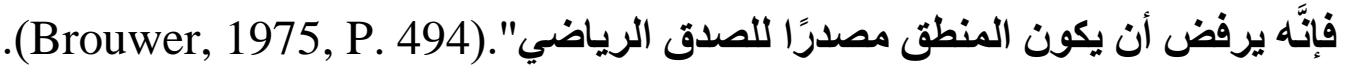

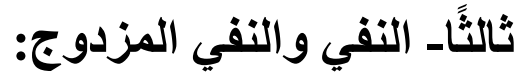

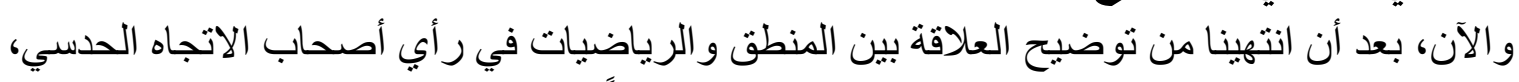

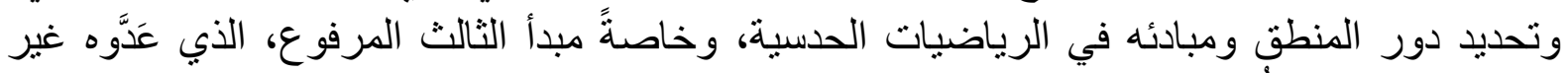

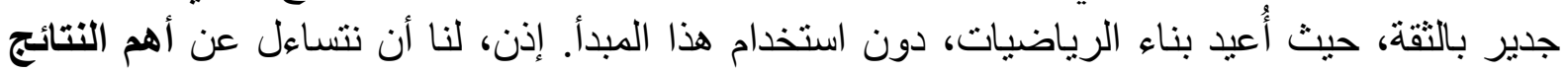

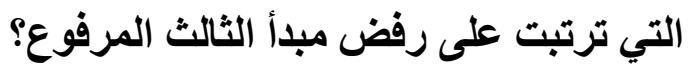

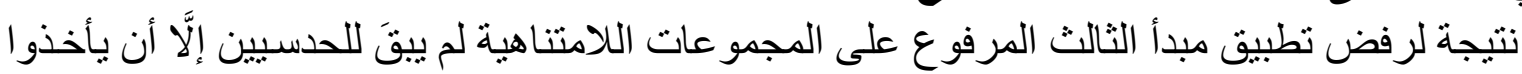

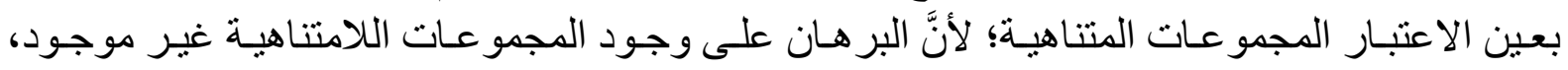

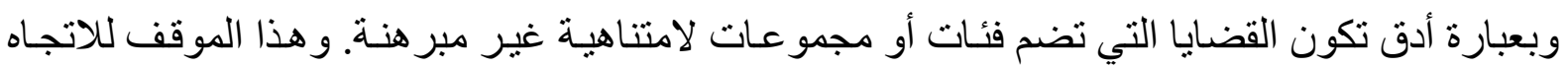

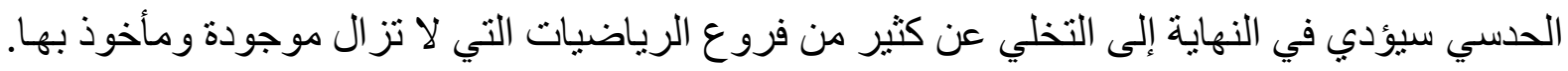

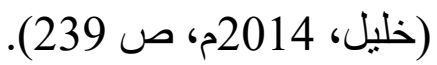

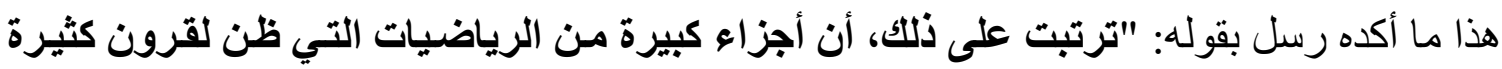

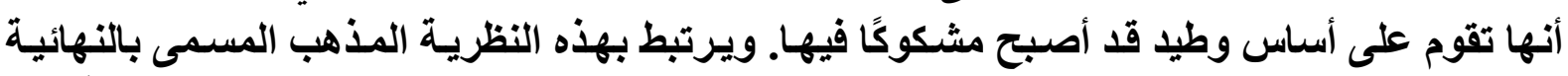

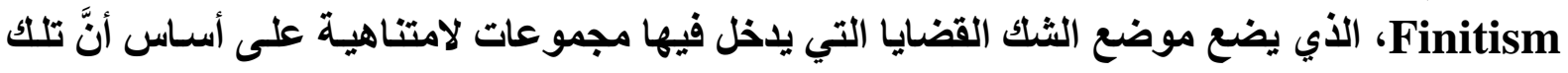

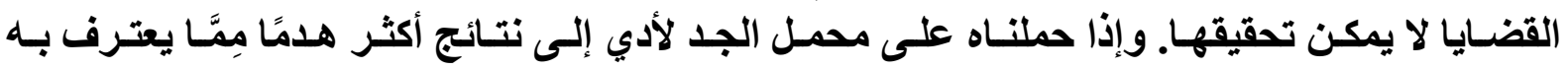

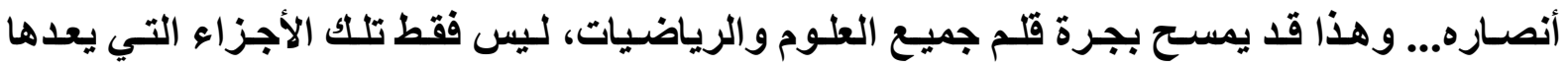

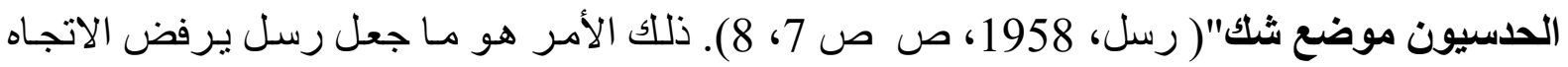

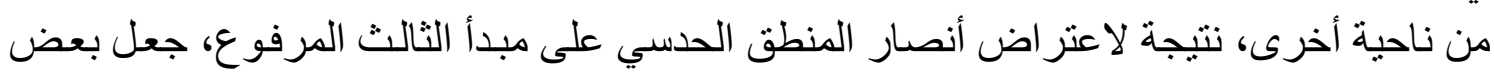

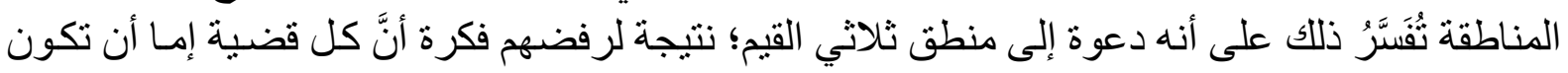

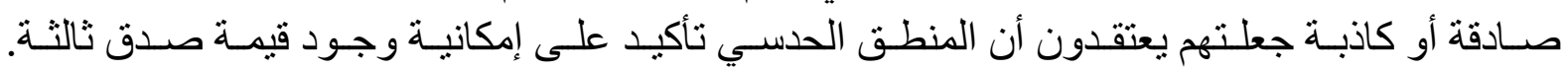
(Granström, 2011, P. 166) من أهم الآثار المترتبة على رفض أنصار المنطق الحدسي لمبدأ الثالث المرفوع اختلاف مفهوم

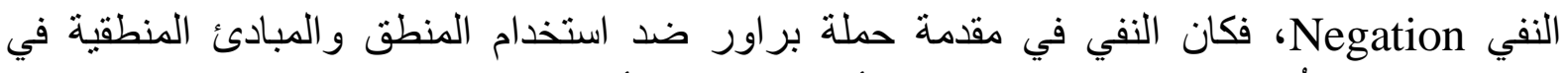

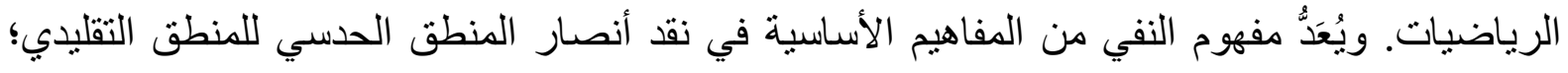

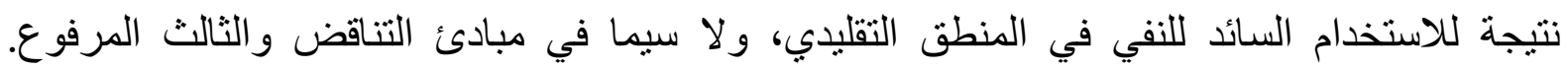

.(Stigt, 1990, P. 238 )

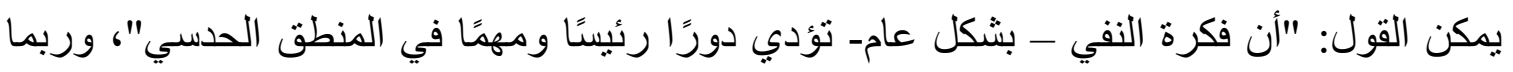

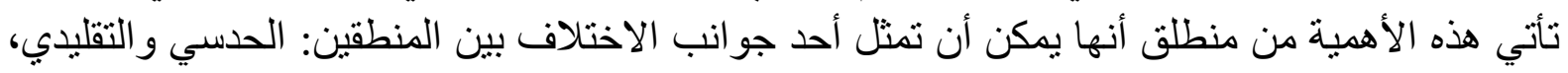

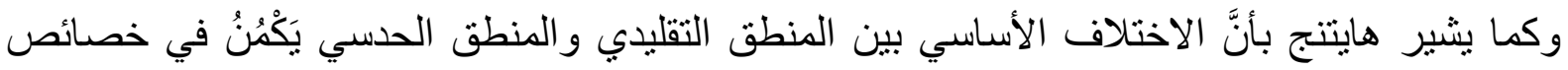

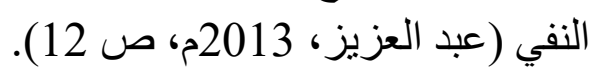

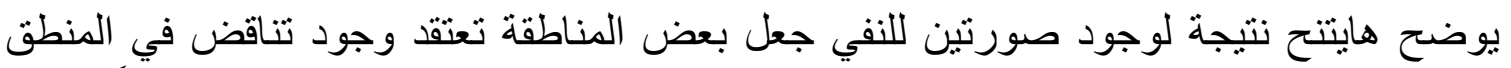

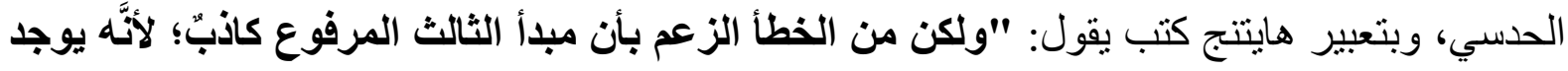

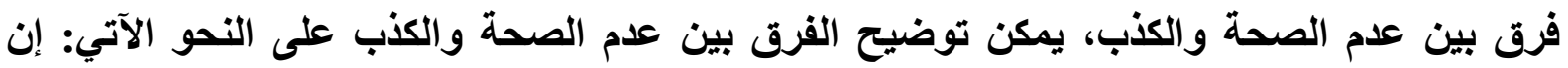

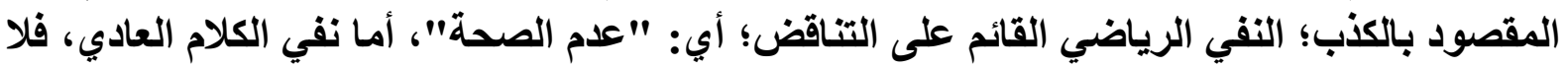


يعني على الإطلاق تناقضًا. في القضية الرياضية يحدث النفي من النوع الأول فقط، ولكن في القضبة

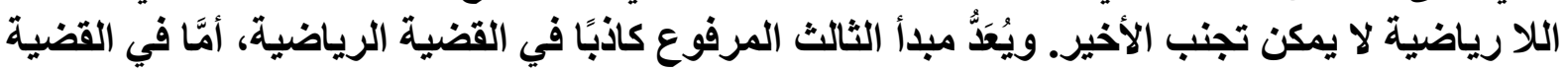

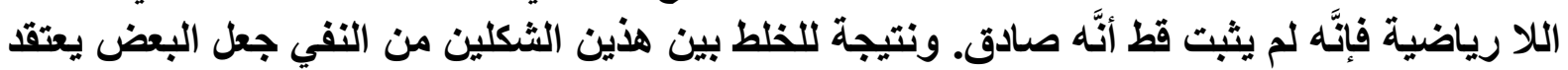
بوجود تناقض في المنطق الحدسي". (Heyting, 1958, P. 109). بناءً على ذللك، يظهر اختلاف مفهوم النفي بين أنصار المنطق التقليدي وأنصار المنطق الحدسي؛

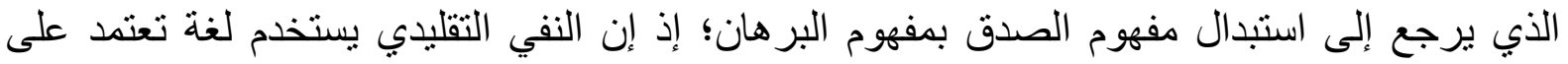
مفاهيم الصدق والكذب، في حين النفي الحدسي يستخدم لغة تعتمد على مفاهيم قابلية البرهان وقابلية

يُعَبَّرُ هايتتج عن المقصود بالنفي بقوله: "يمكنتا أن نثبت نفي القضية "a" إذا استتتجنا تناقضًا من

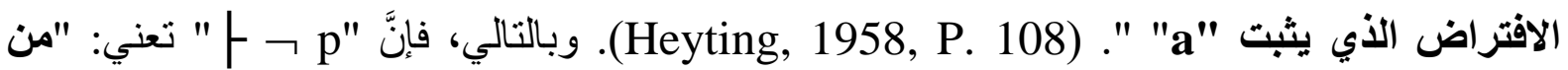

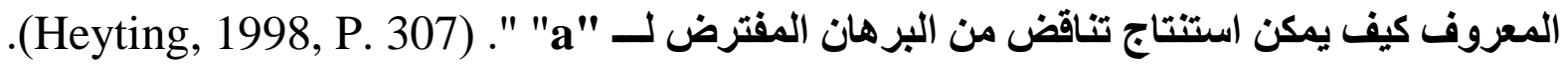

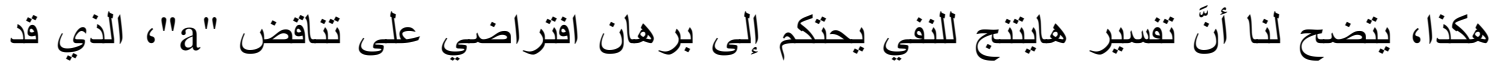

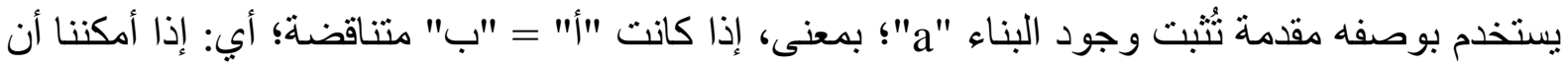

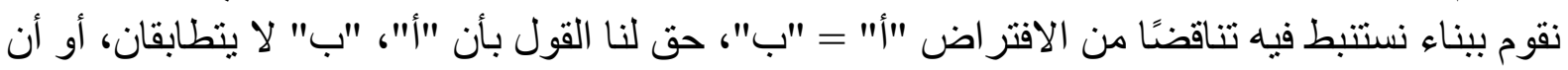

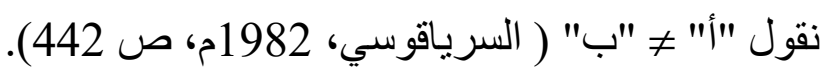
يأتي تفسير هايتتج للنفي من خلال قر اعة براور لمبدأ الثالث المرفوع، حيث قدم براور تعريفًا للنفي

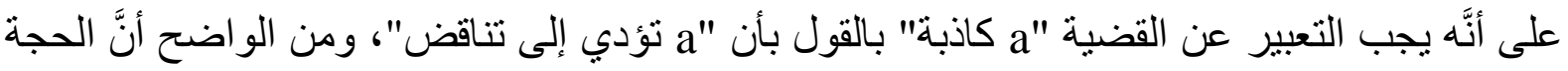
التي قدمها بر اور تتناسب مع تفسيره للصدق. ولكن لا يوجد توضيح لمثل هذه الحجة بالتفصيل في كتاباته

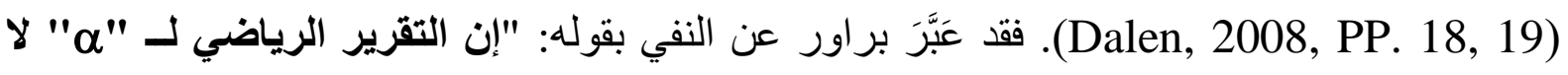

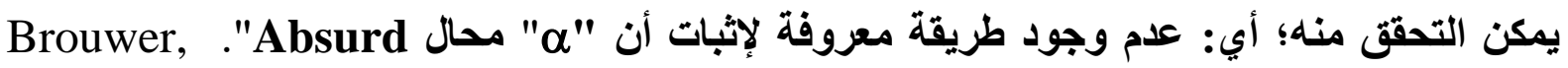

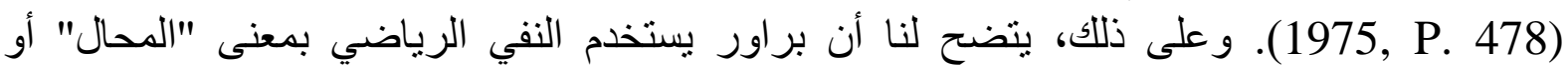

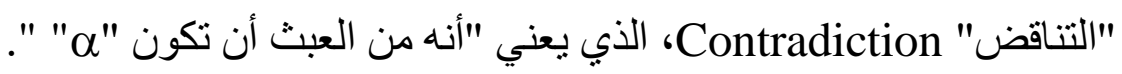

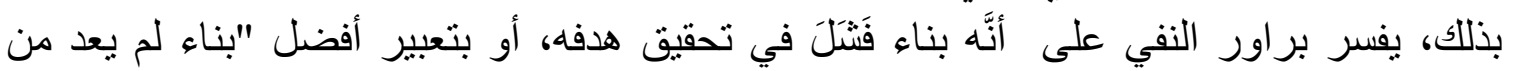

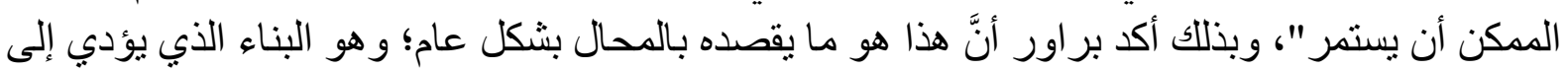

التناقض (Franchella, 1995, P.309).

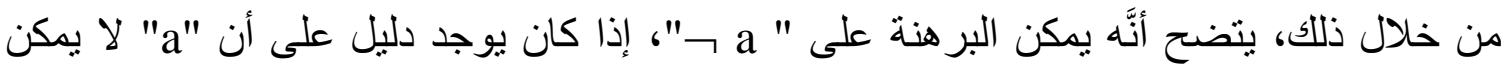

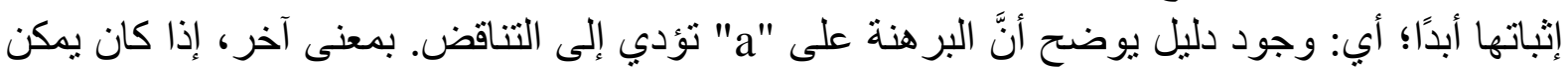

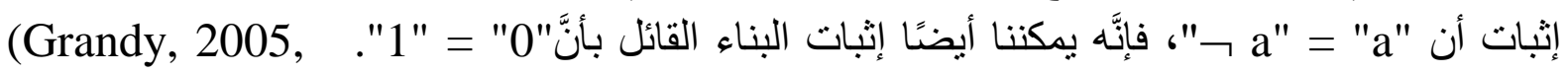

بهذا المعنى، يتضح لنا الاختلافات الجوهرية بين الحدسيين و التقليديين في تفسير النفي، فنجد النفي

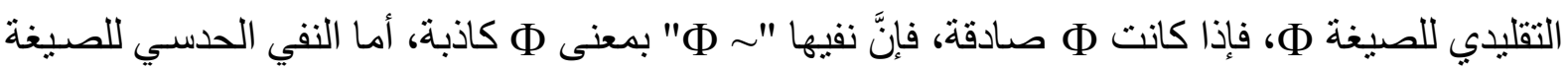

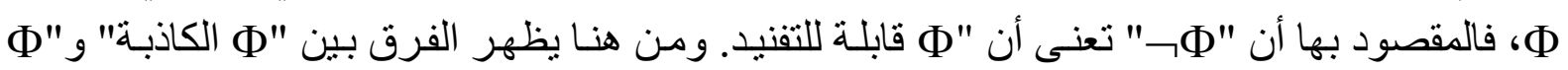

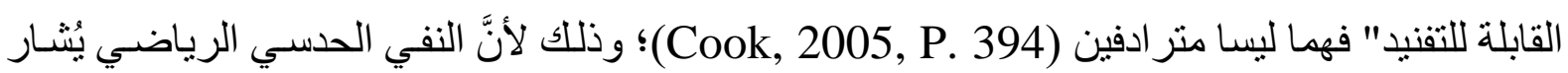

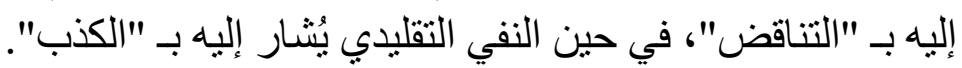

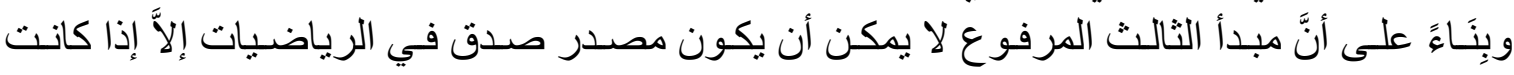
الحقائق التي يتضمنها يمكن تجريبها؛ و التجربة تعني هنا الحدس الذي يتم به بناء الكيانات الرياضية، نجد 


\section{موقف المنطق الحدسي من مبادئ المنطق التقليدي}

أن الحدسيين قد واجهتم مشكلة كبيرة لم ينتبه إليها هايتنج قامت على النفي الحسسي. فقد أقر كلُّ من براور

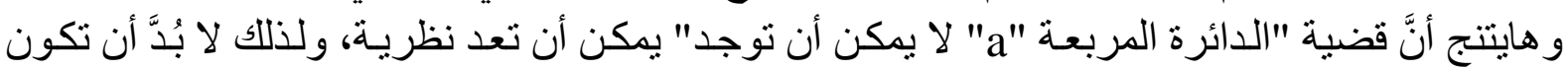

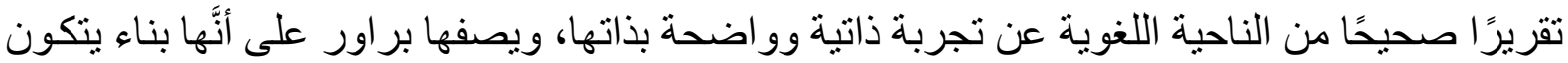

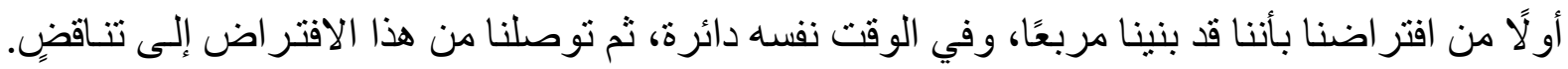
(Heyting, 1971, P. 124)

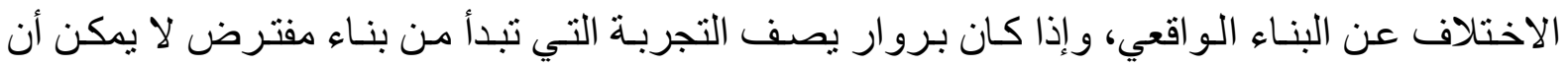

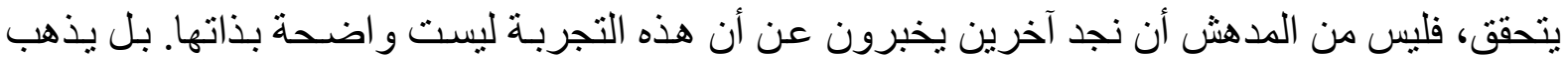

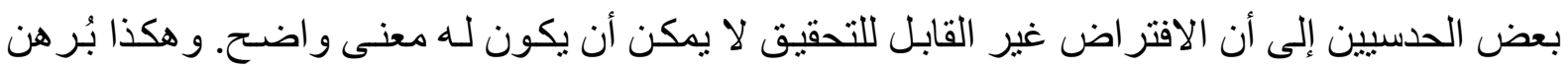

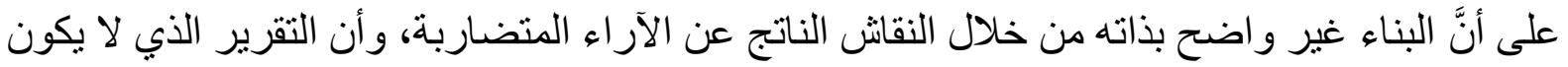

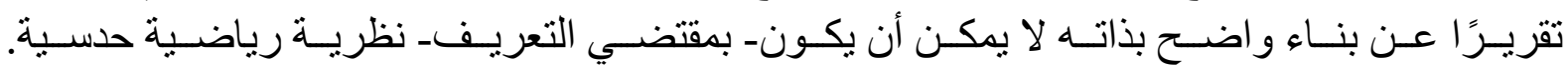

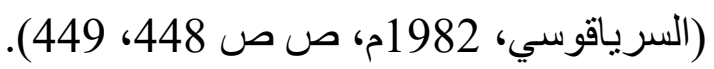

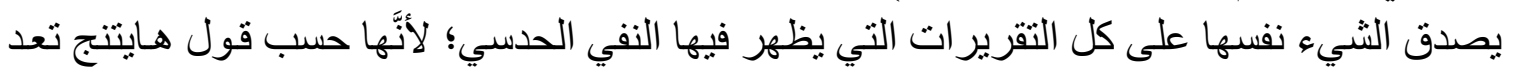

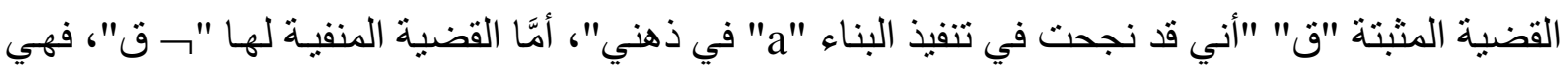

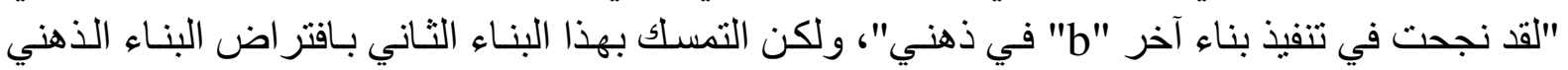

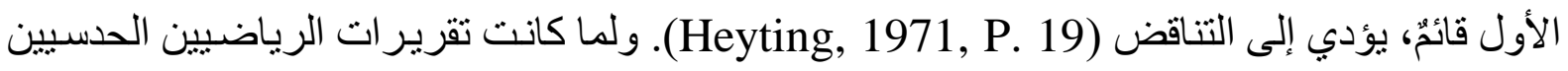
عن هذا النوع من التجربة متناقضة، فلا يمكن أن توجد تجربة قابلة للتعبير عنها بواسطة النفي الحدسي

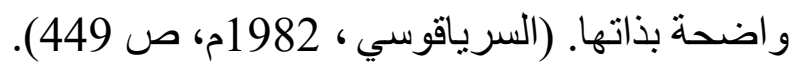

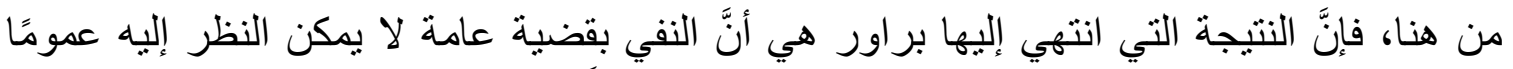

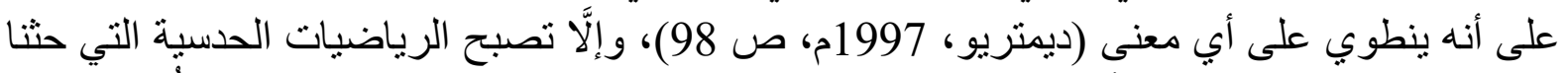

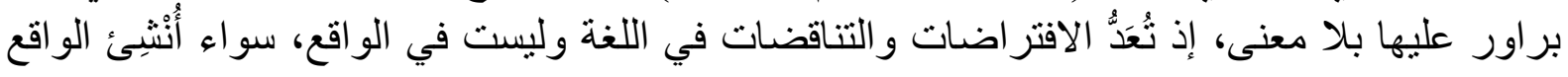
الرياضي أم لا؛ لذا فمن الضروري أن ترحل فكرة النفي، وبالتالي تخلي المنطق الحدسي بالفعل عن الفي

الكثير من الرياضيات التقليدية التي تتضمن نفيًا. (Brown, 1999, P. 99).

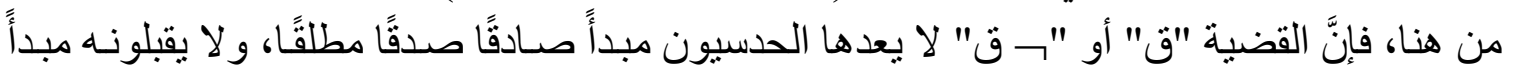

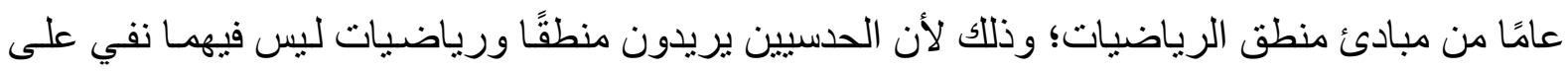

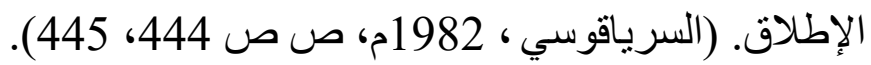

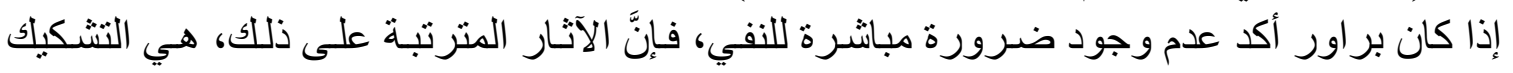

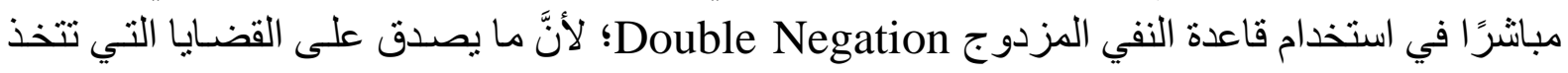

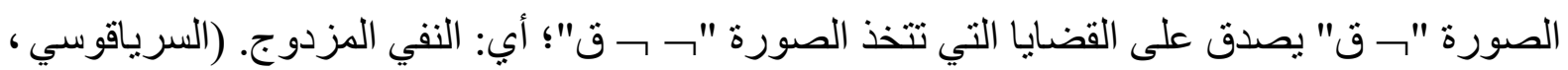

1982م، ص ص 1949).

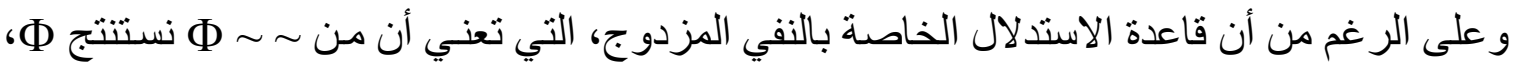

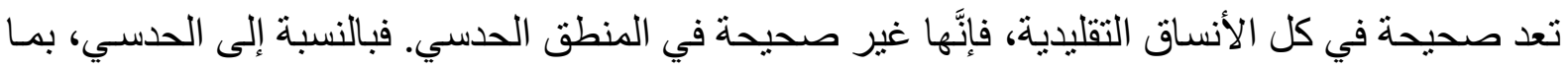

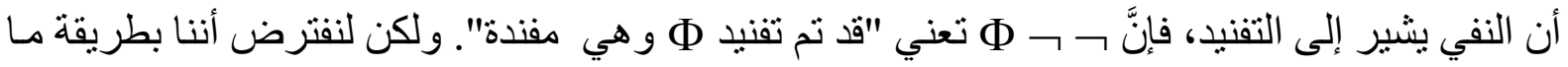

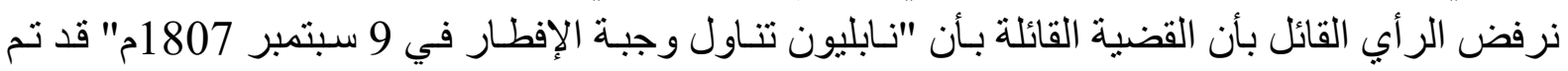

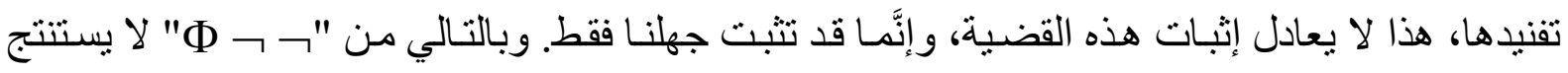

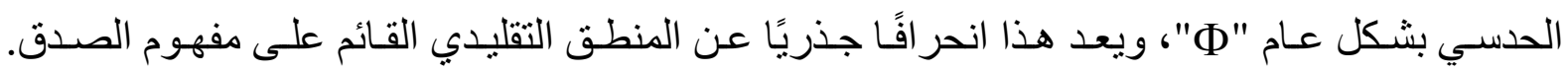

.(Nolt, 1997, P. 429) 
يمكن توضيح أكثر لقاعدة النفي المزدوج في المنطق التقليدي من خلال المثنال الآتي: "من الكذب

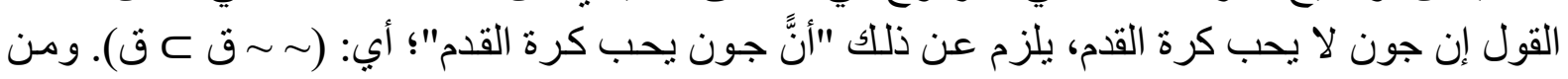

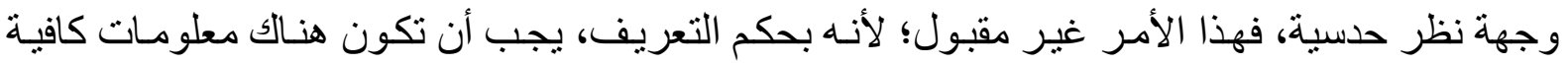

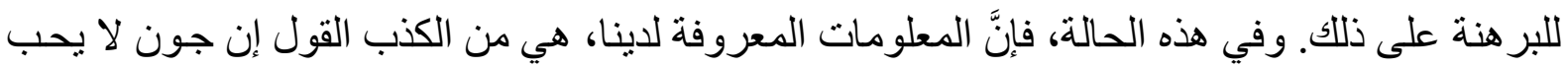

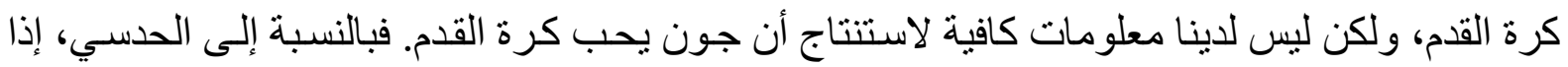

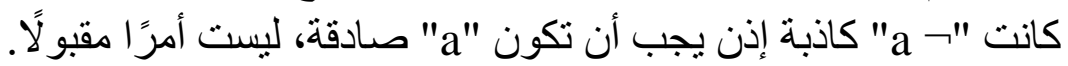

في عام 1923م قدم براور مقالة بعنوان "انشقاق الحدسية من المفاهيم الأساسية للارياضيات"Intuitionistic Splitting of the Fundamental Notions of Mathematics بتحليل النتائج التي ترتبت على وجهة نظره حول مفهومه للنفي، الذي وصفه على أنه تناقض للمنطق

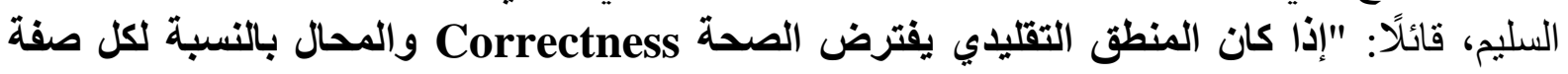

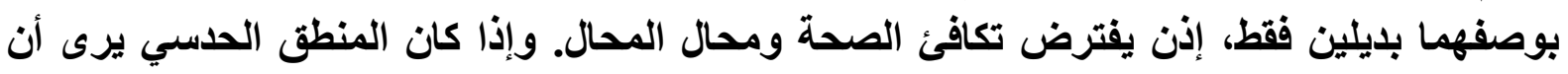

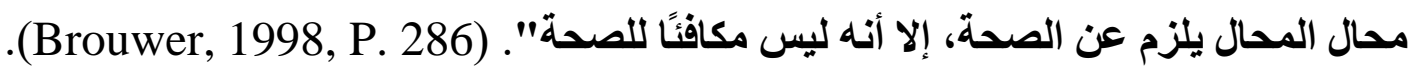

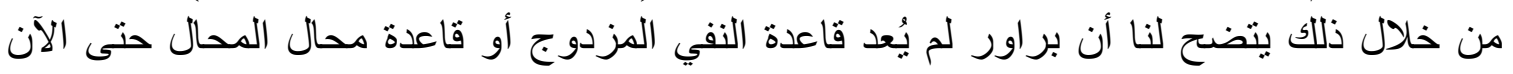

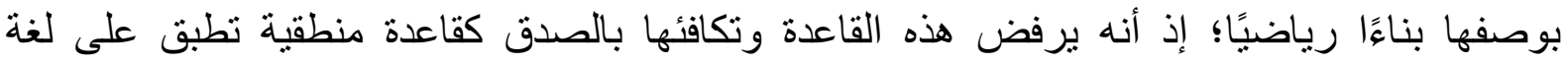

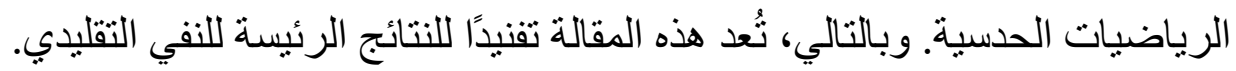

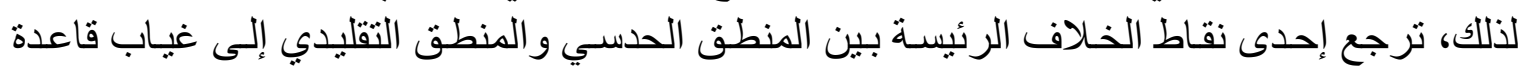

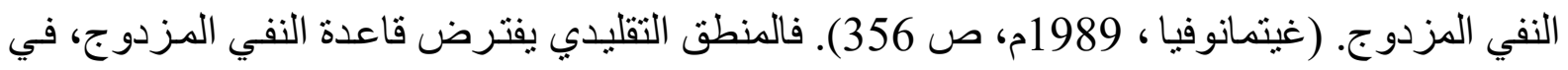

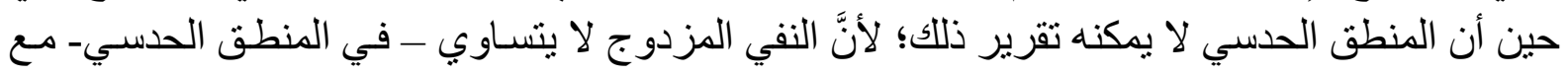

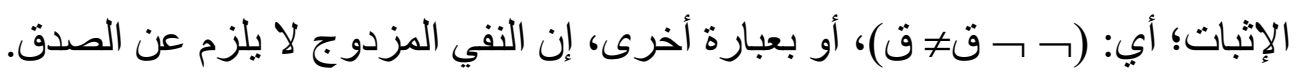

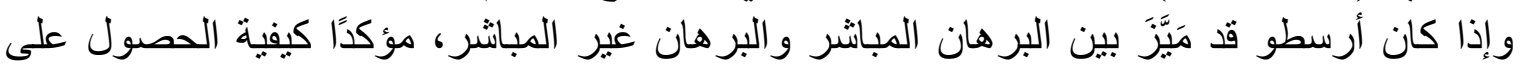

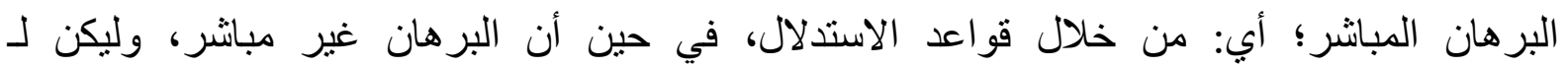

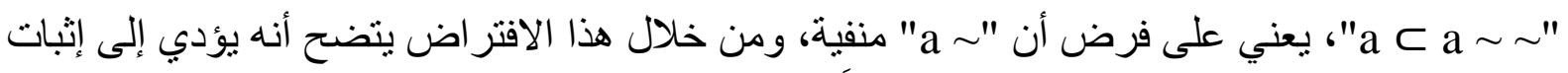

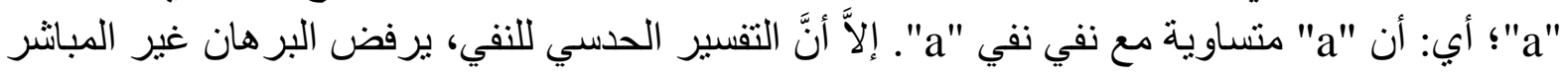
لـ A A

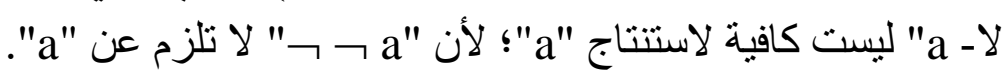
بتعبير آخر، إذا كان بر اور يشرح النفي من خلال ربطه بالبناء الذي يؤدي إلى المحال، فإن قضية

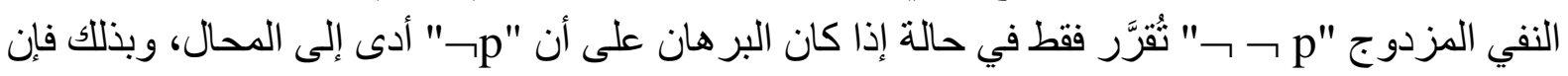

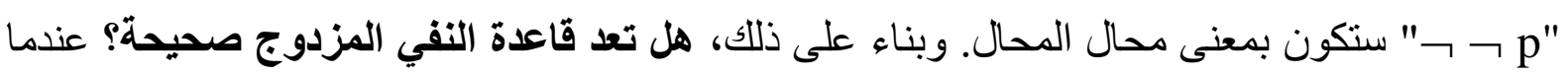

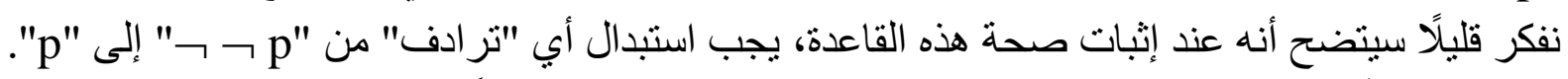

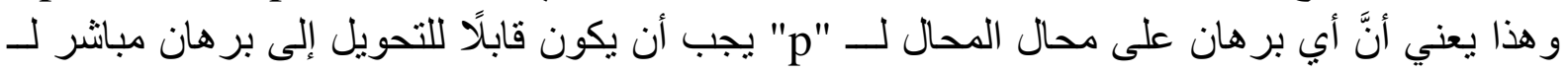

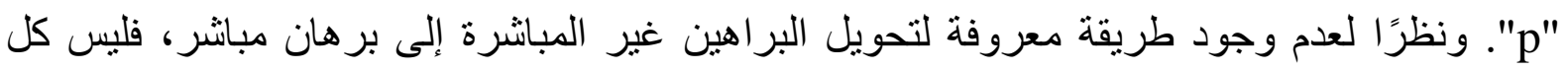

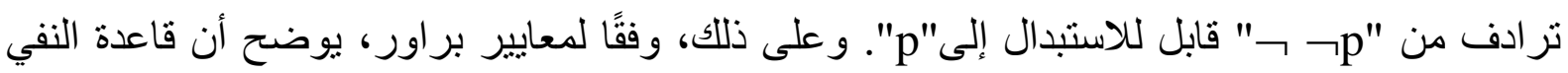

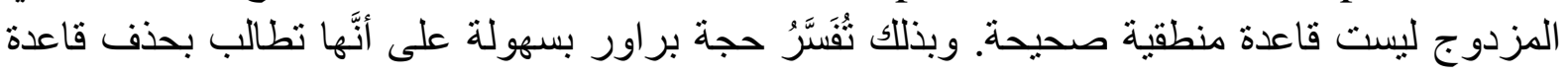

النفي المزدوج. (Placek, 1999. PP. 69, 70). بذللك يتضح لنا، أسباب عدم قبول أنصار المنطق الحدسي البرهان غير المباثر، هو مطالبة المنطق

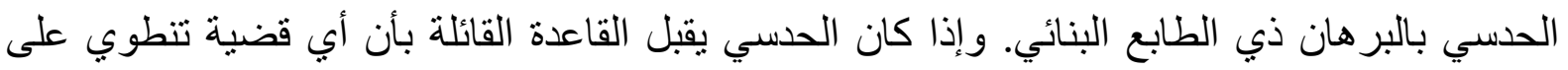


تناقض يجب أن تكون كاذبة، هذا لا يعني السماح باستخدام مبدأ الثالث المرفوع، ولا النتيجة اللازمة عنه؛

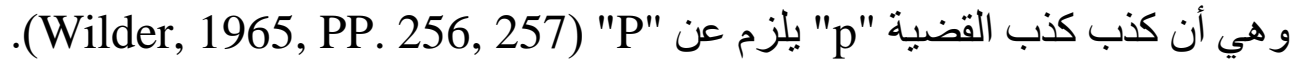

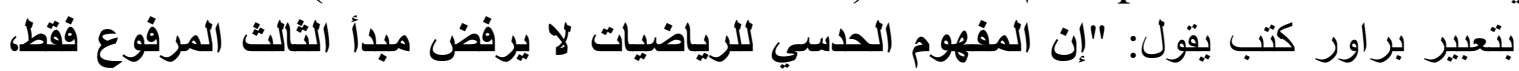

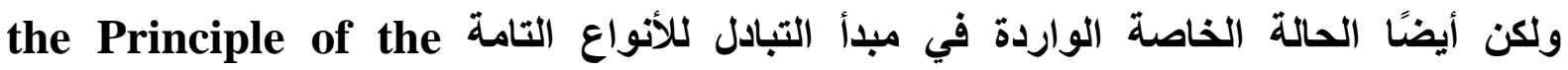
نReciprocity of the Complementary Species نسث رياضي، تلزم عن استحالة إثبات محال هذه الصفة". (Brouwer, 1998, P. 286). يؤكد براور من خلال هذا النص رفضه لمزيد عندأ التبادل التام التقليدي كحالة خاصة من مبدأ الثالث المرفوع، حيث يرفض التكافؤ التقليدي للنفي المزدوج والصدق. ولكن لم بفسر براون اور النفي على أنه

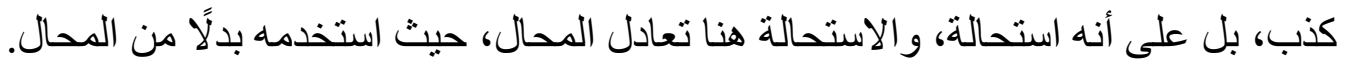

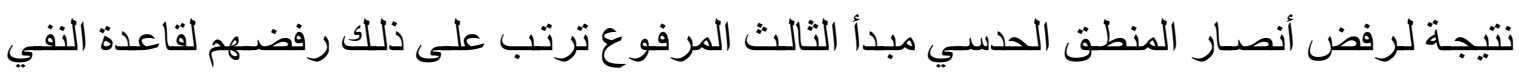

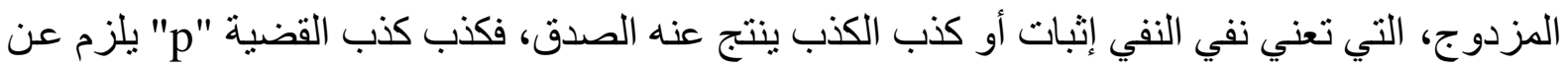

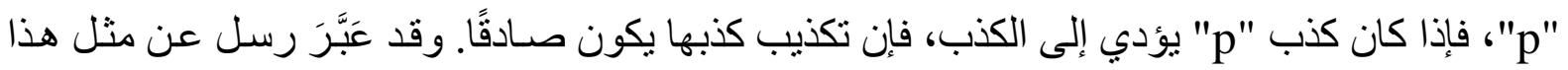

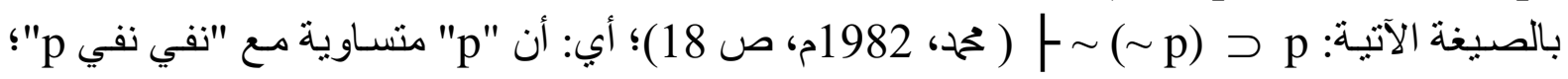

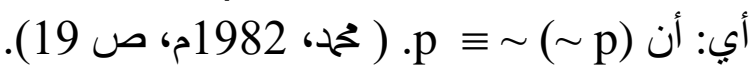

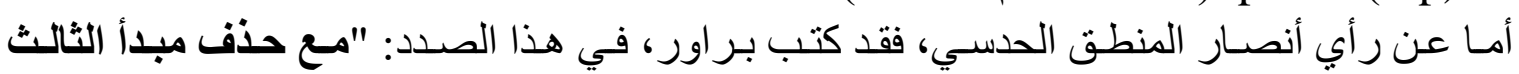

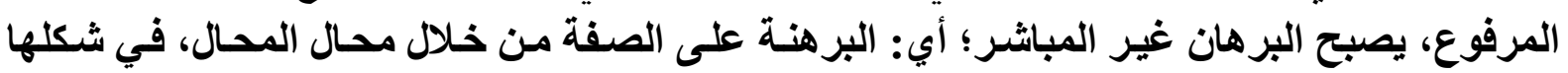
العام غير صحيح أيضًا". (Brouwer, 1998, P. 52). بذلك تصبح قاعدة النفي المزدوج ( ق 三 ق ق) ليست صـحيحة في المنطق الحدسي، نلك القاعدة

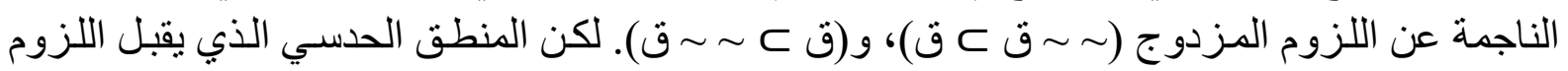

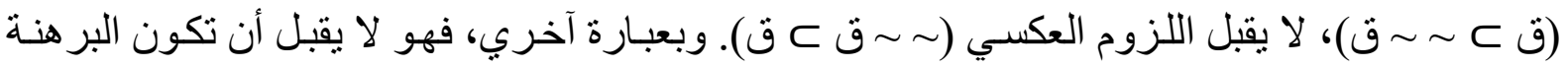

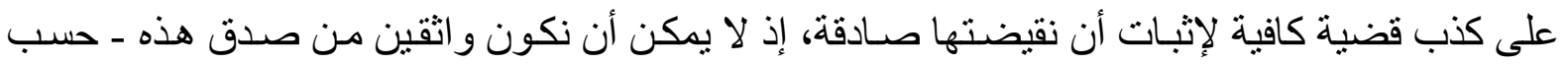

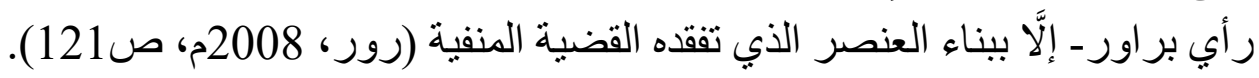

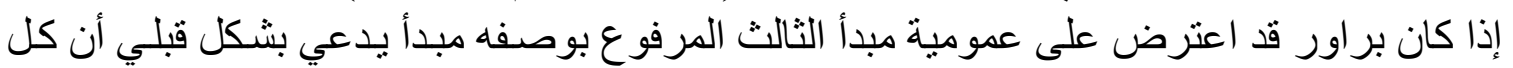

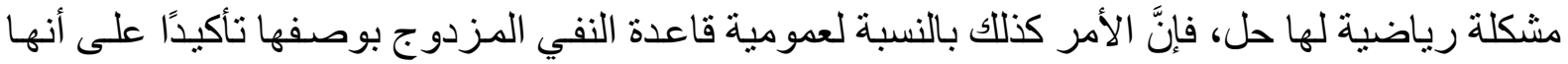

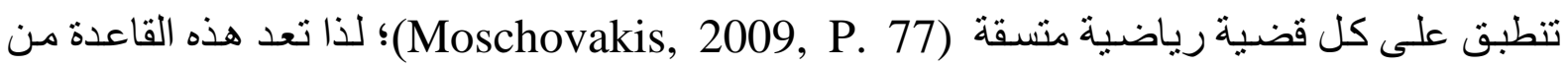

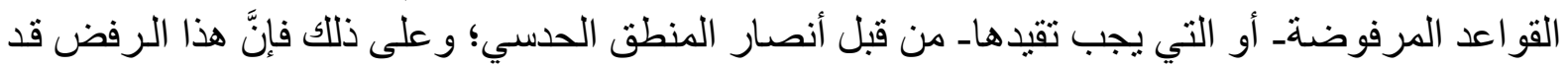

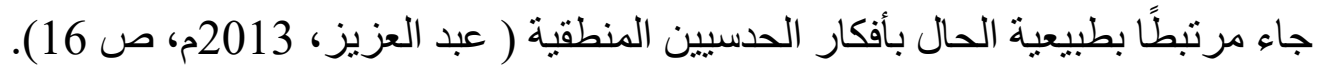

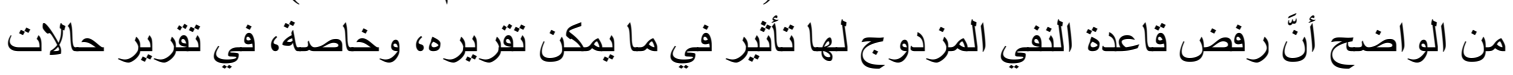

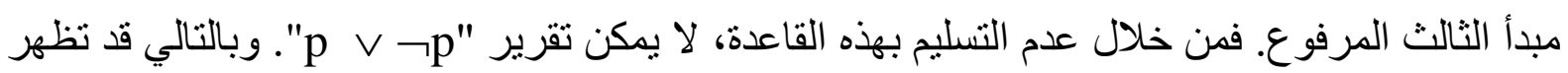
الاعتر اضات على صحة مبدأ الثالث المرفوع لرفض قاعدة النفي المزدوج. غير أن كما ظهر في مقالات

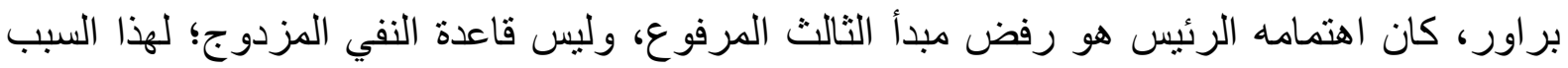

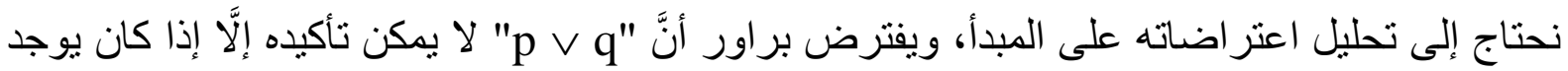

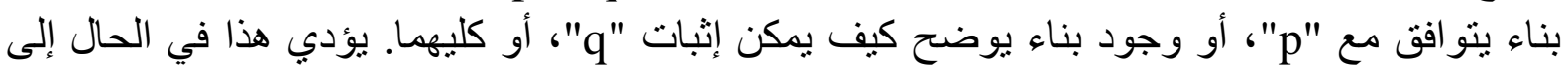

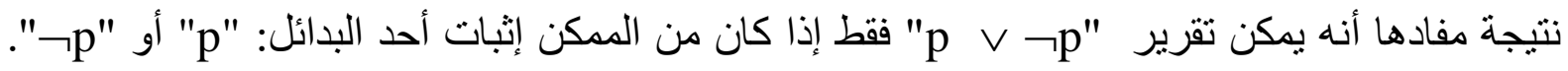

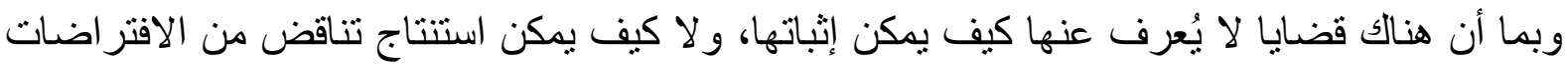

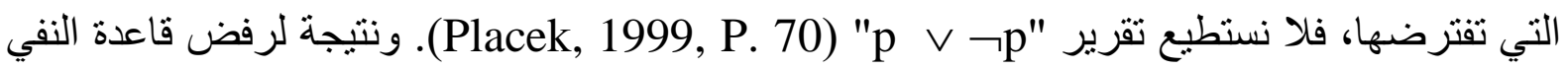


المزدوج، فإن بعض مبادئ المنطق التقليدي تتوقف عن كونها صحيحة كليًّا، وعلى الأخص مبدأ الثالث المرفوع. (Placek, 1999, P. 74). لذا نستطيع القول: إن من أسباب رفض الحدسيين لمبدأ الثالث المرفوع ارتباطه برفضهم بقاعدة حذف دف

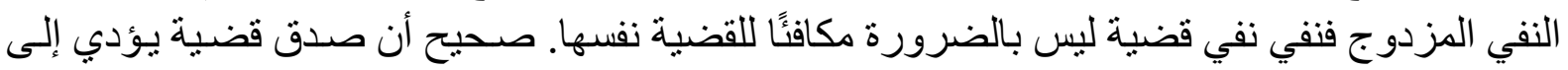

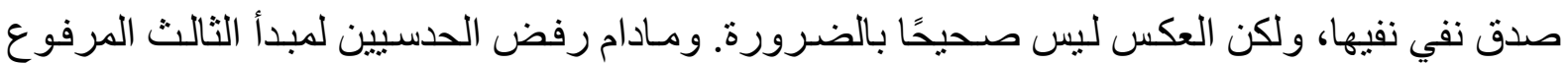

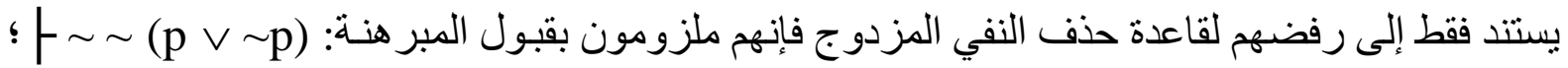

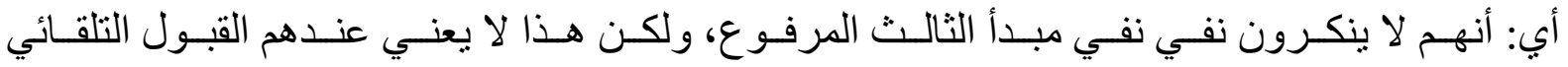

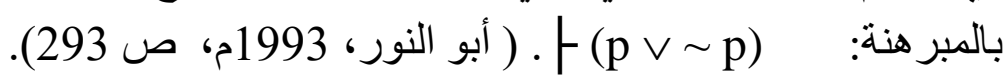

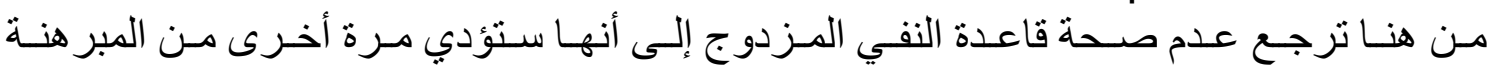

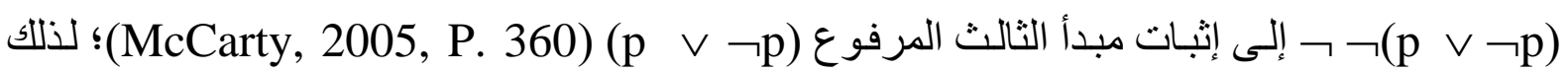
يرفض الحدسي قاعدة النفي المزدوج حتى لا يمكن إثبات مبدأ الثالث المرفوع.

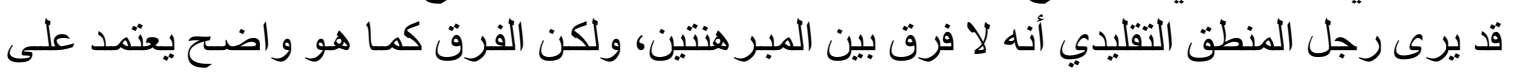

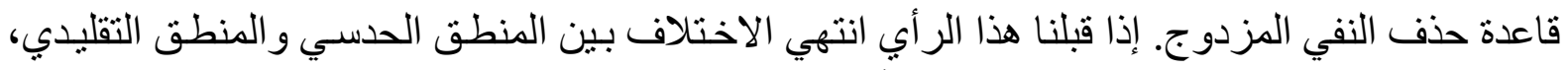

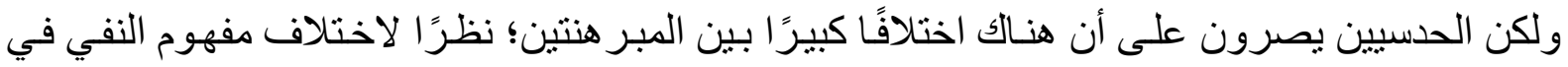
المنطقين، فتعريف النفي التقليدي يستند إلى شروط الصدق، أمَّا النفي الحدسي فيعتمد على فئ فكرة التفنيد؛

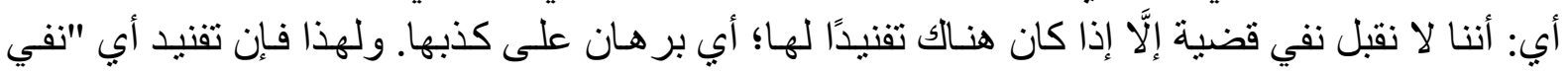

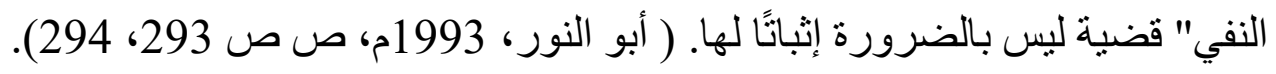

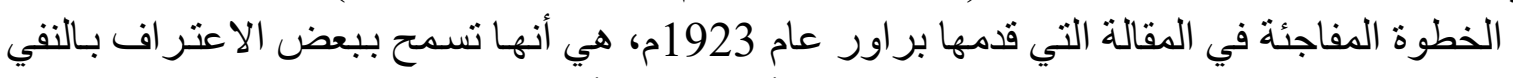
المزدوج، حيث لم يستغنِ براور عن النفي تمامًا، فقد أدى بحثه الأولي في طبيعة الرياضيات إلى إلى الاقتناع

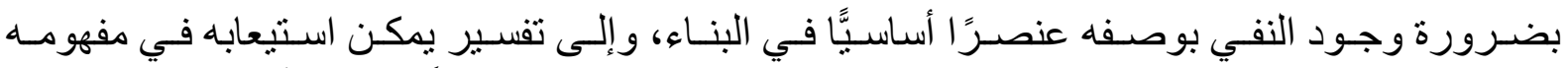

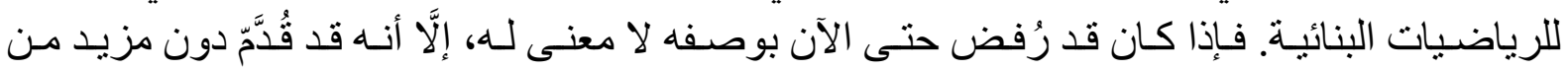

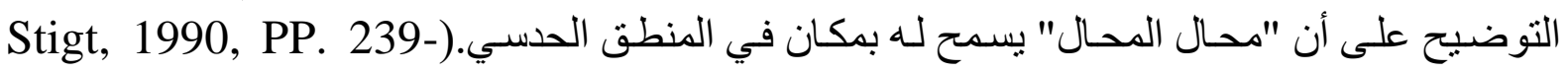

على الرغم من أن براور لم يقدم نسقًا للمنطق الحدسي، فإنه أثبت نظرية منطقية جديدة، فما هذه

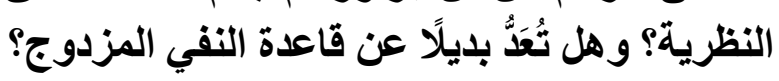

قام براور بإثبات نظرية منطقية جديدة قائمة على اقتر اح بديل للنفي في المنطق التقليدي و النفي المزدوج، وهي A A Absurdity -of- Absurdity -of - Absurdity is Equivalent to Absurdity بقوله: "أولًا إذا كانت الصفة y تلزم عن الصفة x، إذن من المحال أن تلزم عن محال x. وبما أنَّ محال

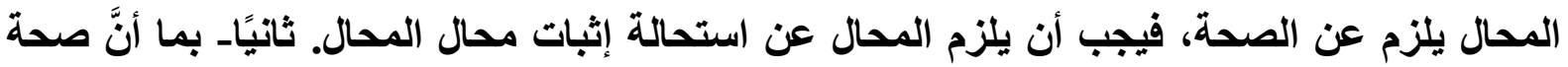

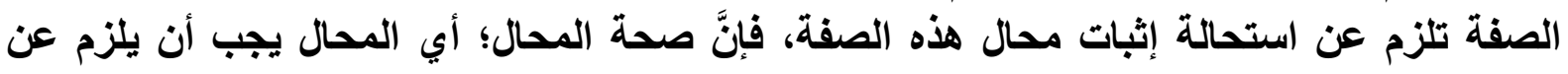

استحالة إثبات محال المحال". (Brouwer, 1998, P. 287).

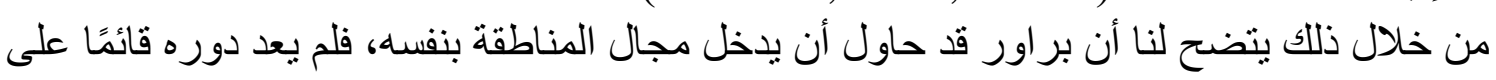
رفضه واعتر اضه لبعض المبادئ المنطقية فقط، بل أثبت نظرية جديدة مستخدمًا قياس الإثبات

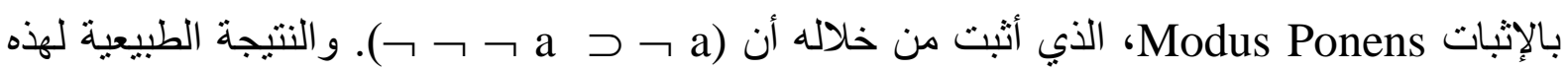

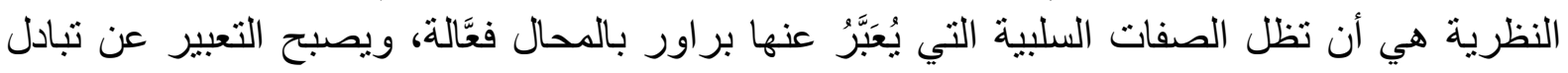




\section{موقف المنطق الحدسي من مبادئ المنطق التقليدي}

المحال في الرياضيات الحسية إما بالمحال أو باستحالة إثبات المحال، على عكس الرياضيات التقليدية

التي يُعَبَّرُ عن المحال إما بالصحة أو أو بالمحال.

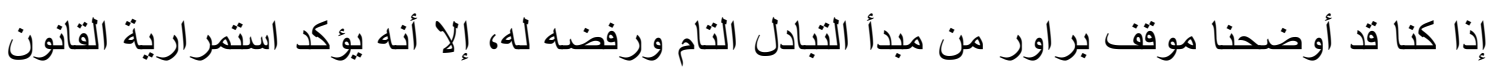
المعاكس له، وهو (

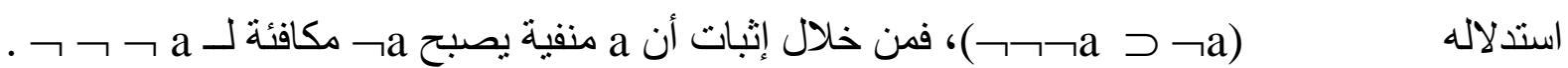

(Franchella, 1995, P.315) هكذا، يتضح لنا أنَّ أنصار المنطق الحسي يؤكدون أن منطقهم قائم على النفي الثنلاثي، بدلًا من تأكيدهم النفي المزدوج (Granström, 2011, P. 156)؛ أو بتعبير آخر، إن إثبات هذه النظرية قائم على إلغاء قاعدة النفي المزدوج Zach \& Badesa, ) يمكن توضيح النتائج المنرتبة على تحليل براور لمفهوم النفي على النحو الآتي :2010, P. 103

1- - إن محال المحال- وفقًا للاتجاه الحدسي- يلزم عن الصحة وليس العكس. 2- طرح بر اور نظرية منطقية جديدة، وهي "استحالة إثبات المحال محال يكافئ المحال".

في النهاية، يمكن القول إن الاختلاف الأساسي بين المنطق التقليدي والمنطق الحدسي يرجع إلى الى التى

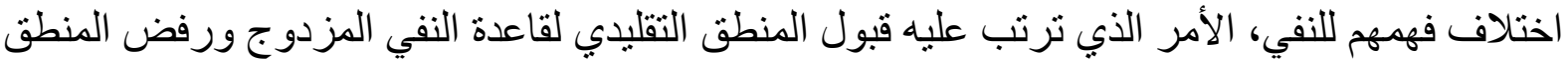
الحدسي لها. ولكن، ذلك لا يعني أن أحدهما على صو اب و الآخر على خطأ، بل من الممكن أن يكون كل

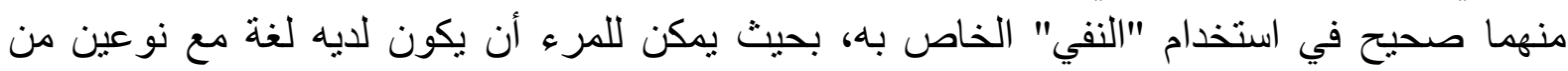
"النفي"، إحداهما كلاسيكي والآخر حدسي. (Hossack, 1990, PP. 210, 211).

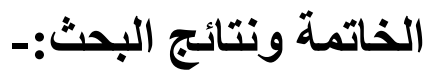
بدايةً، لا بد من توضيح نقطة مهمة؛ وهي أن موقف المنطق الحدسي من مبادئ المنطق التقليدي

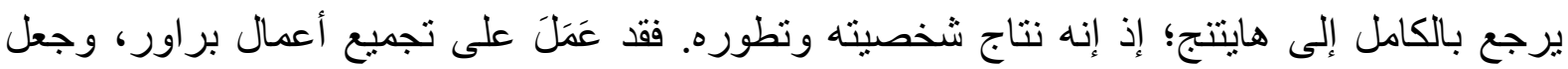

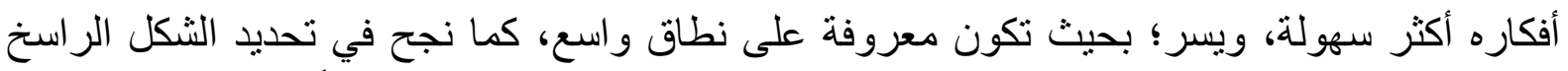

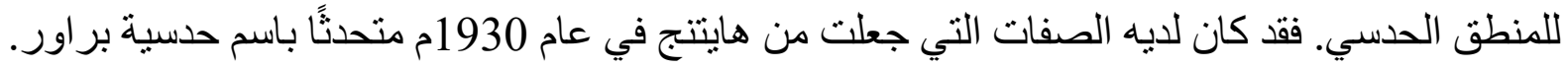

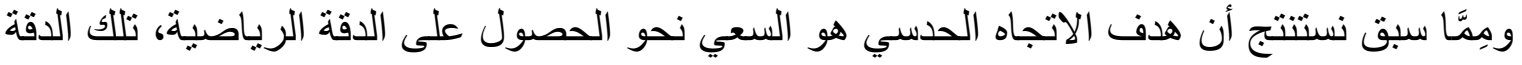

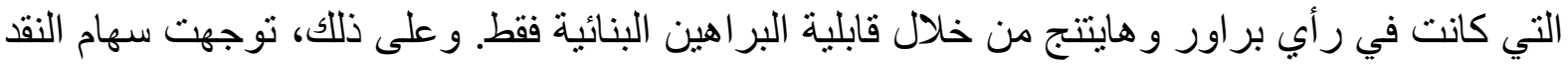

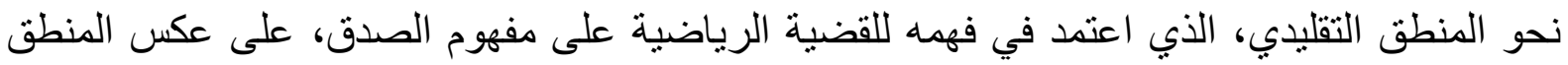
الحدسي الذي يرى ضرورة استبدال مفهوم قابلية البر هان بمفهوم الصدق. بالإضافة إلى ذللك، اتضح لنا أن براور قد رفض مبدأ الثالث المرفوع وتجاوز اته من أجل تحقيق حملته لإصلاح الرياضيات وتطوريها. فإذا كان المنطق الحدسي رفض التطبيق الأعمى لمبدأ الثالث المرفوع وأكد صحته فقط في مجال الأنساق المتناهية، فإنه كان من أجل التخلص من مفارقات رات

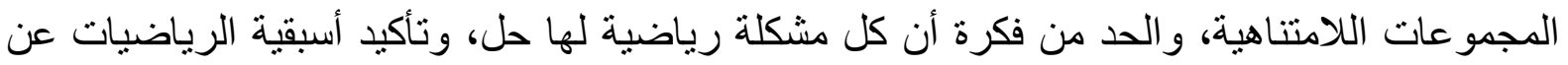
المنطق، و على ذلك يتضح الاختلاف الكبير بين المنطق التقليدي و المنطق الحدسي.

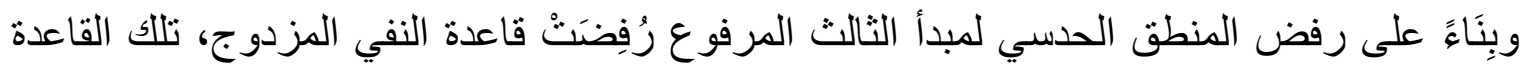

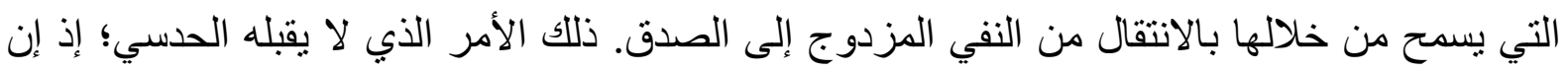

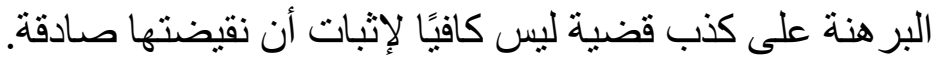


على الرغم من أن براور أكد مررًا وتكررًا ضرورة الفصل بين الرياضيات واللغة من نالحية

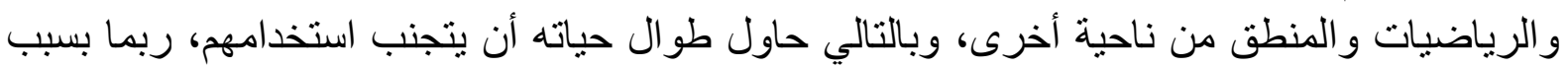

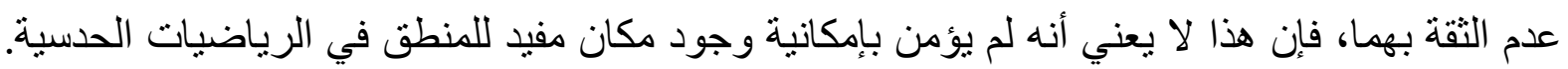

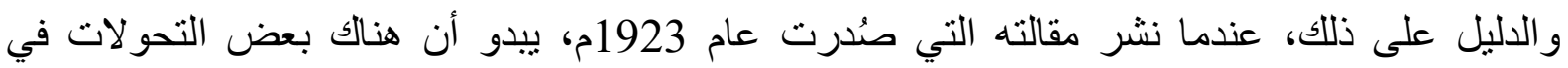

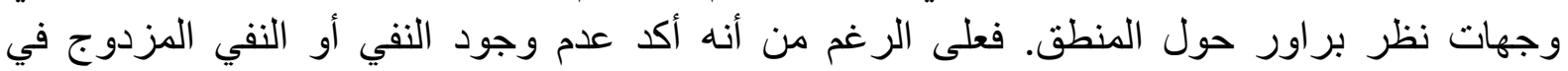

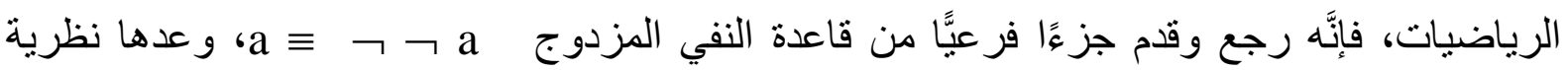

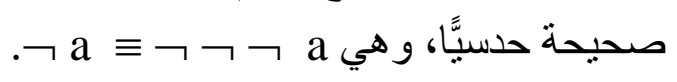

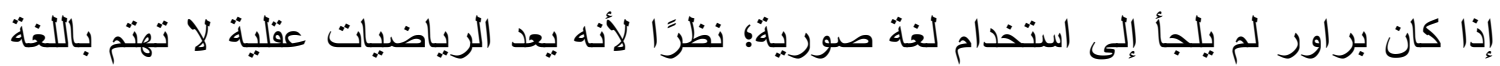

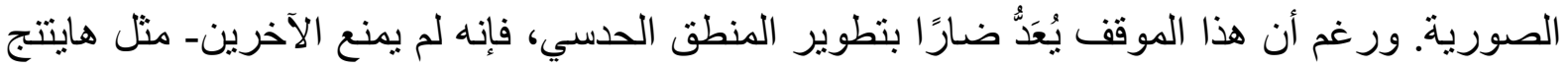

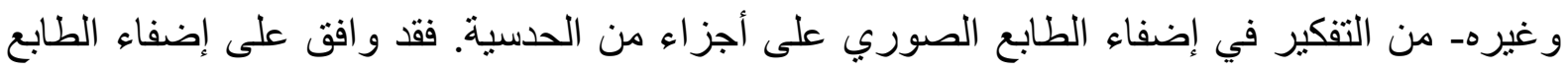

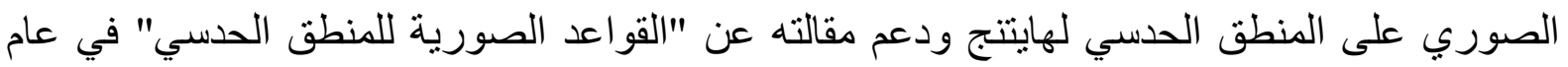

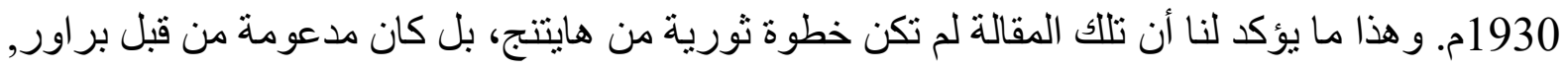

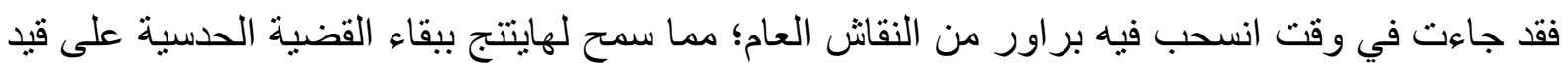

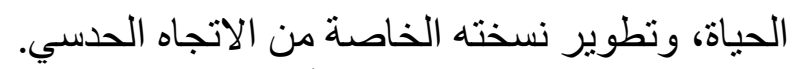

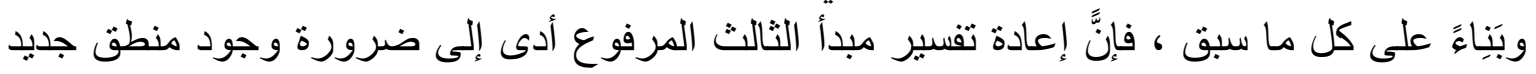

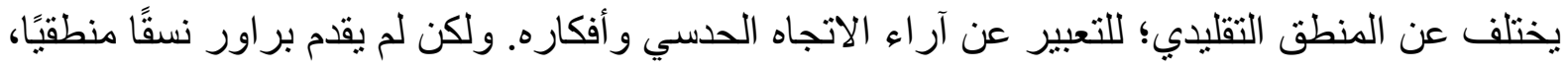

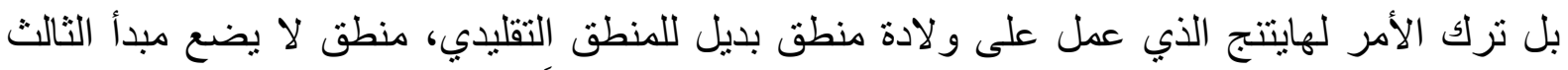

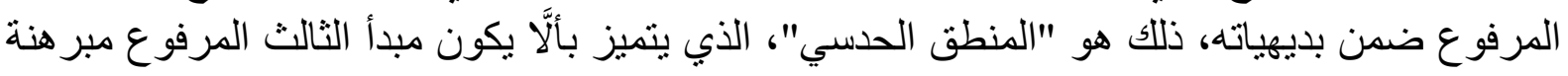
مheorem

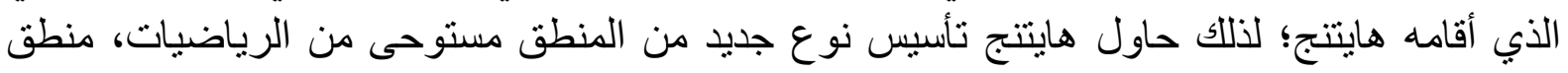

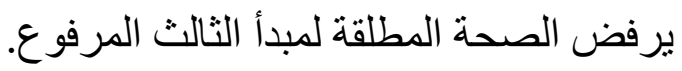




\section{موقف المنظق الحسبي من مبادئ المنظق التقليدي}

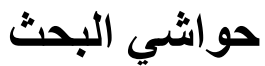

(1) الاتجاه المنطقي أو اللوجنتيقي: الذي أسسه جوتلوب فريجه Gottlob Frege ( ) 1848- 1925)، وطوره برتراند

رسل Bertrand Russell (1970-1872) والفرد نورث وايتهيد Alfred North Whitehead (1947-1861).

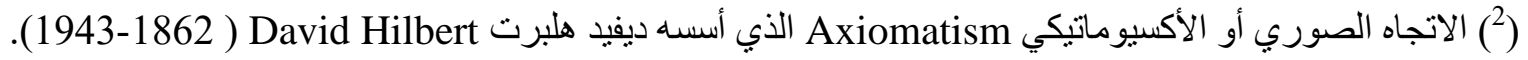

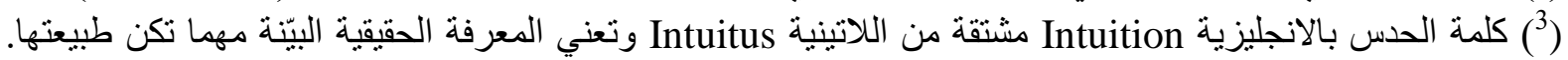

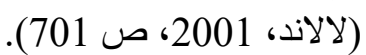

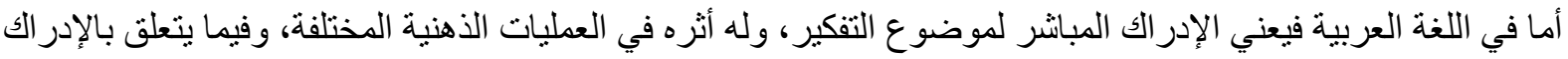

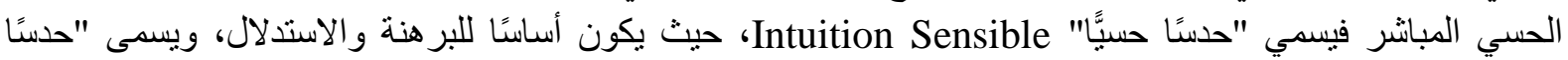

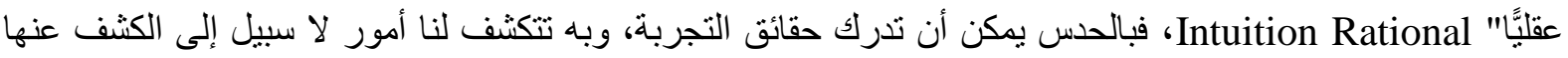

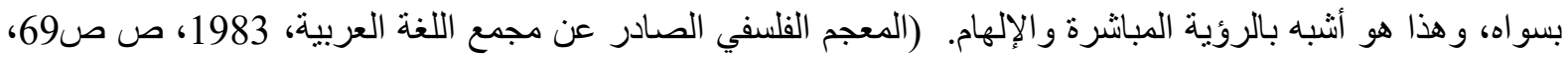

و ولى ذللك، فإن للحدس معاني متعددة، فيمكن تعريفه على أنه الفهم، حيث إنه يتعامل مع ما هو واضح بالنسبة للعقل.

(Gray, 1992, P. 239)

هذا عن معنى الحدس لغويَّا و أنو اعه، ولكن إذا تسألنا هل يمكن أن يستثد المنطق إلى الحدس ؟ فماذا تكون الإجابة؟ وما

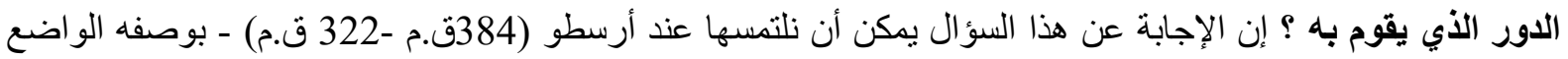
الحقيقي لعلم المنطق- حيث كان أرسطو يؤمن بشكل عام بتكامل طرق المعرفة الإنة الإنسانية، فإنه يؤمن أن لكل منهما دورًا

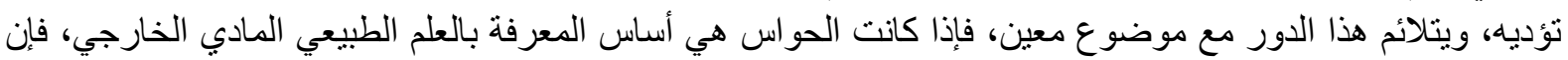

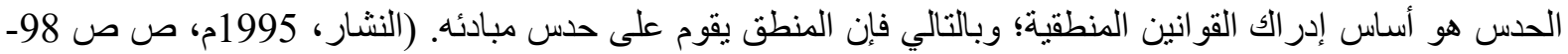

وتوجد صور كثيرة للحدس العقلي، وهي: 1- الحس المصقول Experienced Intuition: هذا الحدس المصقول هو

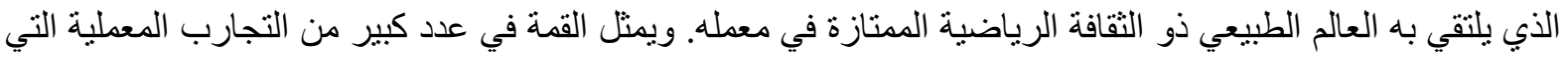

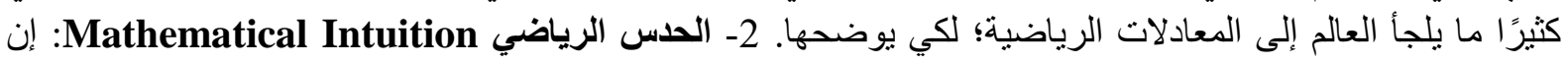

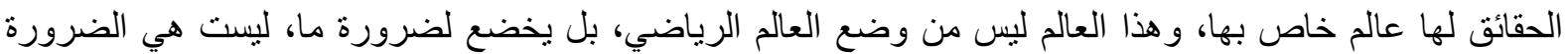

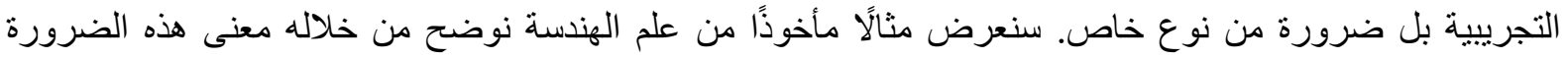

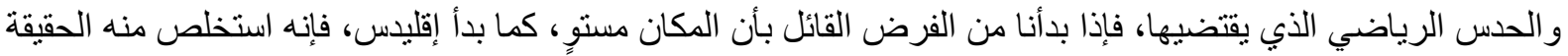

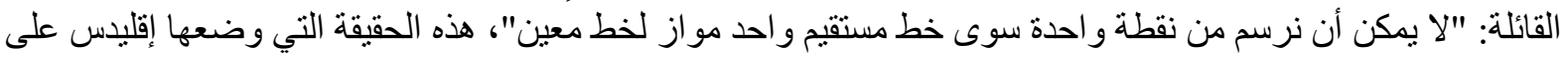

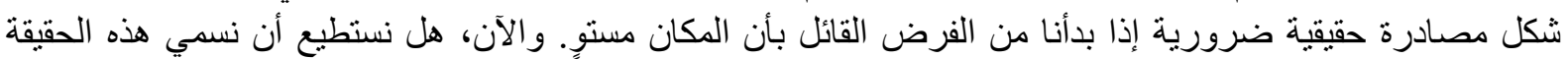

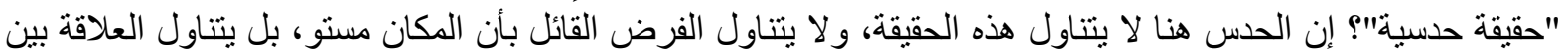

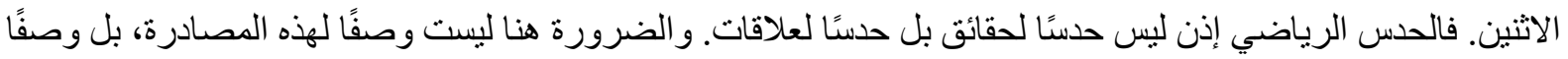

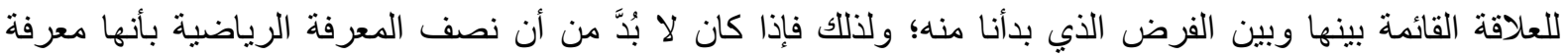

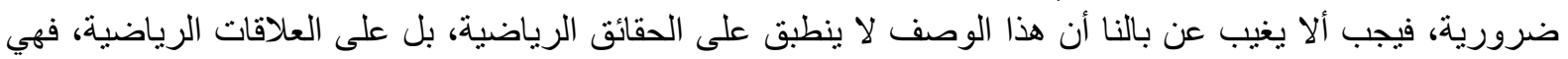

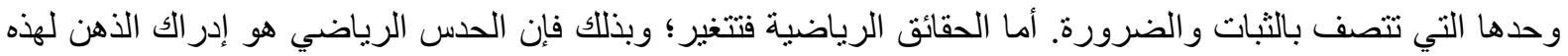

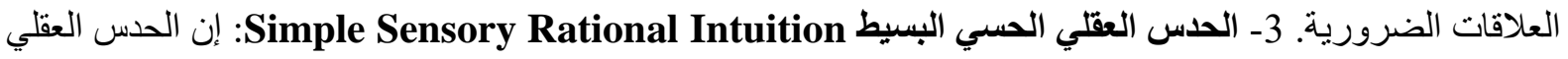

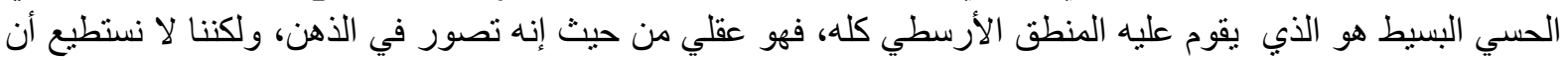

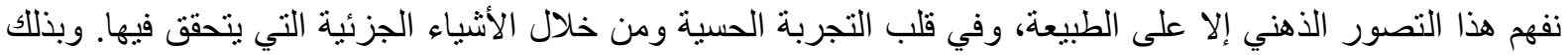

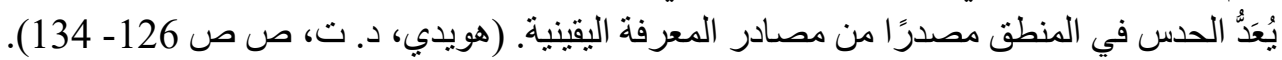

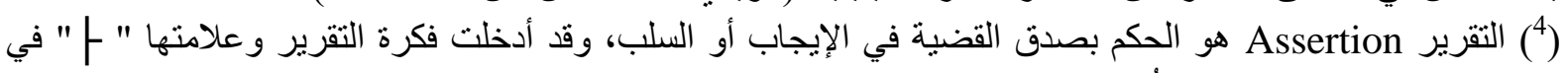

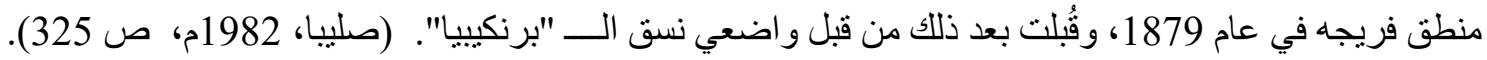

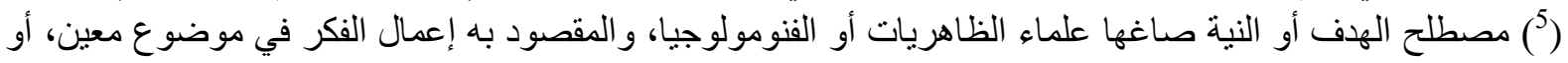

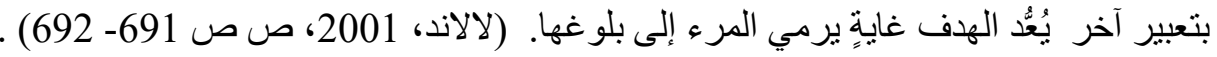

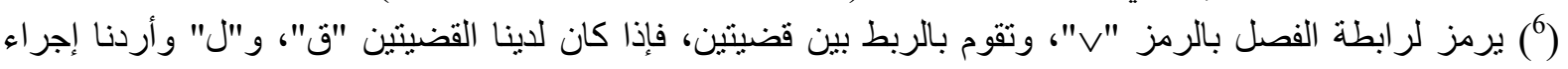

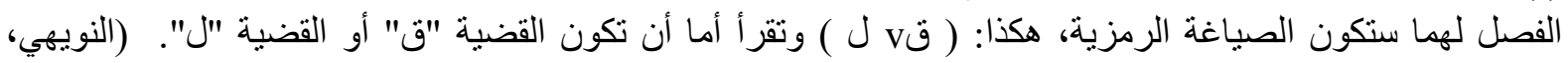

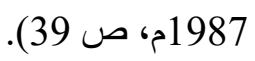




\section{موقف المنطق الحدسي من مبادئ المنطق التقليدي}

(7) يرمز لإجر اء العطف بالرمز "."، فإذا كان لدينا القضيتين "ق"، و "ل" فإن الصياغة الرمزية لقضية العطف المركبة

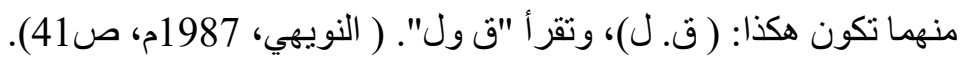

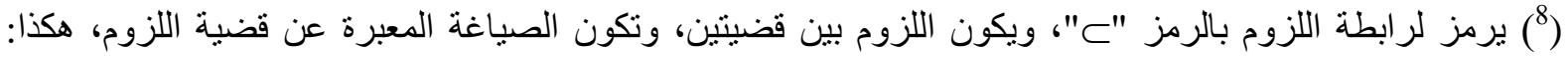

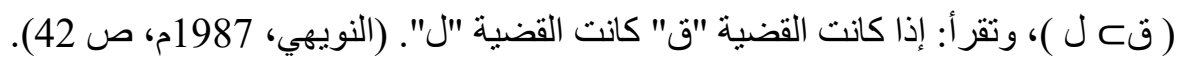

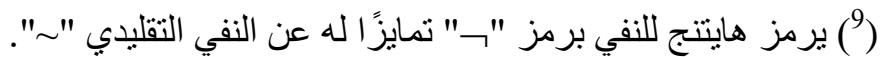

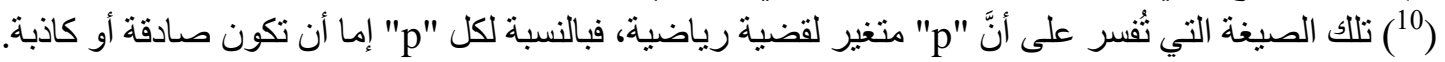

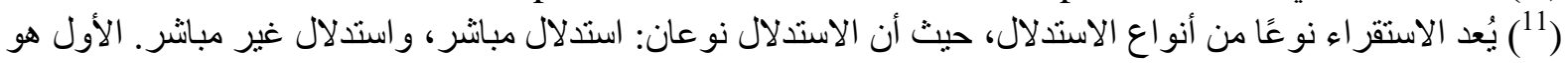

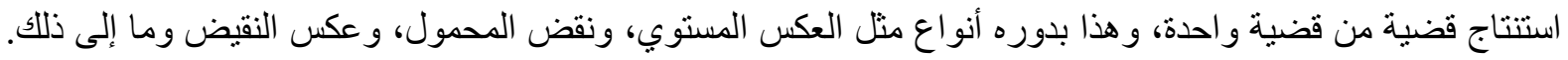

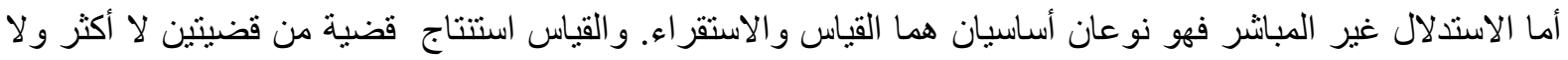

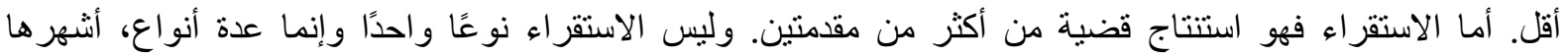

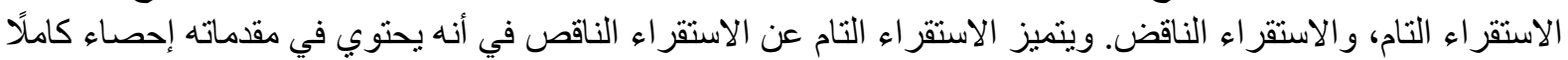

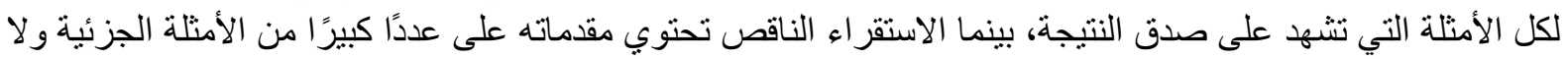

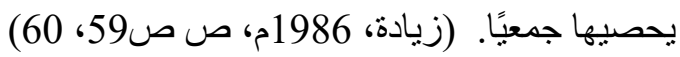

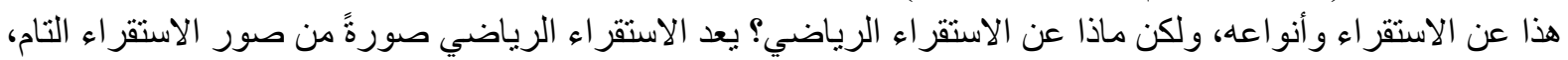

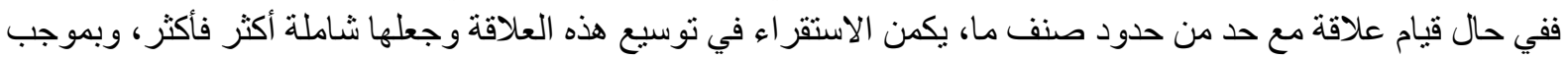

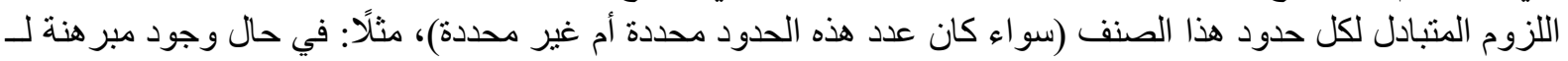

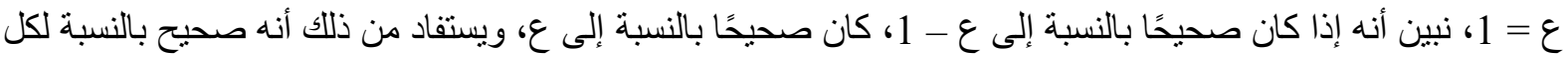

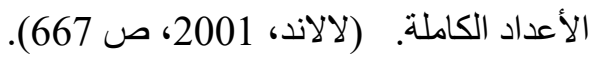

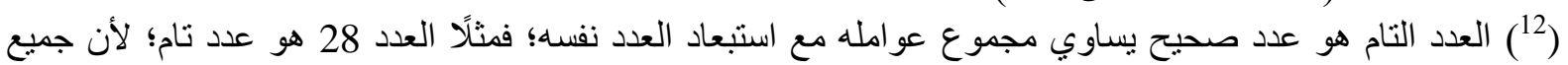

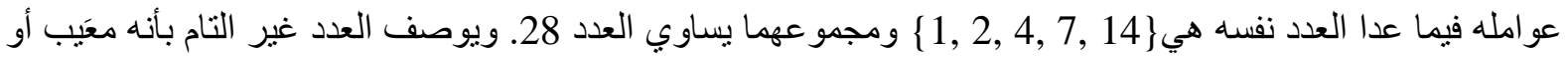

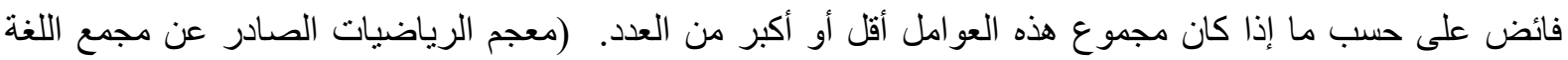

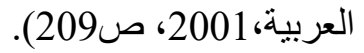

(3) كان بر اور بحاجة إلى بر هان يؤكد بطلان مبدأ الثالث المرفوع المقبول لإسكات منتقديه في أو ائل العشرينات، وهو

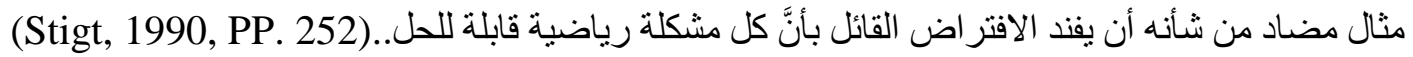

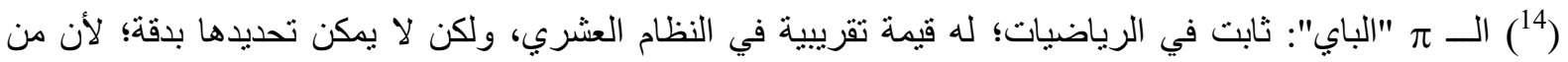

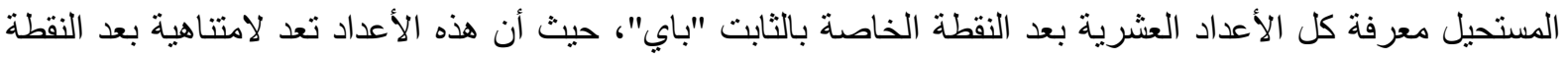
العشرية من الثابت "باب".(Crilly, 2007, P. 31).

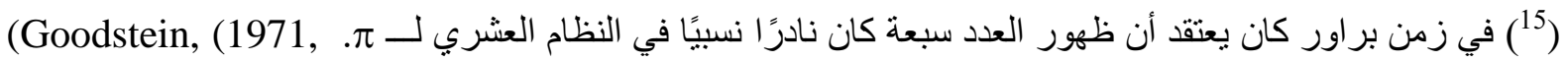




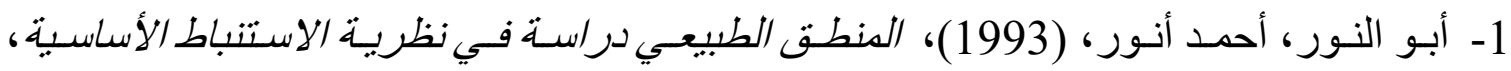

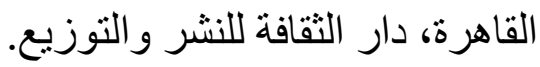
2- الجنابي، أسعد قادر ، (2010)، الدنطق غير التقلبيدي وتطبيقاته: نظري وتمارين محلولة، سوريا،

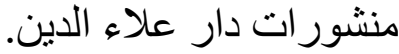

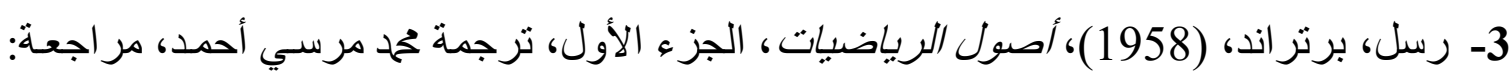

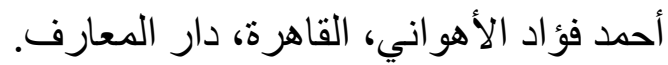

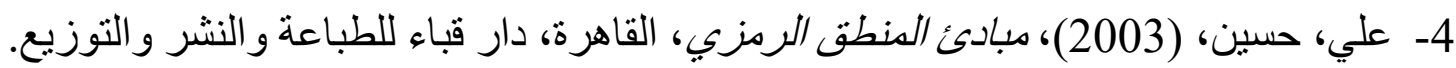

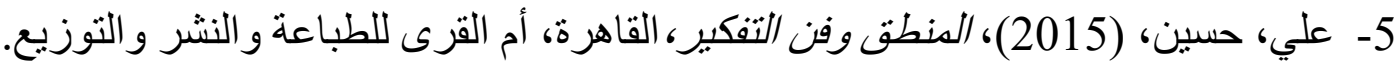

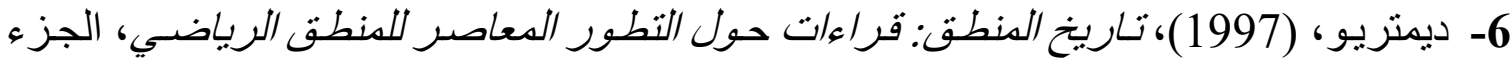

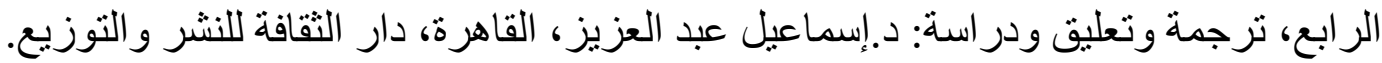

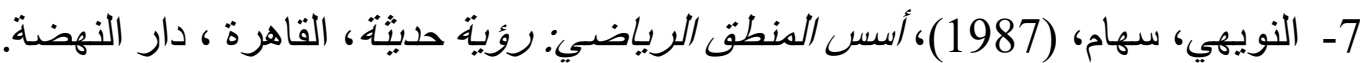

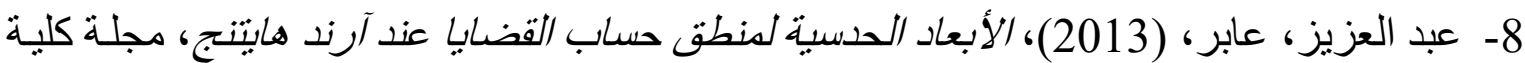

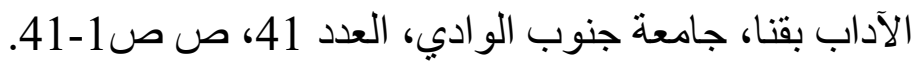

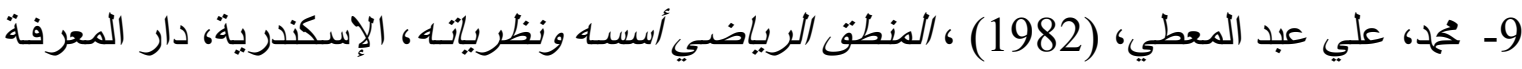

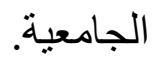

10- غيتمانوفيا، الكسندرا، (1989)، علم الدنطق، لم برد اسم المنرجم، موسكو، دار التقام.

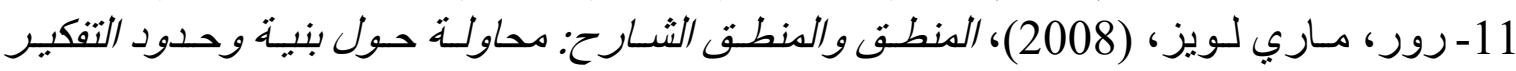

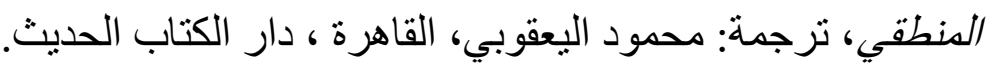

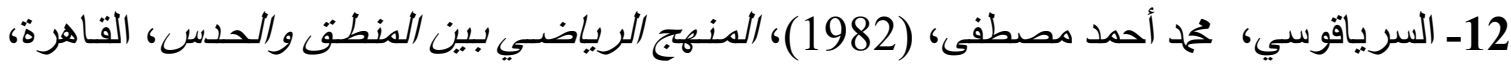
دار الثقافة للطباعة والنشر. 13- الجابري، حمح عابد، (2002)، مدخل إلى فلسفة العلوم: العقلانية الدعاصرة وتطور الفكر العلمي، ط5، بيروت، مركز در اسات الوحدة العربية.

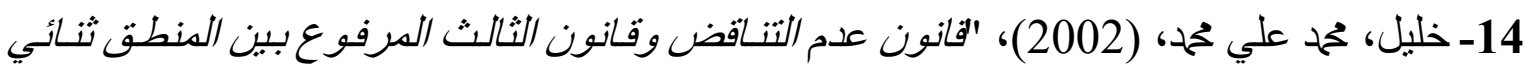

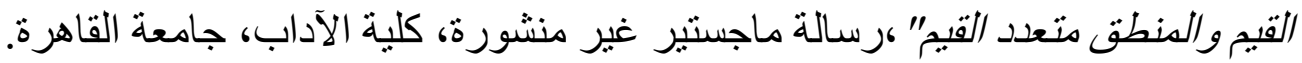

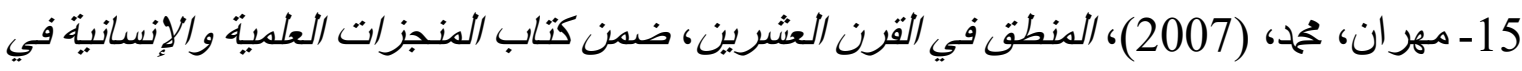

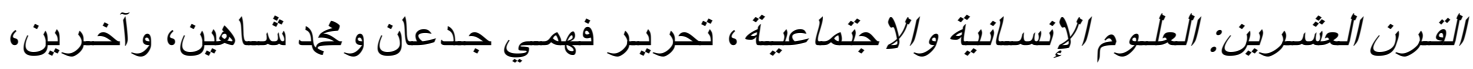
بيروت ، المؤسسة العربية للار اسات و النشر.

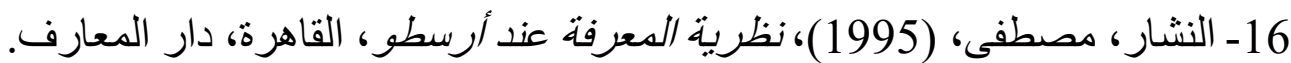

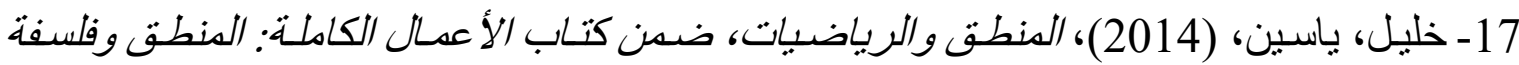

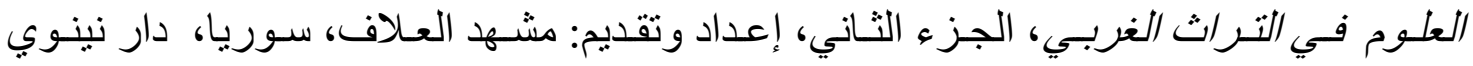
للار اسات و الترجمة و النشر.

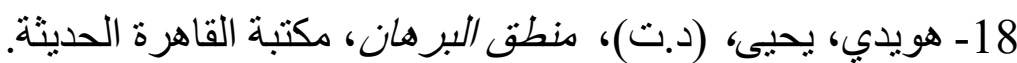

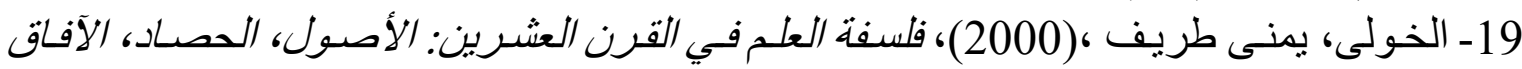
المستقبلية، الكويت، سلسلة عالم المعرفة. 
1- Anderson, John, M., et al., (1962), Natural Deduction: The Logical Basis of Axiom Systems, California, Wadsworth Publishing Company.

2- Atten, Mark van., et al., (2008), One Hundred Years of Intuitionism (1907 - 2007): The Cerisy Conference, Berlin, Birkhäuser Verlag AG.

3- Benacerraf, Paul \& Putnam, Hilary., (1983), Philosophy of Mathematics: Selected Readings, New York, Cambridge University Press.

4- Brouwer, J., (1967), On the Significance of the Principle of Excluded Middle in Mathematics, Especially in Function Theory, In From Frege to Godel: A Source Book in Mathematical Logic, 1879-1931, Edited by J. van Heyenoort, Cambridge, Harvard University Press.

5- Brouwer, J., (1975), Points and Spaces", In Selected Works1:Philosophy and Foundations of Mathematics, Edited by A. Heyting, Amsterdam, North- Holland Publishing Company.

6- Brouwer, J., (1975), The Effect of Intuitionism on Classical Algebra of Logic In Selected Works 1: Philosophy and Foundations of Mathematics, Edited by A. Heyting, Amsterdam, North- Holland Publishing Company.

7- Brouwer, J.,(1975), The Unreliability of the Logical Principles, In Selected Works 1:Philosophy and Foundations of Mathematics, Edited by A. Heyting, Amsterdam, North- Holland Publishing Company.

8- Brouwer, J., (1975), Volition, Knowledge, Language, In Selected Works 1:Philosophy and Foundations of Mathematics, Edited by A. Heyting, Amsterdam, North- Holland Publishing Company.

9- Brouwer, J.,(1975), Consciousness, Philosophy and Mathematics In Selected Works 1: Philosophy and Foundations of Mathematics, Edited by A. Heyting, Amsterdam, North- Holland Publishing Company.

10- Brouwer, J., (1975), On The Foundations of Mathematics, In Selected Works 1: Philosophy and Foundations of Mathematics, Edited by A. Heyting, Amsterdam, North- Holland Publishing Company.

11- Brouwer, J., (1975), Essentially Negative Properties In Selected Works 1: Philosophy and Foundations of Mathematics, Edited by A. Heyting, Amsterdam, North- Holland Publishing Company.

12- Brouwer, J., (1981), Brouwer's Cambridge lectures on intuitionism, Edited by Dalen, D. Van., New York, Cambridge University Press.

13- $\quad$ Brouwer, J., (1998), Intuitionist Reflections on Formalism In From Brouwer to Hilbert: The Debate on the Foundations of Mathematics in 
the 1920s, Edited By Paolo Mancosu, New York, Oxford University Press.

14- Brouwer, J., (1998), Intuitionist Set Theory In From Brouwer to Hilbert: The Debate on the Foundations of Mathematics in the 1920s, Edited By Paolo Mancosu, New York, Oxford University Press .

15- Brouwer, J., (1998), Intuitionistic Splitting of the Fundamental Notions of Mathematics, In From Brouwer to Hilbert: The Debate on the Foundations of Mathematics in the 1920s, Edited By Paolo Mancosu, New York, Oxford University Press.

16- Brouwer, J., (1998), Mathematics, Science, and Language, In From Brouwer to Hilbert: The Debate on the Foundations of Mathematics in the 1920s, Edited By Paolo Mancosu, New York, Oxford University Press.

17- Brown, James Robert., (1999), Philosophy Of Mathematics: An Introduction to the World of Proofs and Pictures, London, Routledge.

18- Crilly, Tony., (2007), Mathematical Ideas: You Really Need to Know, London, Quercus Publishing Plc .

19- Dalen, Dirk van., (2013), L.E.J. Brouwer - Topologist, Intuitionist, Philosopher: How Mathematics Is Rooted in Life, London, Springer.

20- Drucker, Thomas., (2008), Perspectives on the History of Mathematical Logic ,Boston, Birkhauser.

21- Dummett, Michael, (2000), Elements of Intuitionism, Second Edition, New York, Oxford University Press.

22- Gabbay, D.M., \& Guenthner, F., (2002), Handbook of Philosophical Logic, Volume 5, New York, Springer.

23- Gabbay, Dov M., \& Woods, John, (2009), Handbook of the History of Logic: Logic from Russell to Church, Volume: 5, North-Holland, Elsevier B.V.

24- Gillies, Donald., (1922), Revolutions in Mathematics, New York, Oxford University Press.

25- Goodstein, R. L., (1971), Development of Mathematical Logic, Great Britain, Logos Press Limited.

26- Granström, Johan Georg., (2011), Treatise on Intuitionistic Type Theory, New York, Springer Science-Business Media B.V. 
27- Heyting, A., (1958), Intuitionism in Mathematics, in Philosophy in the Mid-Century: A Survey, Edited by Raymond Klibansky, Firenze: La nuova Italia, vol. 1.

28- Heyting, A., (1971), Intutitionism :An Introduction, Amsterdam, North- Holland Publishing Company.

29- Heyting, A., (1983), The Intuitionist Foundations of Mathematics, In Philosophy of Mathematics: Selected Readings, Edited by Paul Benacerraf and Hilary Putnam, New York, Cambridge University Press.

30- Heyting, A., (1998), On Intuitionistic Logic, In From Brouwer to Hilbert: The Debate on the Foundations of Mathematics in the 1920s, Edited By Paolo Mancosu, New York, Oxford University Press.

31- Jacquette, Dale., (2006), A Companion to Philosophical Logic, the United Kingdom, Blackwell Publishing Ltd.

32- Kleene, Stephen Cole., (1971), Introduction to Metamathematics, New York, North - Holland Publishing Company.

33- Kneal, William, \& Kneal Martha., (1962), The Devotement Of Logic, London, Oxford University Prees.

34- Mancosu, Paolo., (2010), The Adventure of Reason: Interplay Between Philosophy of Mathematics and Mathematical Logic, 19001940, New York, Oxford University Press.

35- Marion, Mathieu, (1998), Wittgenstein, Finitism, and the Foundations of Mathematics, Oxford, Clarendon Press.

36- Nolt, John., (1997), Logics, New York, Wadsworth Publishing Company.

37- Placek, Tomasz., (1999), Mathematical Intuitionism and Intersubjectivity: A Critical Exposition of Arguments for Intuitionism, London, Springer.

38- Shapiro, Stewart, (2005), The Oxford Handbook of Philosophy of Mathematics and Logic, New York, Oxford University Press, Inc.

39- Stigt, Walter. P. van, (1990), Brouwer's Intuitionism, North Holland, Elsevier Science Publishers B.V.

40- Wilder, Raymond L., (1965), Introduction To The Foundations Of Mathematics, New York, John Wiley \& Sons, Inc. 
1- Franchella, Miriam., (1994), Heyting's Contribution to the Change in Research into the Foundations of Mathematics, History and Philosophy of Logic, Volume 15, Issue 2, PP. 149-172.

2- Franchella, Miriam., (1995), L. E. J. Brouwer- Toward Intuitionistic Logic, Historia Mathematica, Volume 22, issue 3, PP. 304-322.

3- Franchella, Miriam., (2007), Arend Heyting and Phenomenology: Is the Meeting Feasible?, Bulletin d'Analyse Phénoménologique, Volume: 3 , issue: 2, PP. 1-20.

4- Franchella, Miriam., (2018), Shaping the Enemy: Foundational Labelling by L. E. J. Brouwer and A. Heyting, History and Philosophy of Logic, PP $1-30$.

5- Hansen, Casper Storm., (2015), Brouwer's Conception of Truth, Philosophia Mathematica, Issue 3, September 15, PP. 1-23.

6- Heyting, A., (1974), Intuitionistic Views on the Nature of Mathematics, Synthese, Vol. 27, No. 1-2, On the Foundations of Mathematics, May Jun.,PP. 79- 91.

7- Hilbert, David., (1990), Mathematical Problems, Translated by Dr. Mary Winston Newson, Bulletin of the American Mathematical Society, Volume: 37, issue: 4, PP. 253-297.

8- Hossack, Keith G., (1990), A Problem About the Meaning of Intuitionist Negation, Mind, Vol: 99, Issue: April, PP. 207-219.

9- Kaneko, Hiroshi., (2002), Brouwer's Conception of Language, Mind and Mathematics, Annals of the Japan Association for Philosophy of Science, Volume: 11, Issue: 1,PP. 35 - 49.

10- McCarty, Charles., (2006), At the Heart of Analysis: Intuitionism and Philosophy, Philosophia Scientiæ, Cahier special: 6, PP. 81 - 94.

11- Raatikainen, Panu., (2004), Conceptions of Truth in Intuitionism, History and Philosophy of Logic, Volume: 25, Issue 2: may, PP. 131- 145.

12- $\quad$ Raatikainen, Panu., (2013), Intuitionistic Logic and Its Philosophy, Al-Mukhatabat, A Trilingual Journal For Logic, Epistemology and Analytical Philosophy, Issue 6:, PP. 1-15.

13- Weyl, Hermann., (1946), Mathematics and Logic, The American Mathematical Monthly, Vol. 53, No. 1, PP. 2-13. 


\section{رابعًا: المعاجم والقواميس العربية:}

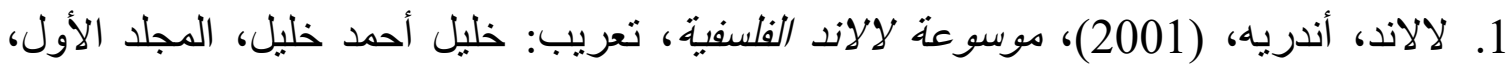
بيروت، منشور ات عويدات.

2. صليبا، جميل، (1982)، الدعجم الفلسفي بالألفاظ العربية والفرنسية والإنكليزية واللاتينية، بيروت، دار الكتاب اللبناني.

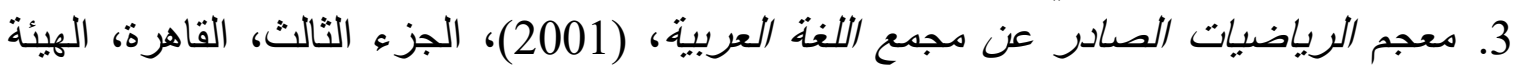
العامة لشئون المطابع الأميرية.

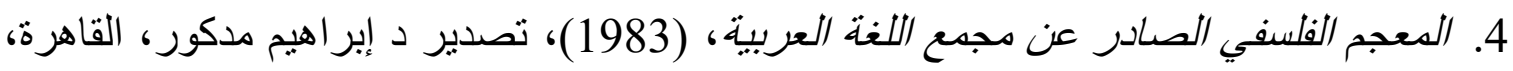
الهيئة العامة لنئون المطابع الأميرية.

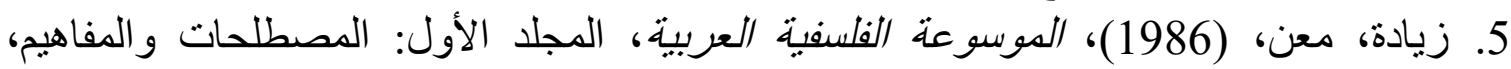
بيروت، معهد الإنماء العربي. 
موقف المنطق الحدسي من مبادئ المنطق التقليدي

\title{
The Position of Intuitionistic Logic on the Principles of Traditional Logic
}

\author{
Huda Mohamed Ghazy Ashmawy Hassanein \\ (PHD) Degree, Department of Philosophical Studies \\ Faculty of Arts, Ain Shams University - Egypt \\ Huda.ghazy@art.asu.edu.eg
}

Prof. Dr. Seham El-Nuahy

Professor of Logic and Philosophy of

Science, Department of Philosophical

Studies, Faculty of Women for Arts,

Science \& Education

Ain Shams University - Egypt

s_alnoaihi2@yahoo.com
Prof. Dr. Hussein Ali

Professor of Logic and Philosophy of Science, Department of Philosophical Studies

Faculty of Arts,

Ain Shams University - Egypt

plato_48@yahoo.com

\section{Abstract}

This paper deals with the position of intuitionistic logic on the principles of traditional logic. The importance of this logic is due to the fact that it is different from traditional logic, as it expresses the views and ideas of the intuitionism, which be appeared as a result of researching into the problem of the foundations of mathematics. That intuitionistic logic is characterized by the non-existence of the principle of the excluded middle being a theorem of the intuitionistic system. That is due to the different concept of mathematical truth in relation to mathematical Propositions, as the proponents of intuitionistic logic reject the idea that truth is the basis of logic and believe instead in the idea of proof. As a result of replacing the concept of proof with the concept of truth, the difference appeared clearly between traditional logic and intuitionistic logic, especially with regard to the concept of negation and double negation. Traditional negation uses a language that relies on the concepts of truth and false, while the used language in the intuitionistic negation relies on the concepts of probability and refutation. One of the main points of controversy between intuitionistic logic and traditional logic is the absence of the rule of double negation at the proponents of intuitionistic logic.

Keywords: Intuitionistic Logic, Traditional Logic, The Principle of the Excluded Middle, Truth, Proof, Negation. 